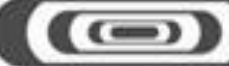 \\ ipen
}

AUTARQUIA ASSOCIADA À UNIVERSIDADE DE SÃO PAULO

ESTUDO E DESENVOLVIMENTO DE NANOCOMPÓSITOS PBT/ARGILA BENTONITA TRATADOS POR RADIAÇÃO IONIZANTE - PREPARAÇÃO E CARACTERIZAÇÃO

MARIANA DO NASCIMENTO SARTORI

Dissertação apresentada como parte dos requisitos para obtenção do Grau de Mestre em Ciências na Área de Tecnologia Nuclear - Aplicações

Orientadora:

Profa. Dra. Esperidiana Augusta Barretos de Moura

São Paulo 
INSTITUTO DE PESQUISAS ENERGÉTICAS E NUCLEARES

Autarquia associada à Universidade de São Paulo

\author{
ESTUDO E DESENVOLVIMENTO DE NANOCOMPÓSITOS PBT/ARGILA \\ BENTONITA TRATADOS POR RADIAÇÃO IONIZANTE - PREPARAÇÃO E \\ CARACTERIZAÇÃO
}

MARIANA DO NASCIMENTO SARTORI

Dissertação apresentada como parte dos requisitos para obtenção do Grau de Mestre em Ciências na Área de Tecnologia Nuclear - Aplicações

Orientadora:

Profa. Dra. Esperidiana Augusta Barretos de Moura

São Paulo 
Aos meus pais Sergio e Fabiola por todo amor e compreensão, sempre, em todos os momentos. 
"A mente que se abre a uma nova ideia jamais voltará ao seu tamanho original" 


\section{AGRADECIMENTOS}

A Dra. Esperidiana Augusta Barretos de Moura pela oportunidade de desenvolver este trabalho.

Ao Prof. Dr. Francisco Rolando Valenzuela Diaz, pelo fornecimento das argilas, por abrir as portas do seu laboratório para que eu pudesse realizar a modificação das argilas, por sempre me ajudar quando tinha dúvidas e estar presente desde o início deste trabalho e fazer parte da minha banca no exame de capacidade, seminário de área e defesa.

A todos os alunos que passaram pelo grupo ao longo do desenvolvimento deste trabalho e que me ajudaram em diversos momentos: Beatriz Nogueira, Cristina Pozellato, Lia Fazzio, Diego Lima, Jaciele Gonçalves, Valquíria Alves, Michelle Gomes, Julia Arraçaba, André Pari em especial a Amanda Sandoval que iniciou essa jornada junto comigo e que mesmo tendo seguido seu caminho sempre esteve ao meu lado me apoiando e me dando forças para seguir em frente.

Aos Engenheiros Elizabeth S. R. Somessari e Carlos Gaia da Silva pela irradiação das amostras e também por todas as conversas, e paciência para me ajudar sempre.

Aos alunos do CTR, desde os participantes da aposta e a todos que me acompanharam e ajudaram ao longo desse projeto, Carla Souza, Robinson, Diego Vergaças, Rodrigo Kirita, Mara Mello, Clécia Souza, Aline Morais, Bruna Teiga, Marcos Benega, Rodrigo Tiezzi. 
Aos colegas do CQMA que me receberam tão bem nessa mudança de centro no meio do trabalho, por todo apoio, boas conversas e ajuda: Luiza Mello, Maria José Oliveira, Henrique Perez, Gustavo Varca.

Ao Msc. Djalma Batista por toda ajuda com os ensaios mecânicos e análises térmicas e principalmente por todas as conversas e apoio.

A minha querida amiga Maiara Salla, por estar ao meu lado em todos os momentos, principalmente nos mais difíceis, por me fazer acreditar que tudo acontece por um motivo e que no final tudo vai dar certo.

Ao Conselho Nacional de Desenvolvimento Científico e Tecnológico (CNPq), pelo apoio financeiro.

À Ticona pela doação da matriz polimérica PBT.

À Nélio Zaude pela confiança e por ter me permitido realizar os ensaios no laboratório da NZ Cooperpolymer e a todos os seus funcionários pela disposição e auxilio.

À Dra. Ticiane Valera do Departamento de Engenharia Metalúrgica e de Materiais (PMT) da Escola Politécnica pela utilização da máquina injetora e a Kleber Vaccioli pela ajuda na obtenção dos corpos de prova.

Ao Dr. Shaik Jeelani, Dr. Vijaya Rangari e ao Dr. Marresh Hosur da Universidade Tuskegee pela oportunidade de intercâmbio e todo auxilio oferecido no período em que estive nos Estados Unidos. 
À minha família pelo incondicional apoio, por me dar forças e ser meu porto seguro em todas as dificuldades e obstáculos. Chegar em casa depois de um dia difícil e saber que vocês estavam lá para me acolher foi sem dúvida o fator fundamental para que eu concluísse esta etapa. 


\title{
ESTUDO E DESENVOLVIMENTO DE NANOCOMPÓSITOS PBT/ARGILA BENTONITA TRATADOS POR RADIAÇÃO IONIZANTE - PREPARAÇÃO E CARACTERIZAÇÃO
}

\author{
Mariana do Nascimento Sartori
}

\section{RESUMO}

Este trabalho apresenta a preparação e caracterização de compósitos baseados em poli (tereftalato de butileno) - PBT e argila brasileira modificada preparados por intercalação por fusão. Os nanocompósitos de PBT com 3 e $5 \%$, em peso, de argila organicamente modificada, pela adição de um sal quaternário amônio, foram preparadas pelo processo de extrusão utilizando-se uma máquina extrusora dupla rosca. Após o processo de extrusão, os materiais foram injetados para obtenção de corpos-de-prova para os ensaios de caracterização. Parte dos corpos-de-prova foram submetidos ao processo de irradiação utilizando-se um acelerador de feixes de elétrons de 1,5 MeV, à temperatura ambiente e na presença de ar. As amostras de PBT puro e nanocompósitos irradiadas e não irradiadas foram caracterizadas por meio de ensaios mecânicos de tração, flexão e impacto, ensaios de temperatura de distorção térmica (HDT), difração de raios - X (DRX), microscopia eletrônica de varredura (MEV), índice de fluidez, termogravimetria (TG) e calorimetria exploratória diferencial (DSC) e a correlação entre as propriedades foi discutida. Os resultados mostraram que a adição da argila, em ambas as porcentagens, promoveu aumento superior a $50 \%$ na resistência a tração na ruptura e um ganho de cerca de $35 \%$ na temperatura de distorção térmica quando comparado ao polímero puro. $\mathrm{O}$ tratamento por radiação ionizante de feixe de elétrons nas doses utilizadas neste estudo não apresentaram mudanças significativas nas propriedades dos materiais. 


\title{
STUDY AND DEVELOPMENT OF NANOCOMPOSITES PBT/BENTONITE CLAY TREATED BY IONIZING RADIATION - PREPARATION AND CHARACTERIZATION
}

\author{
Mariana do Nascimento Sartori
}

\begin{abstract}
This work describes the preparation and characterization of composites based on poly (butylene terephthalate) - PBT and brazilian modified clay prepared by the melt intercalation. PBT nanocomposites with 3 and $5 \%$ by weight of organically modified clay, by the addition of a quaternary ammonium salt, were prepared by extrusion using a twin-screw extruder machine. After the extrusion process, the materials were injected to obtain specimens tests samples for the characterization tests. Part of the specimens samples were irradiated using an electron beam accelerator with $1.5 \mathrm{MeV}$ at room temperature in the presence of air. Samples of pure PBT and irradiated and non-irradiated nanocomposites were characterized by mechanical tests of tensile, flexural and impact, heat distortion temperature (HDT), X - ray diffraction (XRD), scanning electron microscopy (SEM), melt flow index (MFI) thermogravimetry (TG) and differential scanning calorimetry (DSC) and the correlation between the properties was discussed. The results showed that the addition of clay, in both percentages, promoted an increase greater than $50 \%$ in tensile strength at break and a gain of around $35 \%$ in heat distortion temperature when compared to the pure polymer. The treatment with ionizing radiation of electron beam at the doses used in this study showed no significant changes in material properties.
\end{abstract}




\section{SUMÁRIO}

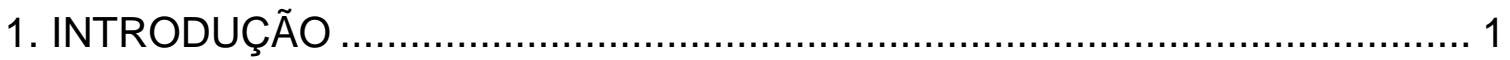

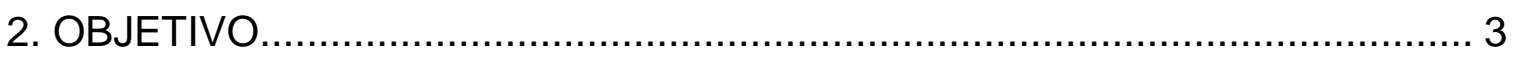

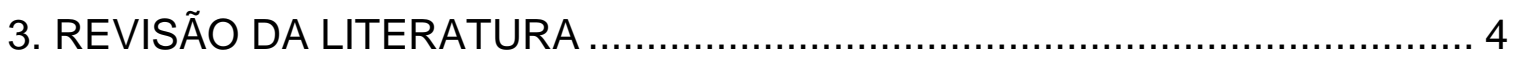

3.1. Poli (tereftalato de butileno) - PBT ................................................... 4

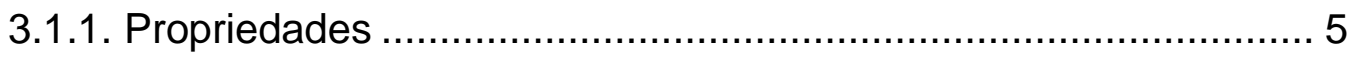

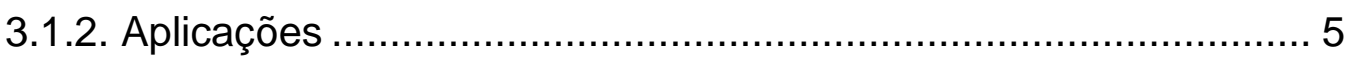

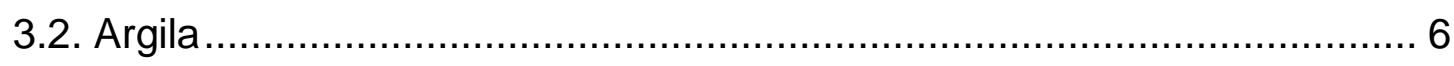

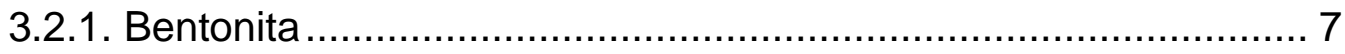

3.2.2. Bentonita no Brasil .............................................................

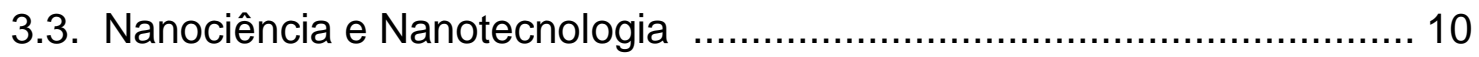

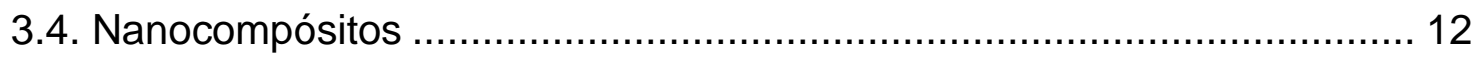

3.4.1. Nanocompósitos de matriz polimérica …………….................. 13

3.4.2. Nanocompósitos polímero / argila .............................................. 14

3.4.2.1. Métodos de obtenção ..................................................... 14

3.4.2.2. Tipos de estrutura ....................................................... 15

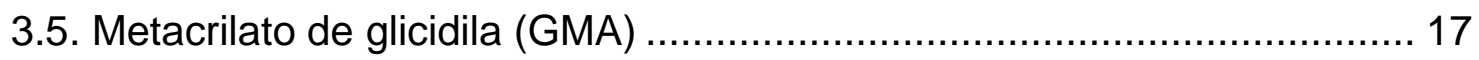

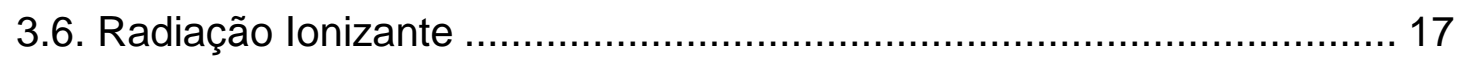

3.6.1. Efeitos da radiação em polímeros ................................................ 18

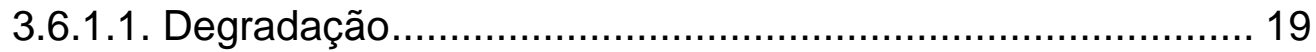

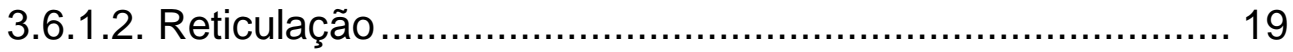

3.7. Técnicas de caracterização …………………………………...... 19

3.7.1. Difração de raios $X(X R D)$..................................................... 20

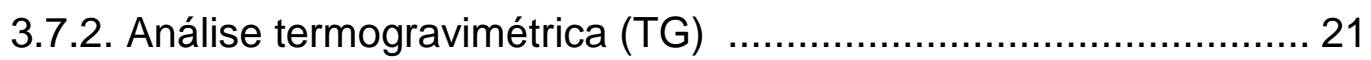


3.7.3. Calorimetria exploratória diferencial (DSC) .............................. 21

3.7.4. Microscopia eletrônica de varredura (MEV) ............................... 21

3.7.5. Microscopia eletrônica de transmissão (TEM) ............................. 22

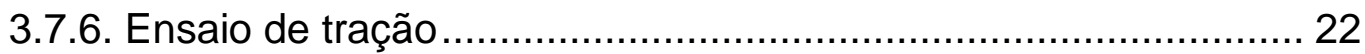

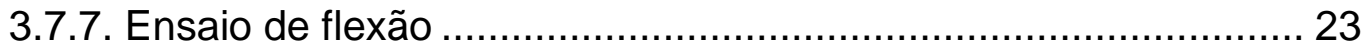

3.7.8. Ensaio de resistência ao impacto ............................................ 23

3.7.9. Temperatura de deflexão térmica (HDT) …………………...... 23

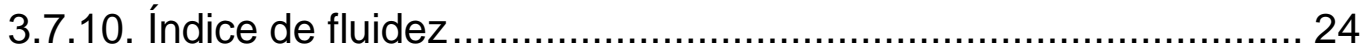

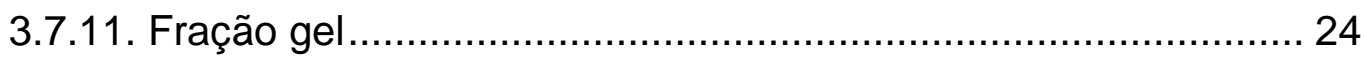

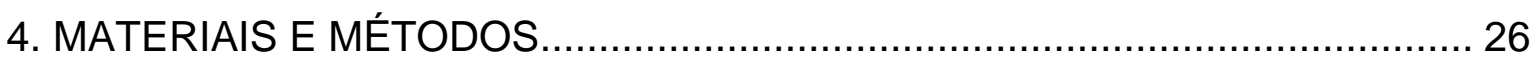

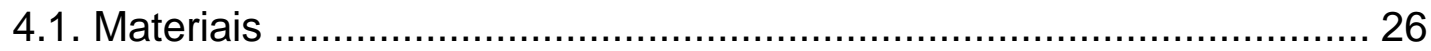

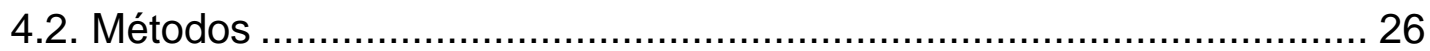

4.2.1. Preparação e modificação da argila ............................................. 26

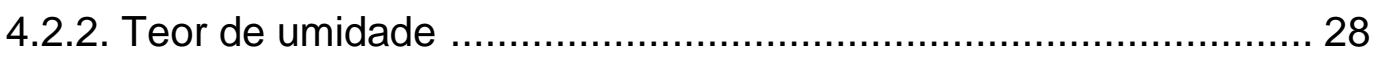

4.2.3. Preparação dos nanocompósitos .............................................. 30

4.2.4. Injeção dos corpos de prova..................................................... 33

4.2.5. Irradiação dos nanocompósitos ................................................. 34

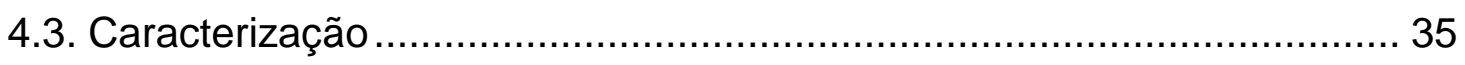

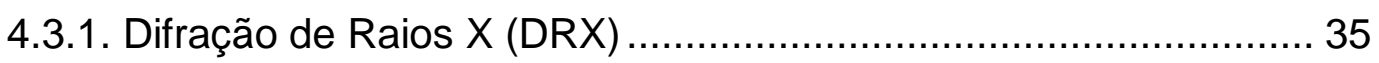

4.3.2. Espectrometria de fluorescência de raios $X$ (WDXRF) ................... 36

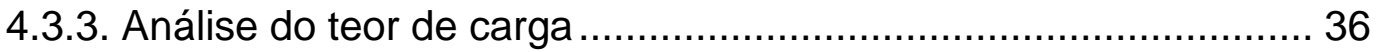

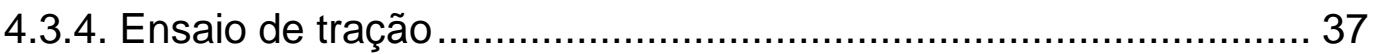

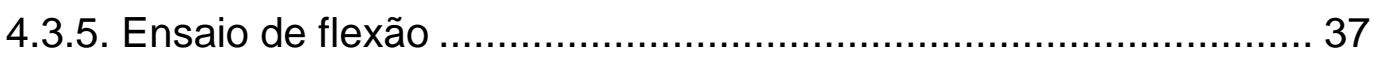

4.3.6. Ensaio de resistência ao impacto .............................................. 38

4.3.7. Ensaio de temperatura de distorção térmica .............................. 39 


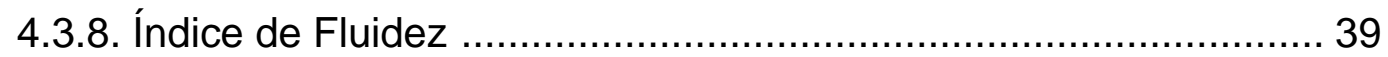

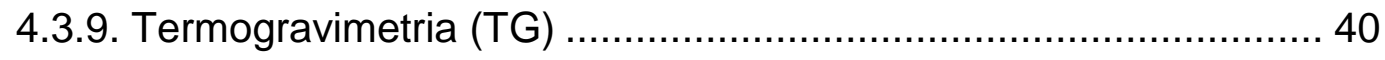

4.3.10. Calorimetria Exploratória Diferencial (DSC)............................. 40

4.3.11. Microscopia Eletrônica de Varredura (MEV) ............................. 41

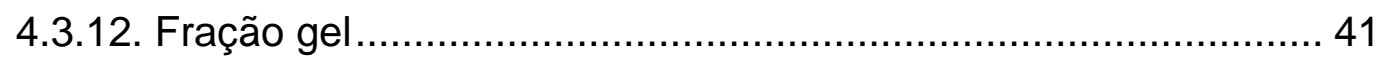

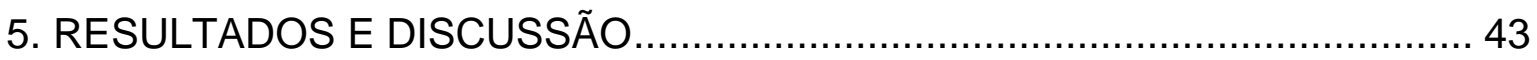

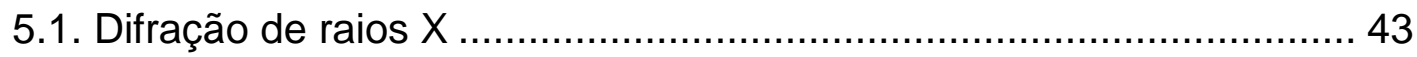

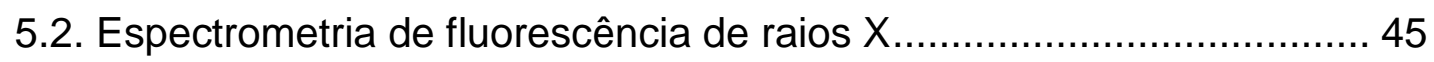

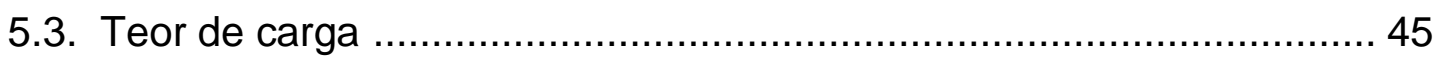

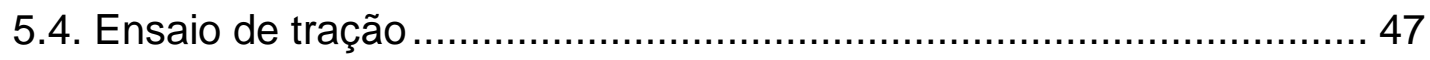

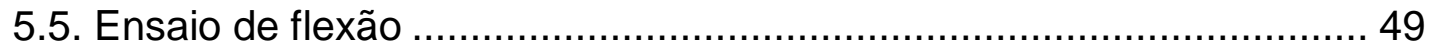

5.6. Teste de resistência ao impacto ……................................................ 50

5.7. Temperatura de distorção térmica ………………….................... 51

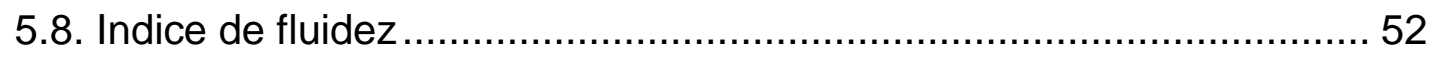

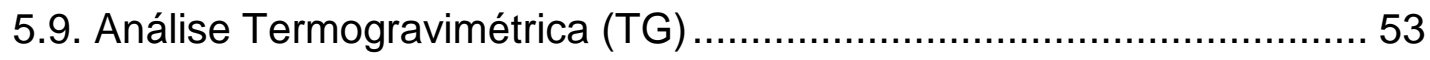

5.10. Calorimetria Exploratória Diferencial (DSC) ...................................... 56

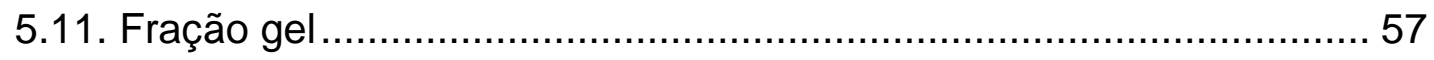

5.12. Microscopia Eletrônica de Varredura (MEV) …………………….... 58

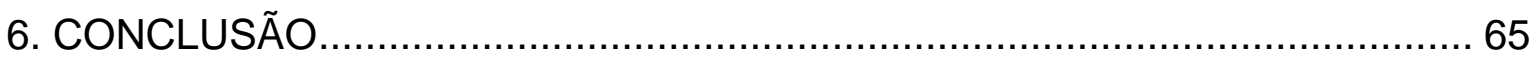

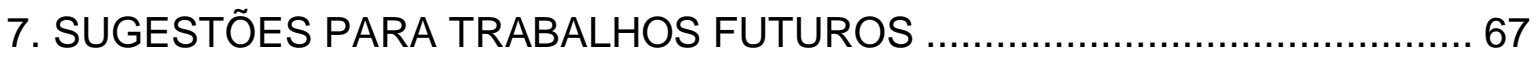

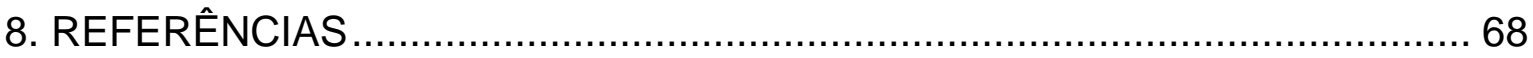




\section{Lista de Figuras}

Figura 1. Estrutura química do PBT (CANEVAROLO, 2010).

Figura 2. Estrutura dos argilominerais 2:1 (PAIVA, 2006) 8

Figura 3. Esquema de troca de íons em argilas através da modificação (adaptado de FISCHER, 2003) 9

Figura 4. Tamanho e comparação de escalas (NANOTECH, s.d.) 11

Figura 5. Estrutura dos nanocompósitos (ALEXANDRE e DUBOIS, 2000) 16

Figura 6. Depósito da argila Chocolate (SILVA, 2010) 27

Figura 7. Modificação da argila. (A) argila sendo dispersa em água destilada; (B) argila modificada seca em estufa; $(\mathrm{C})$ argila modifica peneirada. 28

Figura 8. Equipamento utilizado para medir o teor de umidade localizado no laboratório de qualidade da empresa NZ Cooperpolymer. 30

Figura 9. Extrusora utilizada para obtenção dos nanocompósitos.

Figura 10. Nanocompósitos de PBT/GMA/3\% Argila obtidos no processo de extrusão.

Figura 11. Corpos de prova do PBT/GMA/ $3 \%$ Argila obtidos no processo de injeção.

Figura 12. Difratômetro de raios X modelo Rigaku DMAX 2200 do laboratório do Centro de Materiais Avançados da Universidade Tuskegee.

Figura 13. Análise do teor de carga. (A) Mufla; (B) Mufla com os cadinhos com as amostras). 
Figura 14. Máquina universal de ensaios Instron durante a realização do ensaio de tração.

Figura 15. Ensaio de resistência ao impacto Izod (A) Entalhador elétrico para corpo de prova do teste de impacto; (B) Equipamento utilizado para teste de impacto 38

Figura 16. Equipamento para ensaios de HDT do Laboratório de Qualidade da empresa NZ Cooperpolymer

Figura 17. Plastômetro utilizado para análise do índice de fluidez

Figura 18. Amostras mantidas em malha de aço para ensaio de fração sol - gel ......

Figura 19. Espectro de difração de raios - $X$ de argila chocolate natural e argila chocolate modificada

Figura 20. Espectro de difração de raios - $X$ para as amostras não irradiadas do PBT/GMA, PBT/GMA3 \% Argila e PBT/GMA/5 \% Argila

Figura 21. Cadinhos de porcelanas com a argila residual após a queima

Figura 22. Resultados de resistência à tração na ruptura para as amostras não irradiadas do PBT puro, PBT/3 \% Argila, PBT/5 \% Argila, PBT/GMA, PBT/GMA/3 \% Argila, PBT/GMA/5 \% Argila e para as amostras irradiadas de PBT/GMA, $\mathrm{PBT} / \mathrm{GMA} / 3 \%$ Argila, PBT/GMA/5 \% Argila.

Figura 23. Curva Tensão $x$ Deformação para as amostras não irradiadas do PBT puro, PBT/3 \% Argila, PBT/5\% Argila, PBT/GMA, PBT/GMA/3 \% Argila, $\mathrm{PBT} / \mathrm{GMA} / 5 \%$ Argila

Figura 24. Resultados de resistência à flexão para as amostras não irradiadas do PBT puro, PBT/3 \% Argila, PBT/5\% Argila, PBT/GMA, PBT/GMA $/ 3 \%$ Argila, PBT/GMA/5 \% Argila e para as amostras irradiadas de PBT/GMA, PBT/GMA/3 \% Argila, PBT/GMA/5\% Argila

Figura 25. Resultados do módulo de flexão para as amostras não irradiadas do PBT puro, PBT/3 \% Argila, PBT/5 \% Argila, PBT/GMA, PBT/GMA/3 \% Argila, PBT/GMA/5 
$\%$ Argila e para as amostras irradiadas de PBT/GMA, PBT/GMA/3\% Argila, PBT/GMA/5 \% Argila

Figura 26. Resultados de resistência ao impacto para as amostras não irradiadas do PBT puro, PBT/3 \% Argila, PBT/5\% Argila, PBT/GMA, PBT/GMA/3 \% Argila, $\mathrm{PBT} / \mathrm{GMA} / 5 \%$ Argila e para as amostras irradiadas de PBT/GMA, PBT/GMA/3\% Argila, PBT/GMA/5 \% Argila

Figura 27. Resultados de Temperatura de distorção térmica para as amostras não irradiadas do PBT puro, PBT/3 \% Argila, PBT/5 \% Argila, PBT/GMA, PBT/GMA/3 \% Argila, PBT/GMA/5 \% Argila e para as amostras irradiadas de PBT/GMA, $\mathrm{PBT} / \mathrm{GMA} / 3 \%$ Argila, PBT/GMA/5 \% Argila.

Figura 28. Curva de TG para PBT/GMA NI, PBT/GMA 150 kGy, PBT/GMA 250 kGy e PBT/GMA 350 kGy

Figura 29. Curva de TG para PBT/GMA/3\% Argila NI, PBT/GMA/3 \% Argila $150 \mathrm{kGy}$, $\mathrm{PBT} / \mathrm{GMA} / 3$ \% Argila $250 \mathrm{kGy}$ e PBT/GMA/3 \% Argila 350 kGy.

Figura 30. Curva de TG para PBT/GMA/5 \% Argila NI, PBT/GMA/5 \% Argila 150 kGy, PBT/GMA/5 \% Argila 250 kGy e PBT/GMA/5 \% Argila 350 kGy

Figura 31. Dados de fração gel para o PBT GMA e seus nanocompósitos, irradiados e não irradiados

Figura 32. Micrografia da superfície de fratura do ensaio à tração do PBT/GMA 150 kGy.

Figura 33. Micrografia da superfície de fratura do ensaio à tração do PBT/GMA 250 kGy.

Figura 34. Micrografia da superfície de fratura do ensaio à tração do PBT/GMA 350 kGy.

Figura 35. Micrografia da superfície de fratura do ensaio à tração do PBT/GMA/3 \% Argila NI.

Figura 36. Micrografia da superfície de fratura do ensaio à tração do PBT/GMA/3 \% 
Figura 37. Micrografia da superfície de fratura do ensaio à tração do PBT/GMA/3 \% Argila 250 kGy.

Figura 38. Micrografia da superfície de fratura do ensaio à tração do PBT/GMA/3 \% Argila 350 kGy.

Figura 39. Micrografia da superfície de fratura do ensaio à tração do PBT/GMA/5 \% Argila NI 62

Figura 40. Micrografia da superfície de fratura do ensaio à tração do PBT/GMA/5 \% Argila 150 kGy 63

Figura 41. Micrografia da superfície de fratura do ensaio à tração do PBT/GMA/5 \% Argila 250 kGy...... 63

Figura 42. Micrografia da superfície de fratura do ensaio à tração do PBT/GMA/5 \% Argila 350 kGy. 


\section{Lista de Tabelas}

Tabela 1. Percentual de umidade do PBT e argila em temperatura ambiente e depois de mantidos em estufa

Tabela 2. Temperaturas utilizadas no processo de extrusão 31

Tabela 3. Formulação dos materiais 33

Tabela 4. Componentes inorgânicos da nanoargila bentonita chocolate 45

Tabela 5. Teor de carga dos materiais

Tabela 6. Valores de índice de fluidez para o PBT/Puro, PBT/GMA e seus nanocompósitos

Tabela 7. Temperatura de degradação térmica para o PBT GMA e seus nanocompósitos, irradiados e não irradiados. 56

Tabela 8. Temperatura de fusão, cristalinidade para o PBT GMA e seus nanocompósitos, irradiados e não irradiados. 


\section{INTRODUÇÃO}

Os nanocompósitos poliméricos oferecem grandes benefícios tecnológicos e econômicos em relação aos compósitos convencionais. A adição de reforço em escala nanométrica pode melhorar significativamente as propriedades do polímero. Dessa forma, os nanocompósitos polímero/argila, também chamados de nanocompósitos do tipo polímero/silicatos lamelares têm atraído muita atenção da indústria e do meio acadêmico ao longo dos últimos anos. (ALEXANDRE e DUBOIS, 2000; RAY, 2013).

A adição de uma pequena quantidade de argila ( $<5 \%)$ em peso do polímero pode mostrar uma melhora significativa nas propriedades mecânicas, térmicas e de barreira, e na resistência à inflamabilidade. Acredita-se que a melhoria das propriedades de nanocompósitos polímero/argila está diretamente relacionada com a esfoliação completa de camadas de silicato na matriz polimérica (ALEXANDRE e DUBOIS, 2000; RAY e OKAMOTO, 2003).

Em relação ao Brasil, o desenvolvimento de nanocompósitos polímero/argila é de grande importância tanto do ponto de vista econômico como ambiental, já que o Brasil é um dos principais fornecedores de argila bruta (bentonitas) do mundo, sendo as argilas encontradas abundantemente na natureza, com um custo relativamente baixo, além de terem a capacidade de esfoliarem em lamelas com espessuras da ordem de um nanômetro $(1 \mathrm{~nm})$. Estas argilas podem ser incorporadas em polímeros como cargas, formando nanocompósitos com propriedades superiores quando comparados ao material em seu estado puro (FREITAS, 2010, SOUZA SANTOS, 1992; GIANNELIS, 1998). 
Nanocompósitos polímero/argila podem ser preparados através de três métodos diferentes: preparação em solução, polimerização in situ e por intercalação do polímero fundido. Entre eles, a intercalação por fusão é o método mais adequado industrialmente devido a sua versatilidade, baixo custo, alta produtividade e compatibilidade com as técnicas atuais de processamento de polímeros (DENNIS et al, 2001, RAY, 2013; CHANG et al, 2005).

O Poli(tereftalato de butileno), PBT, é um termoplástico de engenharia, que apresenta alta resistência mecânica, bom isolamento elétrico e resistência química, sendo comumente utilizado na indústria automotiva e eletroeletrônica. Pode ser reforçado com fibras e receber diversos tipos de aditivos e ainda formar blendas com vários tipos de polímeros (WIEBECK e HARADA, 2005).

A radiação ionizante por feixe de elétrons tem sido aplicada de forma eficiente para a modificação controlável de polímeros. Em geral, a radiação de feixe de elétrons é aplicada para introduzir reticulação ou degradação entre as moléculas de polímero. Como resultado do tratamento da irradiação ionizante materiais poliméricos apresentam melhorias nas propriedades térmicas e mecânicas (RATNAM et al, 2007; NAGASAWA, et al, 2005). 


\section{OBJETIVO}

O objetivo deste trabalho é o desenvolvimento de nanocompósitos por meio da aplicação conjunta da incorporação de nanocargas argilosas na matriz polimérica de poli(tereftalato de butileno) - PBT e do tratamento por radiação ionizante para a obtenção de nanocompósitos. A utilização de reforço nanométrico visa buscar ganhos de propriedades mecânicas e térmicas do PBT com um mínimo de adição de cargas. A irradiação dos nanocompósitos tem por objetivo melhorar a adesão interfacial entre a matriz e o nanoreforço. 


\section{REVISÃO DA LITERATURA}

\subsection{Poli (tereftalato de butileno) - PBT}

O poli (tereftalato de butileno) - PBT é um termoplástico semicristalino e um importante poliéster de engenharia. É obtido a partir da transesterificação, reação entre um éster polifuncional e um poliálcool. Os monômeros utilizados para a obtenção do mesmo são o DMT (dimetil tereftalato) e o 1,4 butanodiol (WIEBECK e HARADA, 2005) (Figura 1).

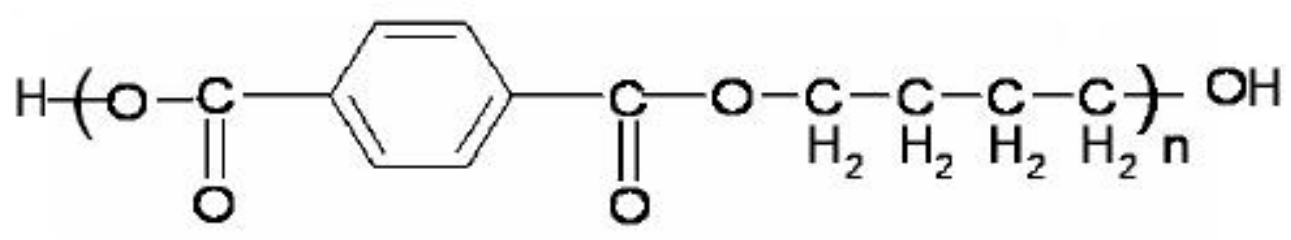

Figura 1. Estrutura química do PBT (CANEVAROLO, 2010).

O PBT foi trazido ao mercado pela Celanese no final da década de 60 . Em 1970, a Celanese introduziu os compostos de PBT reforçado com $30 \%$ de fibra de vidro. As características-chave que tornaram o PBT um material termoplástico amplamente utilizado são a moldabilidade, estabilidade dimensional e propriedades elétricas estáveis. Hoje em dia há uma variedade de grades de PBT no mercado, e além do polímero puro, há também PBT reforçado com fibras de vidro e fibras de carbono, talco, mica, modificadores de impacto, estabilizadores UV, entre outros. (RADUSCH, 2002; TICONA, 2014). 


\subsubsection{Propriedades}

O PBT apresenta uma boa resistência mecânica e térmica, elevada rigidez, resistência à abrasão e a solvente, rápida cristalização, boa resistência a intempéries, baixo coeficiente de atrito, entre outros (HAMMOND, 2001; Wu e Yang, 2009; HAJIRAISSI e PARVINZADEH, 2011).

A natureza semicristalina do PBT o torna resistente aos compostos orgânicos (hidrocarbonetos, hidrocarbonetos halogenados, álcoois, cetonas, ésteres e gasolina) em temperaturas moderadas (WIEBECK e HARADA, 2005).

\subsubsection{Aplicações}

O PBT é um material termoplástico resistente às intempéries e ao calor, e por isso é destinado para ser utilizado em muitos tipos de produtos, tais como, automóveis, peças elétricas e eletrônicas, componentes industriais e bens de consumo (OLABISI, 1997).

$\mathrm{Na}$ indústria automobilística é utilizado para ambas as partes internas e externas e sob o capô dos automóveis. Os exemplos incluem painéis, maçanetas, componentes do sistema de freio, engrenagens, válvulas de ar condicionado, sistema de breque tampas de distribuidor, bomba d' água, bobinas de ignição. A indústria elétrica e eletrônica utiliza o PBT para bobinas, conectores, interruptores, relés, placas de terminais, porta-escovas de motor, sintonizadores de TV, caixas de fusíveis, placas de circuitos integrados e tomadas. Por serem leves, fáceis de moldar e com boas propriedades de atrito, as resinas PBT são usadas em secadores de 
cabelo, ferro de passar roupa, torradeira, cabos de panela. A alta relação resistência-peso e resistência à corrosão e à produtos químicos fazem do PBT uma escolha ideal para estes e outros componentes industriais (BAYER, 1990; BASF, 2000; TICONA 2014; WESTDYK e MCNAIIY,1990).

\subsection{Argila}

A utilização das argilas remete ao princípio da civilização onde colaborava para satisfazer as necessidades de alimentação, habitação, vestuário e estética. As argilas fazem parte de quase todos os tipos de solo e também podem ser encontradas no estado puro em depósitos minerais (VALENZUELA-DÍAZ, 1994).

A argila é um material natural, terroso, de granulação fina formada quimicamente por silicatos hidratados de alumínio, ferro e magnésio, mas podendo também conter minerais acessórios (quartzo, cristobalita, micas, feldspatos e outros) além de matéria orgânica e outras impurezas. É constituída essencialmente por argilominerais (SANTOS, 1975; SANTOS, 1992).

Os argilominerais podem ser divididos de diferentes maneiras: quanto ao grau de ocupação na folha octaédrica; à possibilidade de as camadas basais se expandirem pela introdução de moléculas polares, aumentando a distância interplanar basal; e ao tipo de arranjo ao longo dos eixos cristalográficos. De acordo com essas divisões, os argilominerais podem ser classificados nos seguintes grupos principais: caulinitas, esmectitas, vermiculitas, micas hidratadas e cloritas (SANTOS, 1992). 
Um importante argilomineral do grupo esmectítico é a montmorilonita, o principal constituinte da argila bentonita. Esta argila é uma escolha muito usual na fabricação de nanocompósitos devido às suas partículas pequenas, o que facilita a difusão do polímero nas partículas (BALJINDER, 2001).

\subsubsection{Bentonita}

O termo bentonita foi dado em função da descoberta de uma rocha em Fort Benton, Wyoming - EUA. Embora, originalmente, o termo bentonita se referisse à rocha argilosa descoberta, atualmente designa argila constituída, principalmente, do argilominerais esmectíticos. A bentonita pode ser cálcica ou sódica, e a cálcica possui uma característica física muito particular: expandir várias vezes o seu volume, quando em contato com a água, formando géis tixotrópicos. (SANTOS, 1975).

As argilas mais utilizadas para a preparação de nanocompósitos polímero/argila são as pertencentes à família dos silicatos em camadas 2:1, também conhecidos como filossilicatos 2:1, como a montmorilonita (MMT), que é geralmente o principal constituinte das bentonitas. Sua estrutura cristalina é formada por camadas constituídas de duas folhas tetraédricas de sílica com uma folha central octaédrica de hidróxido de alumínio, unidas entre si por átomos de hidrogênio (RAY e OKAMOTO 2003; BORDES et al, 2009). A figura 2 apresenta uma representação esquemática da estrutura das argilas montmoriloníticas mostrando o empilhamento de um argilomineral 2:1. 


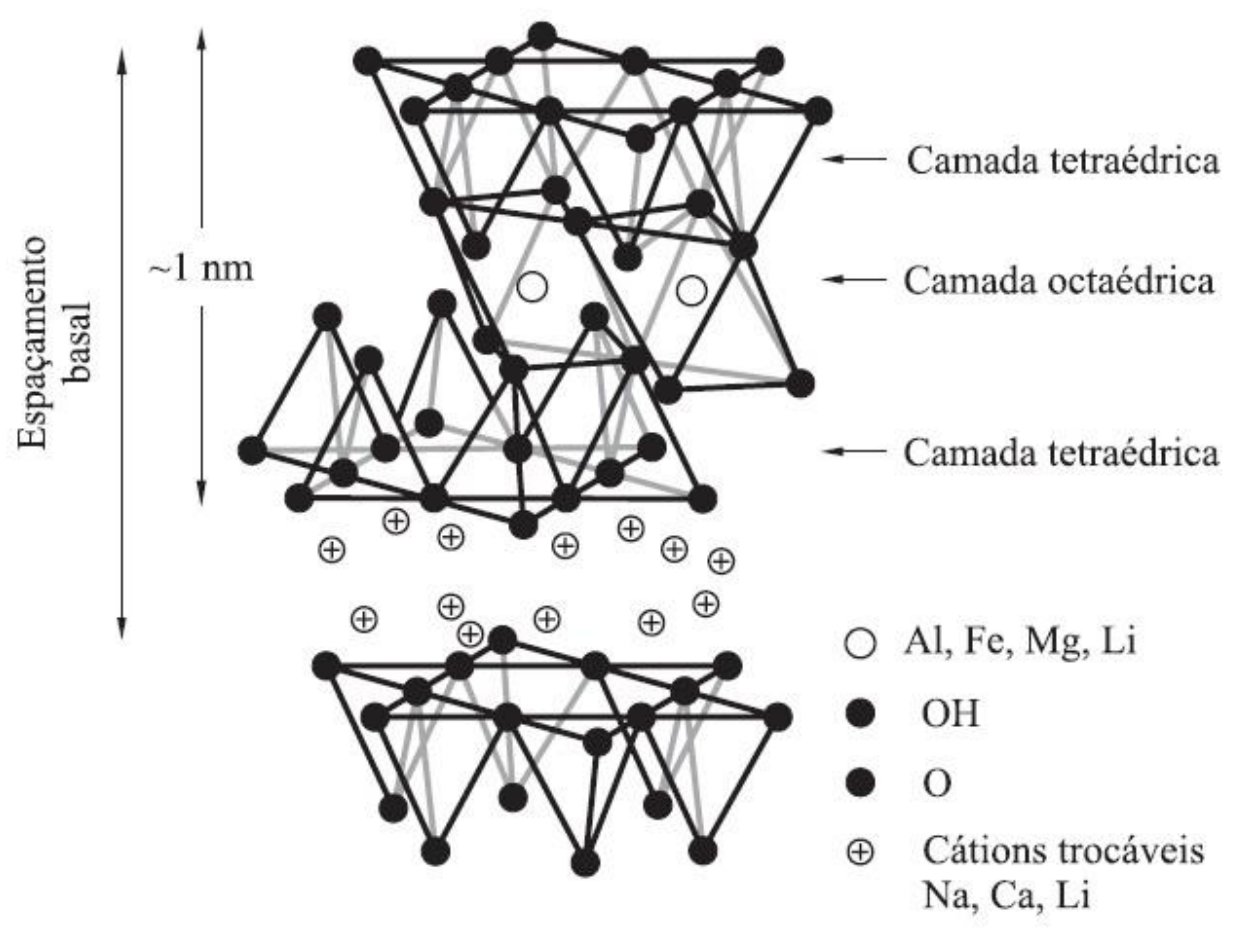

Figura 2. Estrutura dos argilominerais 2:1 (PAIVA, 2006).

Cada camada possui aproximadamente $1 \mathrm{~nm}$ de espessura e dimensões laterais que podem variar entre $30 \mathrm{~nm}$ a alguns micrometros, dependendo do tipo de argilomineral. Estas camadas permanecem empilhadas por forças de Van de Waals, e entre elas existe lacunas denominadas espaço interlamelar ou galeria (RAY e OKAMOTO, 2003).

No Brasil e em outros países onde não há bentonitas naturalmente sódicas, utiliza-se carbonato de sódio para sua transformação em sódica, para inchar em água. É realizado também o tratamento com o sal quaternário de amônio para transformar as argilas de hidrofílica para organofílica, uma vez que a argila organicamente modificada possui reduzida energia superficial, maior espaçamento entre as lamelas, melhorando assim a interação com a matriz polimérica (VALENZUELA-DÍAZ, 1994). A Figura 3 ilustra o processo de troca de cátions em 
argilas através da modificação, tornando a argila natural em organicamente modificada (argila organofílica).

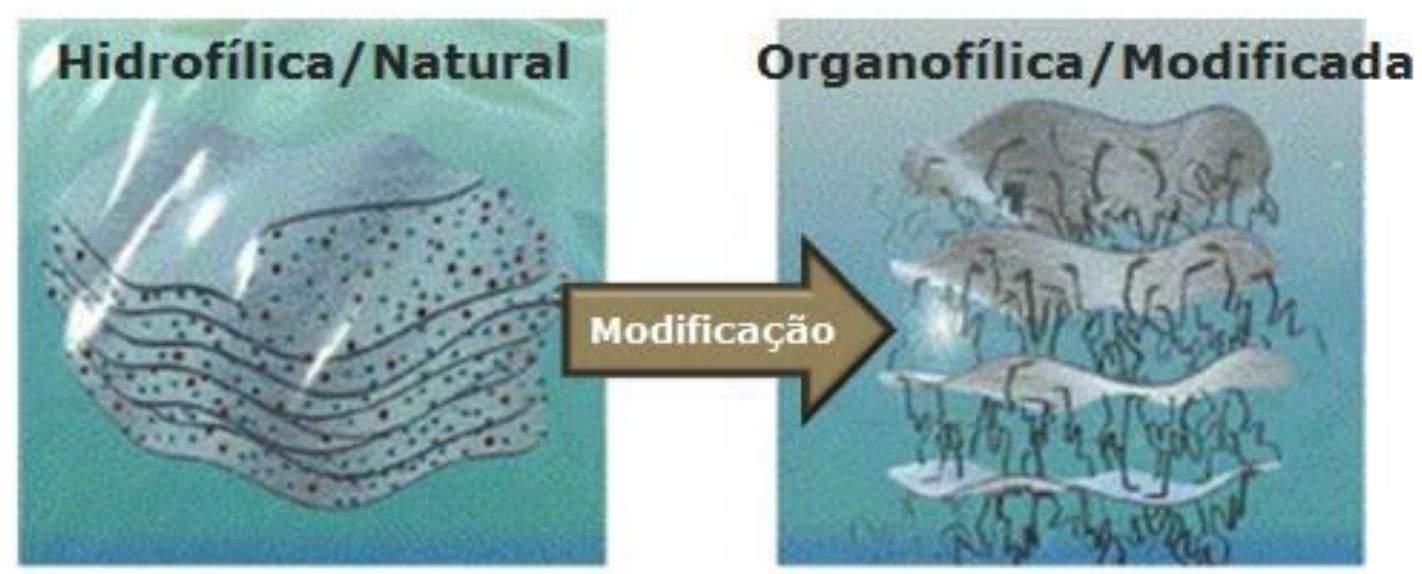

Figura 3. Esquema de troca de íons em argilas através da modificação (adaptado de FISCHER, 2003).

A penetração de moléculas orgânicas no espaço interlamelar é chamada de intercalação. A penetração do composto orgânico nas galerias das argilas promove uma mudança na característica da superfície do material. Quando contêm somente cátions metálicos a argila apresenta um comportamento hidrofílico, mas quando ocorre a troca do cátion metálico pelo cátion orgânico a mesma muda seu comportamento e passa a ser organofílica (ALEXANDRE e DUBOIS, 2000).

\subsubsection{Bentonita no Brasil}

De acordo com os últimos dados do Departamento Nacional de Produção Mineral (DNPM, 2013) o estado da Paraíba é o maior produtor de argila bentonita, suas principais jazidas estão localizadas no município de Boa Vista e Cubati e sua produção concentra 79,6 \% de toda produção nacional, seguido por Bahia com 13 
\%, São Paulo com 7 \% e Paraná com 0,4 \%. Com uma produção bruta de bentonita de 512.975 toneladas.

O Brasil exporta bentonita para outros países, a quantidade exportada foi de 18.150 toneladas. O principal produto exportado foi a bentonita bruta, com $95,6 \%$ de toda quantidade exportada. Os principais destinos das exportações de bentonita primária foram: África do Sul (47\%), Argentina (12\%), Austrália (6\%), Equador (5 \%) e Chile (4\%). Já de bentonita ativada foram Panamá (55\%), Venezuela (20\%), Uruguai (10 \%), Angola (9 \%) e República Dominicana (4 \%) (DNPM, 2013).

\subsection{Nanociência e nanotecnologia}

Os termos nanociências e nanotecnologias se referem, respectivamente, ao estudo e às aplicações tecnológicas de objetos e dispositivos que tenham ao menos uma de suas dimensões físicas menor que, ou da ordem de, algumas dezenas de nanômetros. O prefixo nano (do grego: "anão") é usado nas ciências para designar uma parte em um bilhão e, assim, um nanômetro $(1 \mathrm{~nm})$ corresponde a $10^{-9}$ metros, ou seja, a bilionésima parte de um metro (MELO e PIMENTA, 2004). A Figura 4 apresenta um referencial comparativo de escalas. 


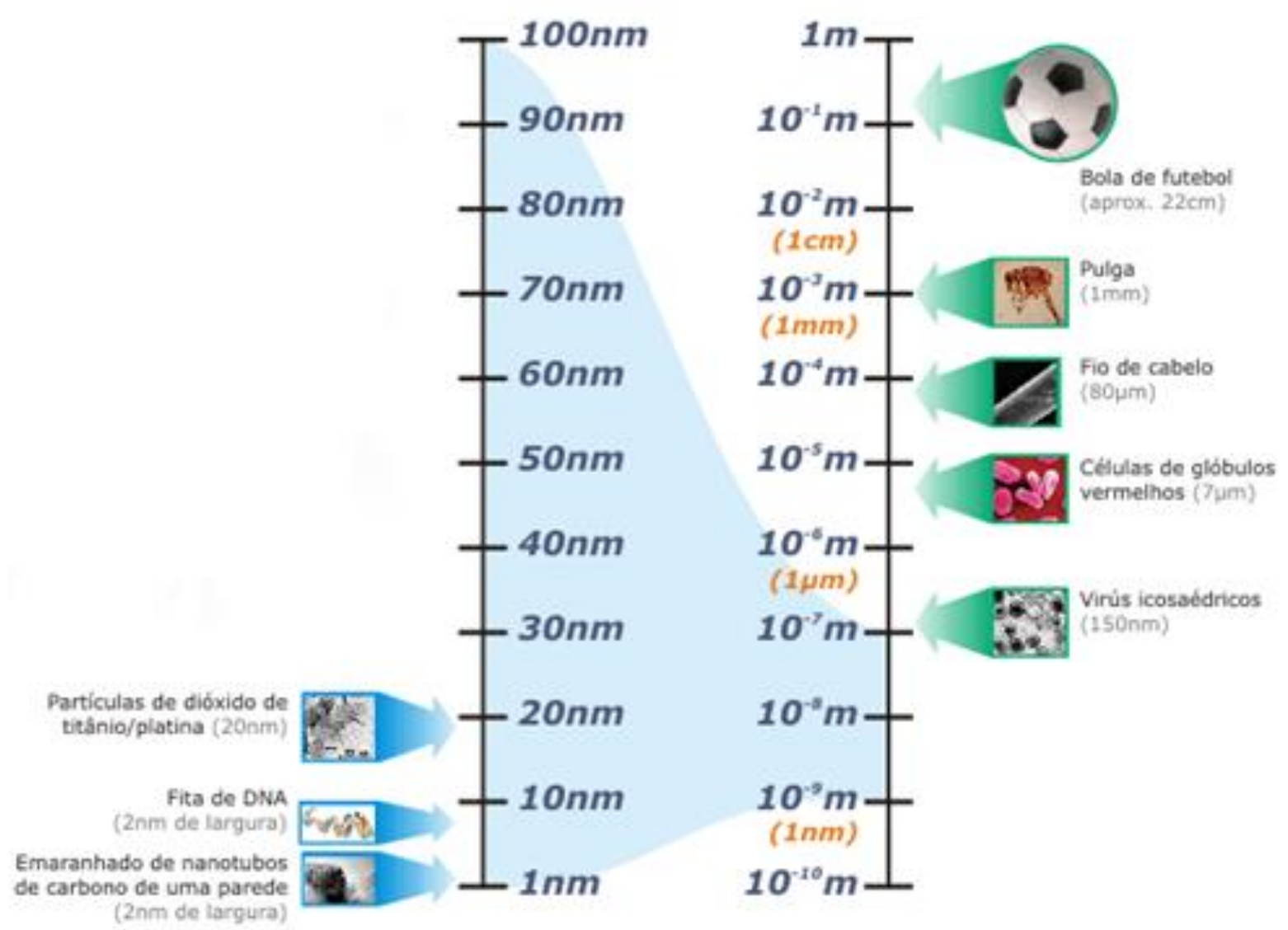

Figura 4. Tamanho e comparação de escalas (NANOTECH, s.d.).

Para efeito de comparação, um nanômetro está para o metro assim como uma bola de gude está para a Terra. A cabeça de um alfinete tem um milhão de nanômetros, enquanto o diâmetro de um fio de cabelo mede 80 mil nanômetros. $E$ os menores objetos que o ser humano consegue ver a olho nu medem cerca de 10 mil nanômetros (MARTINS e FERNANDES, 2009).

O desenvolvimento da nanotecnologia começou em meados da década de 70 e se intensificou no início dos anos 2000. Áreas como medicina, química e engenharia já contam com importantes contribuições dessas inovações. O setor industrial é outro que possui grande campo de atuação nanotecnológico, apresentando, ainda, grande potencial de crescimento para as próximas décadas (SESI, s.d.). 
A grande motivação para o desenvolvimento de objetos e dispositivos nanométricos está no fato de serem observadas novas e incomuns propriedades físicas e químicas, ausentes para o mesmo material quando de tamanho microscópico ou macroscópico. A alteração das propriedades de um material ao atingir a escala nanométrica se deve à combinação de dois fatores: o primeiro é que em objetos com partículas nano os efeitos quânticos se manifestam de maneira mais evidente, e o segundo está no fato de que quanto menor for o tamanho da amostra, mais importantes se tornam os efeitos de superfície, pelo aumento da proporção entre sua área e seu volume. (MELO e PIMENTA, 2004).

\subsection{Nanocompósitos}

Compósito é um material resultante da combinação de dois ou mais materiais onde se busca a melhoria das propriedades de cada componente. Nanocompósito é um material compósito no qual um dos componentes possui uma dimensão nanométrica, ou seja, menor que cem nanômetros $(<100$ nm) (TWARDOWSKI, 2007; MAl e YU, 2006).

Enquanto os compósitos tradicionais utilizam cerca de $40 \%$ em peso de reforço para obter ganho de propriedades, os nanocompósitos podem apresentar melhorias com adição de menos de $5 \%$ em peso de carga (TWARDOWSKI, 2007).

Os nanocompósitos são definidos também como uma nova classe de materiais compósitos, podendo ser uma matriz polimérica, cerâmicas ou metálica, reforçadas com cargas dispersas que possuam pelo menos uma de suas dimensões na escala nanométrica (MORAES, 2007). 
O termo nanocompósito foi utilizado inicialmente em meados dos anos 80 e sua utilização deu-se pela Toyota no ano de 1988 com o desenvolvimento da poliamida 6 reforçada com $5 \%$ em massa de argila montmorilonita, promovendo ganho de propriedades mecânicas e térmicas. Desde então os trabalhos nesta área tem crescido em grande escala. A ciência dos nanocompósitos está presente em todas as áreas de materiais: metais, plásticos, cerâmicos, biomateriais, materiais elétricos e outros (TWARDOWSKI, 2007; YIU e ZHING, 2006).

\subsubsection{Nanocompósitos de matriz polimérica}

Nos últimos anos os nanocompósitos poliméricos têm atraído bastante interesse tanto na indústria quanto nos meios acadêmicos devido à sua favorável relação custo/benefício, considerando que a adição de pequenas quantidades de uma carga em tamanho nanométrico pode promover um aumento na resistência térmica e química, nas propriedades mecânicas, melhoria nas propriedades de barreira à água e ao oxigênio e nas propriedades retardantes de chama de materiais poliméricos, quando comparados ao polímero puro. Este conjunto de atrativos implica na crescente utilização de nanocompósitos poliméricos em diferentes aplicações industriais, como em componentes mais leves e resistentes para a indústria automotiva, embalagens alimentícias mais eficazes, tanques de combustível resistentes a ataques químicos, entre outros (WU et al, 2005; HUANG, 2008). 


\subsubsection{Nanocompósitos polímero / argila}

O reforço mais utilizado na preparação de nanocompósitos poliméricos são as bentonitas (argilas esmectitícas). Devido à boa capacidade de delaminação somada à alta resistência a solventes e estabilidade térmica necessária aos processos de polimerização e de extrusão, levaram à sua popularização como carga para nanocompósitos com eficácia comprovada (PAIVA et al, 2006).

\subsubsection{Métodos de obtenção}

Como anteriormente comentado a obtenção de nanocompósitos polímero/argila, pode ser realizada através de três principais métodos: a polimerização in situ, a mistura em solução e a intercalação por fusão.

A polimerização in situ, consiste na dispersão da argila com um monômero até seu intumescimento para realizar a reação de polimerização. O monômero deve ter uma boa afinidade com a argila para que o sistema tenha uma dispersão homogênea. A polimerização pode ser iniciada por aquecimento, radiação ou por meio de um iniciador orgânico. Esse foi o primeiro método utilizado para sintetizar nanocompósitos polímero-argila (LEROUX, 2006; KORNMANN, 2000).

A preparação em solução é uma técnica onde o polímero é solubilizado em um solvente orgânico, no qual a argila também possa ser dispersa. O sistema pode ser agitado de forma que o mesmo se torne homogêneo onde o polímero é misturado na dispersão de silicatos lamelares, difundindo suas cadeias poliméricas entre as camadas de argila. Quando o solvente é removido, as cadeias poliméricas 
ficam adsorvidas na superfície da argila resultando em um nanocompósito. Por utilizar uma grande quantidade de solvente e envolver gastos significativos em equipamentos e energia não é uma técnica indicada para produção industrial (KORNMANN et al., 2001; RAY, 2013).

A intercalação por fusão é um processo onde a argila é incorporada ao polímero que se encontra em estado fundido. A mistura de polímeros e silicatos lamelares é feita em uma temperatura acima do ponto de amolecimento do polímero. Se houver uma boa interação entre o polímero e a argila, é possível obter estruturas intercaladas e esfoliadas. Este método oferece diversas vantagens sob os demais, como uma relativa simplicidade do processo, compatibilidade com processos industriais, como a extrusão e a moldagem por injeção, e não requer o uso de solvente, sendo assim menos danoso ao meio ambiente (GIANNELIS, 1996). Este método foi o escolhido para obtenção de nanocompósitos neste trabalho por ser o processo mais utilizado na indústria.

\subsubsection{Tipos de estrutura}

Quando uma argila é adicionada a uma matriz polimérica pode resultar em três principais tipos de estrutura, como apresentado na figura 5 . 


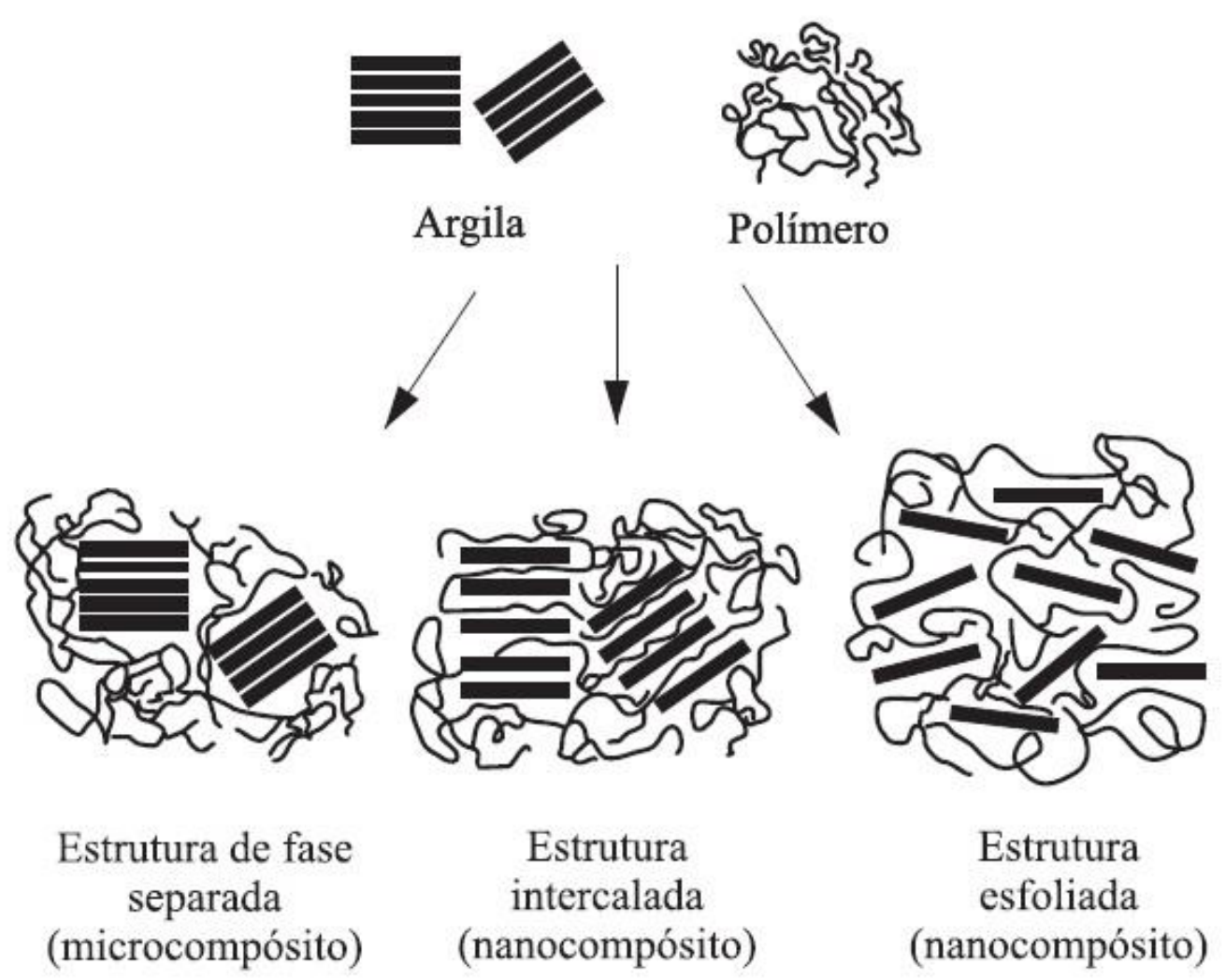

Figura 5. Estrutura dos nanocompósitos (ALEXANDRE e DUBOIS, 2000).

- Microcompósito de estrutura separada: quando as cadeias poliméricas não são capazes de intercalar com as camadas de argila resultando em uma estrutura de microcompósito, com propriedades similares às de um compósito convencional sem alcançar os benefícios desejados;

- Nanocompósito intercalado: Em um nanocompósito do tipo intercalado as cadeias poliméricas são intercaladas entre as camadas de argila e a distância entre as camadas de silicato é aumentada por causa da difusão de polímero entre as lamelas de argila. Apresenta propriedades superiores à de um compósito convencional;

- Nanocompósito esfoliado: as camadas de silicato são completa e uniformemente dispersas na matriz do polímero. A estrutura é completamente 
esfoliada e os benefícios dos compósitos em nanoescala são obtidos, levando a significativas melhorias nas propriedades físicas e mecânicas (PAIVA et al, 2006; RAY e OKAMOTO, 2006; ACIERNO e SCARFATO, 2004; LUO e DANIEL, 2003).

\subsection{Metacrilato de glicidila (GMA)}

Metacrilato de glicidila (GMA) tem atraído um grande interesse devido ao seu grupo epóxi reativo, o qual pode sofrer uma série de reações químicas sob condições adequadas. Além disso, alguns homo e copolímeros à base de GMA possuem uma variedade de aplicações práticas, tais como a modificação de superfície e agentes de compatibilização para misturas de polímeros. O GMA contém a estrutura carbonila $\alpha, \beta$-insaturado, que pode levar a reticulação ou forte adesão interfacial. O GMA tem sido utilizado para preparar copolímero estirenoacrilonitrila / nanoargila organicamente modificada (DENG et al, 2008; DEVI et al, 2012).

\subsection{Radiação lonizante}

A radiação ionizante ou radiação de energia alta são normalmente utilizadas para designar radiação eletromagnética (gama $(\mathrm{Y})$ e raios $-\mathrm{X}$ ), ou emissões de partículas alfa $(\alpha)$, beta $(\beta)$ ou feixes de partículas aceleradas (elétrons, prótons, nêutrons, dêuterons, entre outros), (O'DONNELL e SANGSTER, 1970; SWALLOW, 1960; VÉRTES, 2003). 
As radiações ionizantes possuem energia de valor superior à energia da ligação química e perdem a sua energia principalmente pela interação com os elétrons orbitais das moléculas localizadas ao longo da sua trajetória, originando estados excitados ou ionizando-as e gerando íons ou radicais livres. A energia de ligação é a quantidade de energia necessária para romper a ligação (CLOUGH et al, 1996; DOLE, 1972; DROBNY, 2002).

\subsubsection{Efeitos da radiação em polímeros}

A interação da radiação ionizante com a matéria promove eventos físicos, químicos e físico-químicos. Quando submetido à radiação ionizante um determinado polímero ou filme polimérico pode sofrer várias modificações na sua estrutura física e química induzidas pela interação da radiação com o polímero. Essa interação da radiação ionizante com compostos orgânicos produz principalmente cátions, ânions, radicais livres e podem ficar aprisionadas por algum tempo na matriz polimérica causando transformações denominadas efeitos pós-irradiação (VERTES, 2003; CLEGG, 1991).

Em decorrência da interação da radiação ionizante com os polímeros podem ocorrer importantes processos de alterações das cadeias poliméricas, a degradação e a reticulação. Tais reações são concorrentes e a predominância de uma sobre a outra está relacionada com a composição do polímero, condições de processo, do tipo de radiação, presença de oxigênio, entre outras (BRADLEY, 1986; CLEGG, 1991). 


\subsubsection{Degradação}

Pode ser classificada como uma série de reações químicas que envolvem também ruptura das ligações da cadeia principal da macromolécula, normalmente com redução da massa molar e consequentemente queda nas propriedades físicomecânicas (CANEVAROLO, 2010).

\subsubsection{Reticulação}

É a formação de ligações intermoleculares na cadeia polimérica. $\mathrm{Na}$ reticulação as moléculas poliméricas se ligam quimicamente, formando uma única molécula, de massa molar média maior. A reticulação de termoplásticos pode ser iniciada por radiação ionizante ou por iniciadores químicos. O processo de reticulação pode proporcionar ao material melhores propriedades mecânicas, mais resistência química e a degradação térmica, melhores propriedades de barreiras, maior estabilidade ao calor e menor fluência. Depende de vários fatores: massa molar, distribuição da massa molar, presença de um terceiro componente, temperatura e pH (RABELLO, 2000).

\subsection{Técnicas de caracterização}

Diversas técnicas são utilizadas para caracterizar materiais nanocompósitos, entre elas a difração de raios $X(X R D)$, análise termogravimétrica $(T G)$, calorimetria exploratória diferencial (DSC), microscopia eletrônica de transmissão (MET). 


\subsubsection{Difração de raios $X(X R D)$}

A difração de raios $\mathrm{x}$ é muito utilizada no estudo de nanocompósitos polímero/argila, pois através dela é possível identificar o grau de intercalação ou esfoliação da nanoargila na matriz polimérica, considerando que a intercalação e esfoliação modificam as dimensões dos espaços entre as camadas de silicato, um aumento na distância das camadas indica que o nanocompósito foi formado. Com a técnica de DRX é possível determinar o espaçamento das camadas do silicato. O cálculo da distância interplanar é realizado segundo a Lei de Bragg:

$$
n \lambda=2 d \operatorname{sen} \theta
$$

onde: $n$ é a ordem de difração; $\lambda$ é o comprimento de onda dos raios - X; $d$ é a distância entre camadas adjacentes de átomos; $\theta$ é o ângulo entre o raio incidente e os planos de difração ( VOSSEN, 2009; RICHARD e CHARLES, 1992).

\subsubsection{Análise termogravimétrica (TG)}

A análise termogravimétrica ou termogravimetria é usada para medir a variação de massa de uma amostra, resultante de uma transformação física ou química, em função do tempo ou da temperatura. Por essa técnica é possível conhecer as modificações que o aquecimento pode causar na massa das substâncias, permitindo estabelecer a faixa de temperatura em que elas adquirem composição química fixa e constante, temperatura de decomposição, entre outras.

O avanço do TG deve-se principalmente ao interesse na determinação de estabilidade térmica de compostos inorgânicos. Sua aplicação na análise de 
polímeros se deu em consequência da necessidade do conhecimento na estabilidade térmica e oxidativa de polímeros (ABPOL, 1998; CANEVAROLO, 2003).

\subsubsection{Calorimetria exploratória diferencial (DSC)}

A análise por DSC é uma técnica de analise térmica utilizada para determinar mudanças físicas ou químicas que são acompanhadas de ganho ou perda de calor. Quando as substancias são aquecidas, varias transformações físicas ou químicas envolvendo absorção ou evolução de calor podem ocorrer (ABPOL, 1998).

Como evento térmico de materiais poliméricos pode-se citar:

- Temperatura de transição vítrea (Tg): é a temperatura abaixo da qual a cadeia principal do polímero não possui mobilidade;

- Temperatura de fusão (Tm): só ocorre em materiais com um mínimo de cristalinidade. Em materiais totalmente amorfos este evento não ocorre;

- Grau de cristalinidade $(X c)$ : as propriedades físicas como dureza, resistência mecânica, densidade, entre outras, variam consideravelmente com o percentual de cristalinidade, que relaciona a quantidade de material cristalino e material amorfo de uma amostra. (LUCAS et al., 2001).

\subsubsection{Microscopia eletrônica de varredura (MEV)}

É utilizada para estudo de estruturas superficiais das amostras, é uma técnica que permite a obtenção de informações estruturais e químicas (através do EDS acoplado ao equipamento) de diversas amostras. Os materiais com baixa 
condutibilidade, como grande maioria dos polímeros, precisam de revestimento condutivo antes da realização do ensaio, tal revestimento tem como objetivo evitar o acúmulo de carga negativa. (CANEVAROLO, 2003).

\subsubsection{Microscopia eletrônica de transmissão (TEM)}

Esta técnica permite analisar de forma qualitativa a estrutura interna, a distribuição espacial de várias fases e defeitos estruturais através da visualização direta e complementa resultados obtidos por difração de raios $\mathrm{x}$, permitindo identificar a morfologia exata do nanocompósito. Quando nanocompósitos são formados, as interseções das camadas de silicato são vistas como linhas escuras que são as secções longitudinais das camadas de silicato, medindo em torno de 1 nm de espessura (WILLIANS e CARTER, 1996).

\subsubsection{Ensaio de tração}

Os ensaios mecânicos de tração é um dos mais populares utilizados na caracterização de resistência de um material, pois é considerado o teste mecânico que apresenta melhor relação entre informações obtidas e custo/complexidade de ensaio. É possível determinar o quanto o material estende ou deforma antes de sua ruptura. O ensaio consiste, basicamente, em se tracionar um corpo de prova sob formas e dimensões padronizadas até a sua ruptura. Deve-se utilizar pelo menos cinco corpos de prova para cada corrida de ensaio de tração. (CANEVAROLO, 2010; ASTM D 638, 2001). 


\subsubsection{Ensaio de flexão}

O ensaio de resistência à flexão determina as propriedades que são especialmente úteis para controle de qualidade e finalidades especificas. É realizado nos mesmos equipamentos utilizados para o ensaio de tração, porém o sentido de deslocamento é descendente, flexionando o corpo de prova até a máxima deformação ou quebra do corpo de prova. Este ensaio fornece dados que permitem avaliar diversas propriedades mecânicas dos materiais como as propriedades de flexão, módulo de flexão, resistência à flexão (ASTM D 790, 2000).

\subsubsection{Ensaio de resistência ao impacto}

É utilizado para avaliar a capacidade de um material absorver energia por meio de impacto. Está subdividido em dois grupos: Izod e Charpy, o primeiro é realizado verticalmente enquanto o segundo horizontalmente. No ensaio de impacto Izod, um pêndulo que é liberado de uma altura fixa, oscila para bater e quebrar uma amostra posicionada no ponto mais baixo da oscilação. Seu movimento continua até uma altura máxima medida no final da primeira oscilação (CANEVAROLO, 2010; ASTM D 256, 2005).

\subsubsection{Temperatura de distorção térmica (HDT)}

É a temperatura na qual um corpo de prova sofre uma determinada deformação quando submetido a uma carga padronizada em um meio fluido sob efeito de uma velocidade constante de aumento de temperatura. Até qual 
temperatura o material preserva suas propriedades. Neste ensaio a amostra é mergulhada em um banho térmico que permite uma velocidade de aquecimento igual a $2 \pm 0,2^{\circ} \mathrm{C} / \mathrm{min}$. No qual é aplicada uma carga de $0,45 \mathrm{MPa}$ ou $1,82 \mathrm{MPa}$ sobre o corpo de prova. $\mathrm{O}$ resultado da temperatura do meio é medida quando o corpo de prova sofre uma distorção igual a 0,25 mm (CANEVAROLO, 2010; ASTM D $648,2007)$.

\subsubsection{0. Índice de fluidez}

A viscosidade dos materiais poliméricos é um importante fator que afeta as suas propriedades. Está diretamente relacionada com a massa molar do material e suas configurações moleculares e pode ser mensurada por várias técnicas como o de índice de fluidez. O teste de índice de fluidez é uma técnica simples, porém amplamente utilizado nas indústrias, principalmente na área automotiva (OTA, 2004).

O índice de fluidez é uma técnica utilizada para medir a viscosidade do polímero fundido. É definida como o fluxo de material polimérico a passar através de um orifício padronizado por 10 minutos a uma determinada temperatura e pressão (ASTM D 1238, 2013).

\subsubsection{Fração gel}

Quando os polímeros são submetidos a radiações ionizantes, reticulação e degradação da cadeia estão entre os efeitos químicos observados. Se o processo 
de reticulação for predominante ao de degradação é observada a formação de um gel insolúvel. A análise de fração em gel de polímeros irradiados permite estimar importantes parâmetros de radiação como o grau de reticulação e degradação, dose de gelificação, e relacioná-las com diferentes propriedades físico-químicas (OLEJNICZAK et al, 1991; ROSIAK, 1998). 


\section{MATERIAIS E MÉTODOS}

\subsection{Materiais}

O polímero utilizado neste estudo foi o Poli (butileno tereftalato) - PBT (Celanex 1600 - Ticona Engineering Polymers), densidade de 1,33 g/ $/ \mathrm{cm}^{3}$.

O nano reforço utilizado foi a argila bentonita Chocolate proveniente do município de Boa Vista - PB. O sal utilizado para transformar essa argila de sódica para organofílica foi o sal quaternário de amônio hexadecitimetilamônio.

O agente de compatibilização empregado foi o metacrilato de glicidila (GMA) da Sigma Aldrich.

\subsection{Métodos}

\subsubsection{Preparação e modificação da argila}

A argila bentonita utilizada neste estudo é denominada Chocolate e é proveniente do município de Boa Vista - PB. Apresenta cor marrom e uniforme. A Figura 6 mostra o depósito onde é retirada a argila Chocolate. 


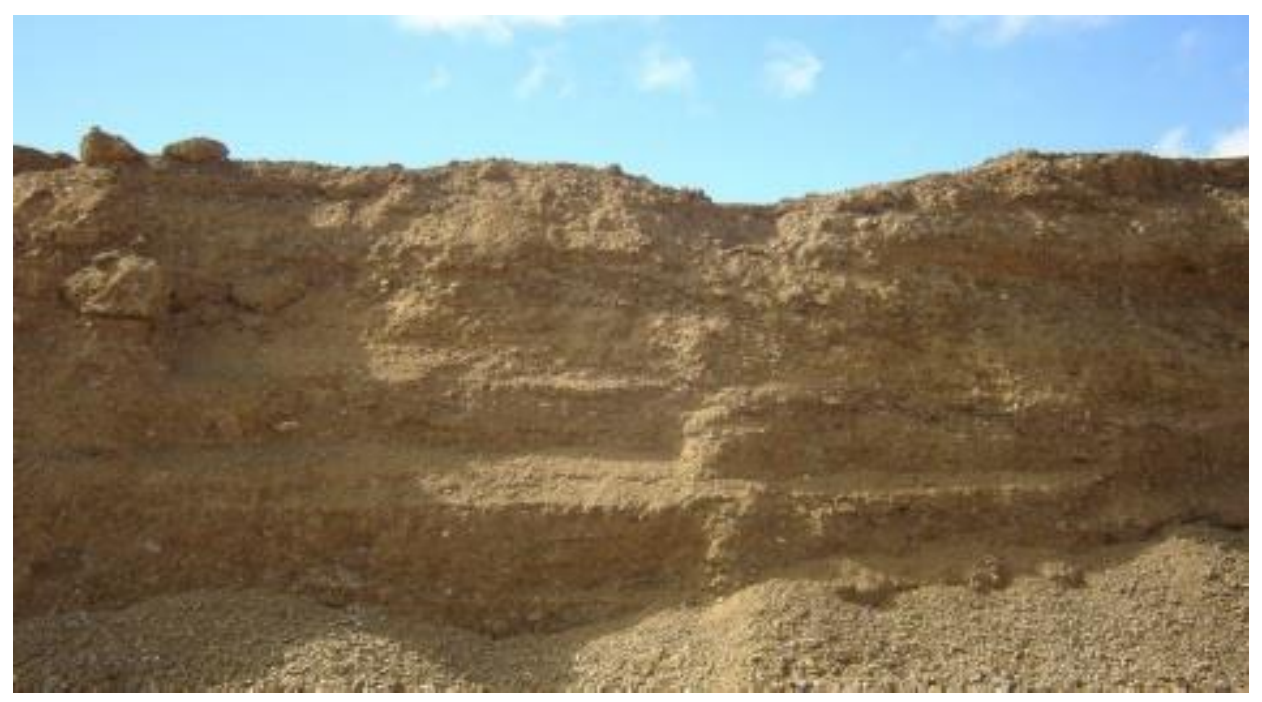

Figura 6. Depósito da argila chocolate (SILVA, 2010).

A argila bentonita chocolate foi modificada organicamente pela reação de troca catiônica com a adição de sal quaternário de amônio.

Foram colocadas $200 \mathrm{~g}$ de argila bentonita chocolate em $4800 \mathrm{~mL}$ de água destilada em agitação mecânica por 60 min. Após esse período foram adicionados 127,8 mL de sal quaternário de amônio (Genamin CTAC 50 - cloreto de hexadecil trimetil amônio) mantendo-se sob agitação mecânica por mais 60 min. Em seguida a dispersão foi filtrada e lavada a vácuo para retirada do excesso de sal, com $5000 \mathrm{~mL}$ de água destilada e seca em estufa a $60^{\circ} \mathrm{C}$, por $48 \mathrm{~h}$. A argila modificada foi moída em moinho de facas rotativas e depois em moinho de bolas para obtenção do pó da argila e, em seguida, passada em peneira ABNT no $200(D=0,074 \mathrm{~mm})$.

Esta etapa foi realizada no laboratório de Materiais Não Metálicos Pérsio de Souza Santos da Escola Politécnica da Universidade de São Paulo - USP, de acordo com metodologia desenvolvida por Valenzuela - Díaz (VALENZUELA - DÍAZ, 1994; PAIVA, et al, 2008; PEREIRA, 2007). 

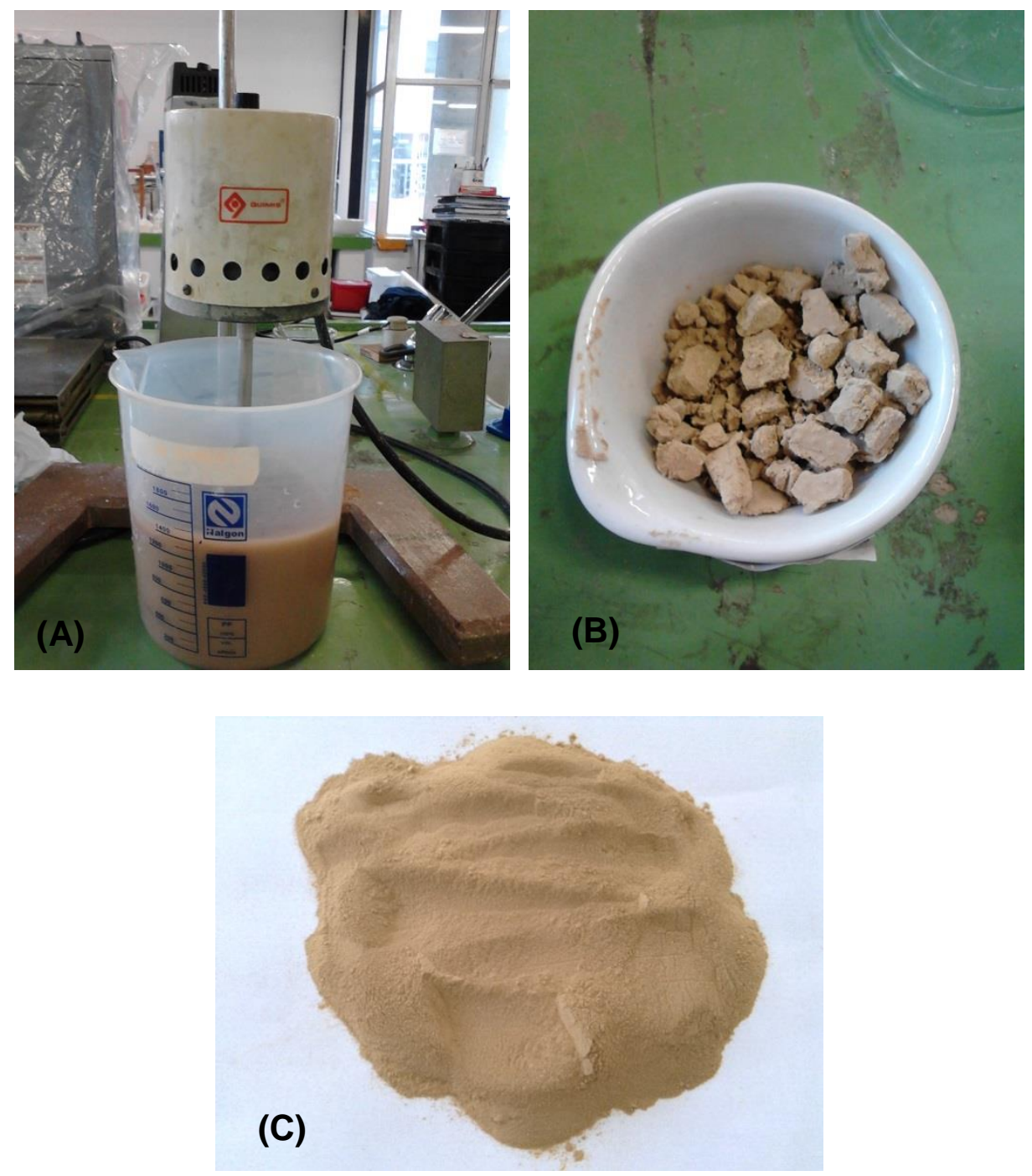

Figura 7. Modificação da argila. (A) argila sendo dispersa em água destilada; (B) argila modificada seca em estufa; $(\mathrm{C})$ argila modifica peneirada.

\subsubsection{Teor de umidade}

A umidade em um material plástico pode causar diversos efeitos indesejáveis, como problemas no processamento, queda nas propriedades mecânicas das peças injetadas ou defeitos visuais. A fim de evitar que a umidade cause problemas no nanocompósito, o PBT e a argila foram mantidos em estufa antes de serem processados. 
O teor de umidade ideal para processamento do PBT deve estar abaixo de $0,03 \%$ e, para tanto, o PBT deve ser mantido em estufa por um período $2 \mathrm{~h}$ a $4 \mathrm{~h}$ antes de ser processado (TICONA, 2014). Ainda não há nenhuma especificação com relação a teor de umidade para processamento das argilas então utilizou-se como referência o teor especificado para o polímero.

Para determinar o tempo ideal de secagem, os materiais foram colocados no desumidificador do laboratório de qualidade da empresa NZ Cooperpolymer com o objetivo de medir o teor de umidade quando em temperatura ambiente.

Foram pesados $20 \mathrm{~g}$ do PBT retirado direto da embalagem e $20 \mathrm{~g}$ da argila bentonita modificada que estava mantida em pote de vidro, e foram colocados no equipamento (Figura 8) para determinar o teor de umidade. Verificou-se que o teor de umidade do PBT era de $0,04 \%$ e o da argila 5,9\%. Esses materiais foram separados em dois vidros de relógio com $10 \mathrm{~g}$ e mantidos em estufa a $100{ }^{\circ} \mathrm{C}$ por duas horas e três horas, respectivamente. Após duas horas foi medida a umidade dos materiais e a argila tinha $1,8 \%$ de umidade e o PBT $0,01 \%$, valor esse considerado ideal pelo fabricante. Após três horas em estufa a argila e o PBT tinham $0,00 \%$ de umidade. A Tabela 1 mostra os percentuais de umidade do PBT e da argila antes e posteriormente à secagem.

Tabela 1. Percentual de umidade do PBT e argila em temperatura ambiente e depois de mantidos em estufa.

\section{Temperatura ambiente $2 \mathrm{~h}$ em estufa $\quad 3 \mathrm{~h}$ em estufa}

\begin{tabular}{c|ccc}
\hline PBT & $0,04 \%$ & $0,01 \%$ & $0,00 \%$ \\
Argila & $5,93 \%$ & $1,85 \%$ & $0,00 \%$ \\
\hline
\end{tabular}


O PBT em duas horas apresentou limites de umidade especificados pelo fabricante, considerando que foi utilizado para os testes uma pequena quantidade de amostra e o processamento deste trabalho será realizado com uma quantidade maior de material, para evitar taxa de erro, o PBT foi mantido em estufa por três horas. Nessas três horas tanto o PBT quanto a argila obtiveram padrões ideais de processamento. Definiu-se, portanto, que para este estudo os materiais seriam mantidos em estufa por três horas a $100^{\circ} \mathrm{C}$ antes de serem processados.

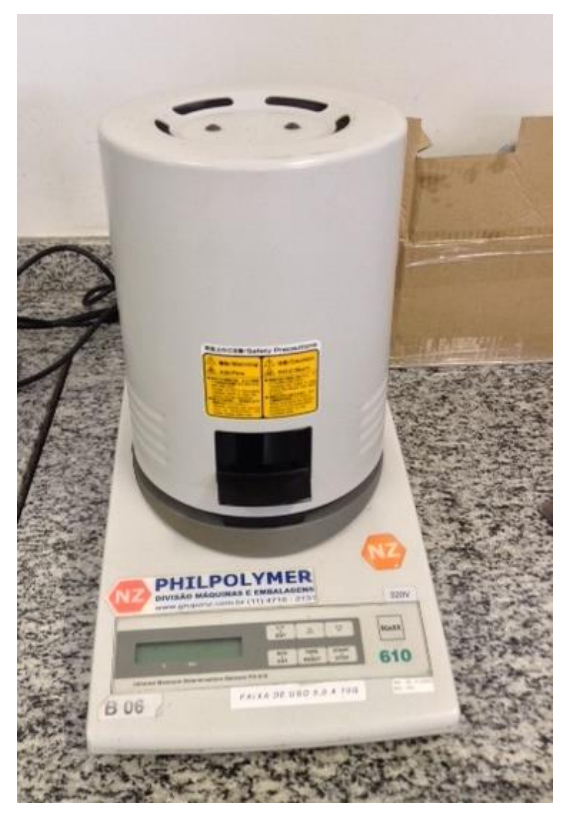

Figura 8. Equipamento utilizado para medir o teor de umidade localizado no laboratório de qualidade da empresa NZ Cooperpolymer.

\subsubsection{Preparação dos nanocompósitos}

A incorporação das nanopartículas de argila na resina PBT foi preparada com a utilização de uma extrusora dupla rosca (“AX16LD40” da AX Plásticos Máquinas Técnicas Ltda) (Figura 9) localizada no Centro de Tecnologia das Radiações (CTR), 
IPEN/CNEN - SP. As temperaturas utilizadas foram de $200^{\circ} \mathrm{C}$ a $240{ }^{\circ} \mathrm{C}$ (Tabela 2) com velocidade de rotação das roscas de 60 rpm e velocidade de alimentação de 25 rpm. O resfriamento do material foi feito primeiramente por ventilação forçada e depois por imersão em água, e foi cortado em grãos por processo contínuo. Após a extrusão os grânulos dos nanocompósitos foram acondicionados em embalagens aluminizadas.

Tabela 2. Temperaturas utilizadas no processo de extrusão.

\begin{tabular}{c|ccccccccc}
\hline Zona & 1 & 2 & 3 & 4 & 5 & 6 & 7 & 8 & Cabeçote \\
\hline Temperatura $\left(\mathrm{C}^{\circ}\right)$ & 200 & 215 & 220 & 220 & 225 & 235 & 235 & 230 & 230 \\
\hline
\end{tabular}

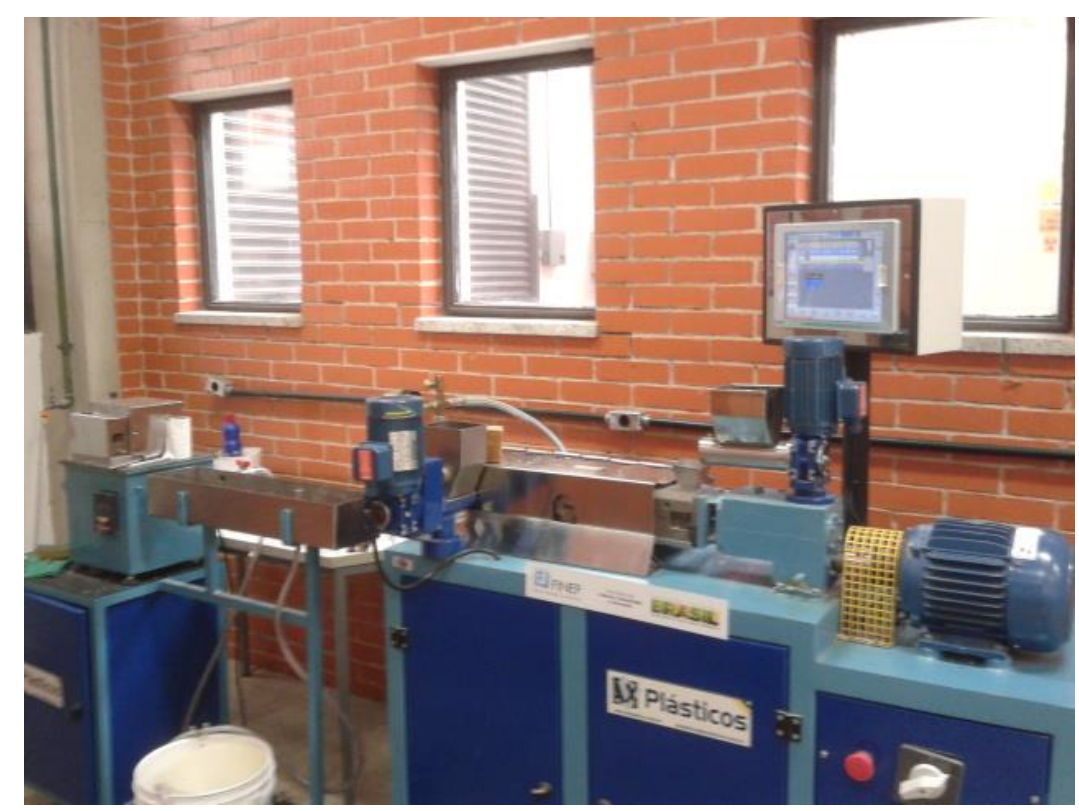

Figura 9. Extrusora utilizada para obtenção dos nanocompósitos. 


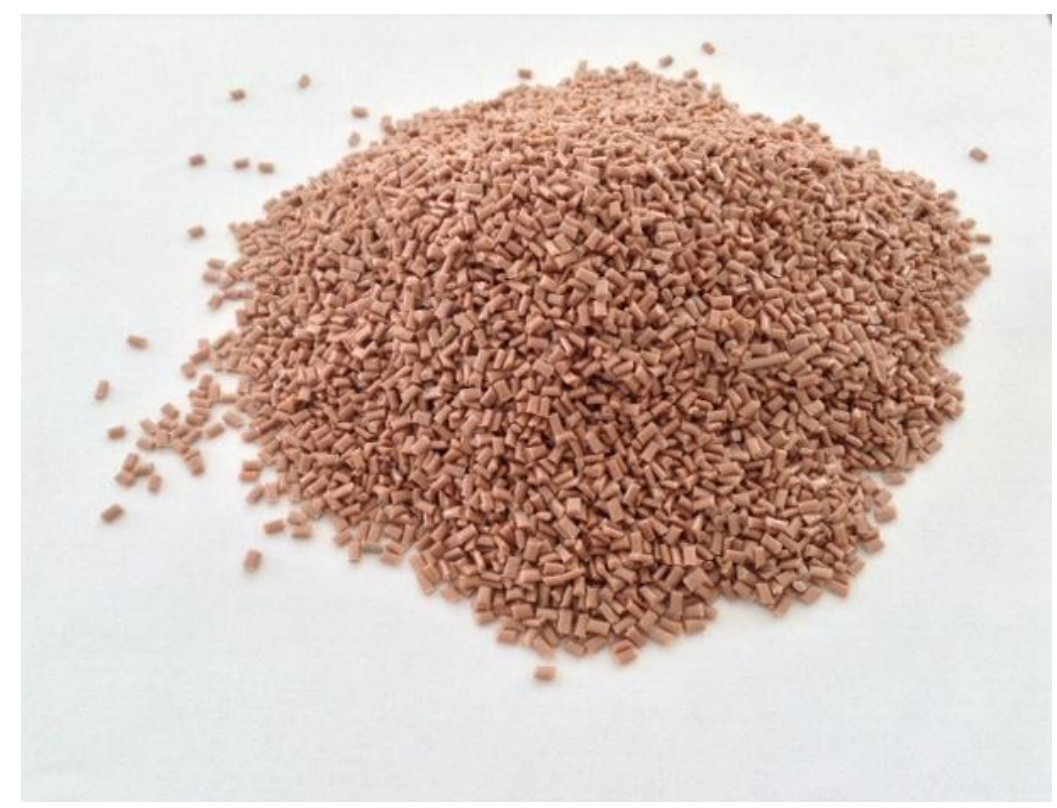

Figura 10. Nanocompósitos de PBT/GMA/3\% Argila obtidos no processo de extrusão.

De acordo com a literatura (NIRUKHE e ESHERTUKDE, 2009; CHOW, 2008; SCATTEIA et al, 2004; WU et al, 2005), a adição de menos de $5 \%$ de argila na matriz polimérica de PBT apresenta ganhos significativos em suas propriedades. Portanto, foram preparadas neste trabalho nanocompósitos com $3 \%$ e $5 \%$ de argila bentonita chocolate mais $0,5 \%$ do agente compatibilizante GMA, foi preparada também uma amostra de PBT com $0,5 \%$ de GMA para realização de todos os ensaios de caracterização e doses de radiação. Para efeito de comparação foram preparados nanocompósitos com $3 \%$ e $5 \%$ de argila bentonita chocolate para caraterização mecânica sem irradiação. 
Tabela 3. Formulação dos materiais.

\begin{tabular}{cccc}
\hline Amostra & PBT & GMA & Argila \\
\hline 1 & 99,5 & 0,5 & - \\
2 & 96,5 & 0,5 & 3,0 \\
3 & 94,5 & 0,5 & 5,0 \\
4 & 97,0 & - & 3,0 \\
5 & 95,0 & - & 5,0 \\
\hline
\end{tabular}

\subsubsection{Injeção dos corpos de prova}

Para a obtenção dos corpos de prova, os grânulos obtidos no processo de extrusão foram mantidos em estufa por três horas a $100{ }^{\circ} \mathrm{C}$ para retirada do excesso de umidade e injetados na máquina injetora Demag Ergotech modelo 35/115, do Departamento de Engenharia Metalúrgica e de Materiais (PMT) - Escola Politécnica - SP, onde o material é submetido à pressão e temperatura, sendo forçado a fluir e a preencher uma cavidade. A figura 11 mostra os modelos de corpos de prova injetados que foram utilizados para os testes de impacto, flexão e tração, respectivamente. 


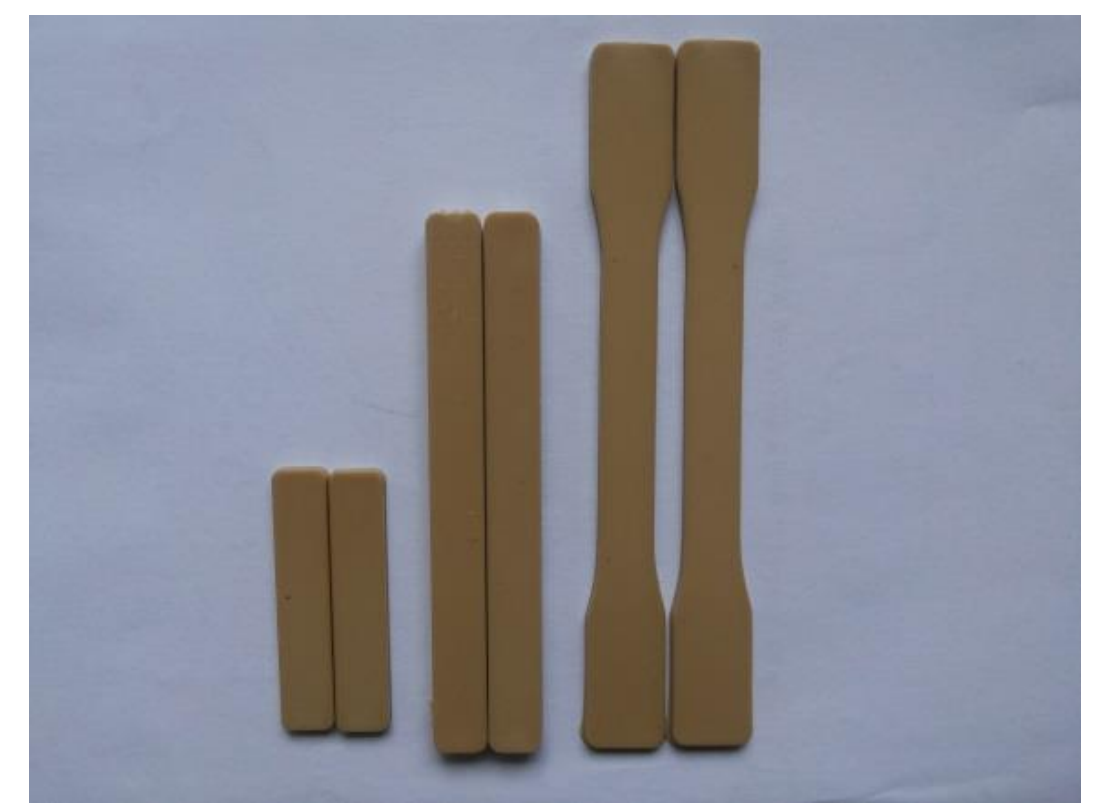

Figura 11. Corpos de prova do PBT/GMA/ 3\% Argila obtidos no processo de injeção.

\subsubsection{Irradiação dos nanocompósitos}

Os ensaios de irradiação foram realizados com doses de radiação de 150 , 250 e 350 kGy, à temperatura ambiente e na presença de ar, no acelerador de elétrons modelo "Dynamitron II" com energia de 1,5 MeV, corrente de 2,81 mA, localizado no CTR-IPEN/CNEN-SP.

Após serem irradiadas, as amostras foram colocadas dentro de embalagens plásticas e mantidas em local seco e protegido de luz, evitando assim os efeitos da pós-irradiação e a influência de luz natural e/ou artificial sobre os resultados das análises até o momento de serem submetidas aos ensaios. 


\subsection{Caracterização}

\subsubsection{Difração de Raios X (DRX)}

Os perfis de difração de raios $x$ dos materiais foram determinados em um difratômetro modelo Rigaku DMAX 2200 localizado no laboratório do Centro de Materiais Avançados (T-CAM) da Universidade Tuskegee (Tuskegee, Alabama, EUA) com radiação CuKa $(\lambda=1.54 \mathrm{~nm})$ operado em $40 \mathrm{kV}$ e $40 \mathrm{~mA}$, com $2 \theta$ variando entre $2^{\circ}$ e $30^{\circ}$. Esta técnica foi realizada para a avaliação da modificação da argila e da formação dos nanocompósitos, pois a mesma possibilita determinar o espaçamento basal $\left(d_{001}\right)$ entre as camadas da argila.

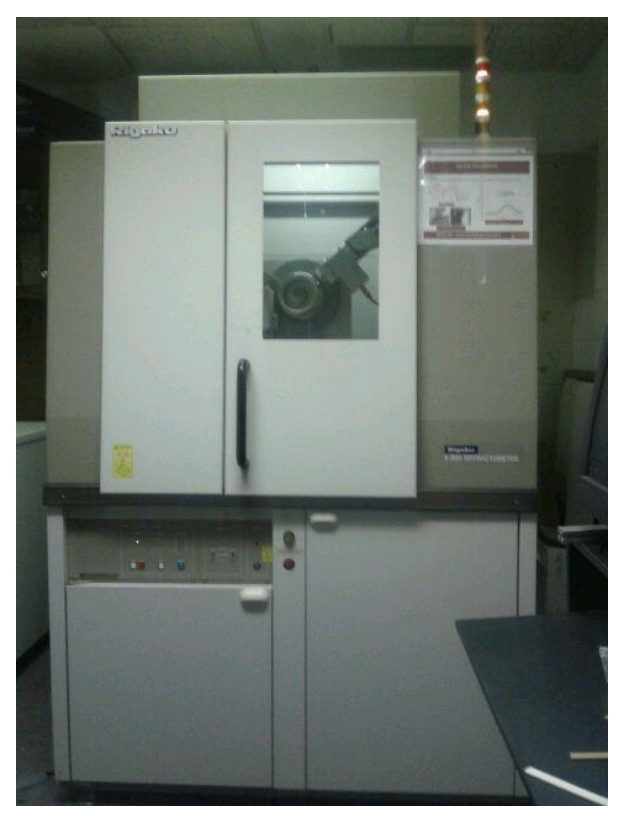

Figura 12. Difratômetro de raios X modelo Rigaku DMAX 2200 do laboratório do Centro de Materiais Avançados da Universidade Tuskegee. 


\subsubsection{Espectrometria de fluorescência de raios X (WDXRF)}

Para avaliar os compostos inorgânicos presentes na argila, foi realizada a análise de WDXRF utilizando um espectrômetro de fluorescência de raios $X$ por dispersão de onda, modelo RIX 300 Rigaku do Laboratório de Fluorescência de Raios x do Centro de Química e Meio Ambiente (CQMA), IPEN/CNEN - SP.

\subsubsection{Análise do teor de carga}

Esta análise foi realizada utilizando uma mufla do Laboratório de Qualidade da empresa NZ Cooperpolymer - SP seguindo a norma ASTM D - 5630. Aproximadamente $10 \mathrm{~g}$ de amostra de cada formulação obtida no processo de extrusão foram colocadas em cadinhos de porcelana e levados à mufla onde foram aquecidos até uma temperatura de $600^{\circ} \mathrm{C}$ por uma hora até a queima total do material. Passado esse período e o resfriamento das amostras, pesaram-se os cadinhos com as cinzas para obter o teor de carga do material (Figura 13).
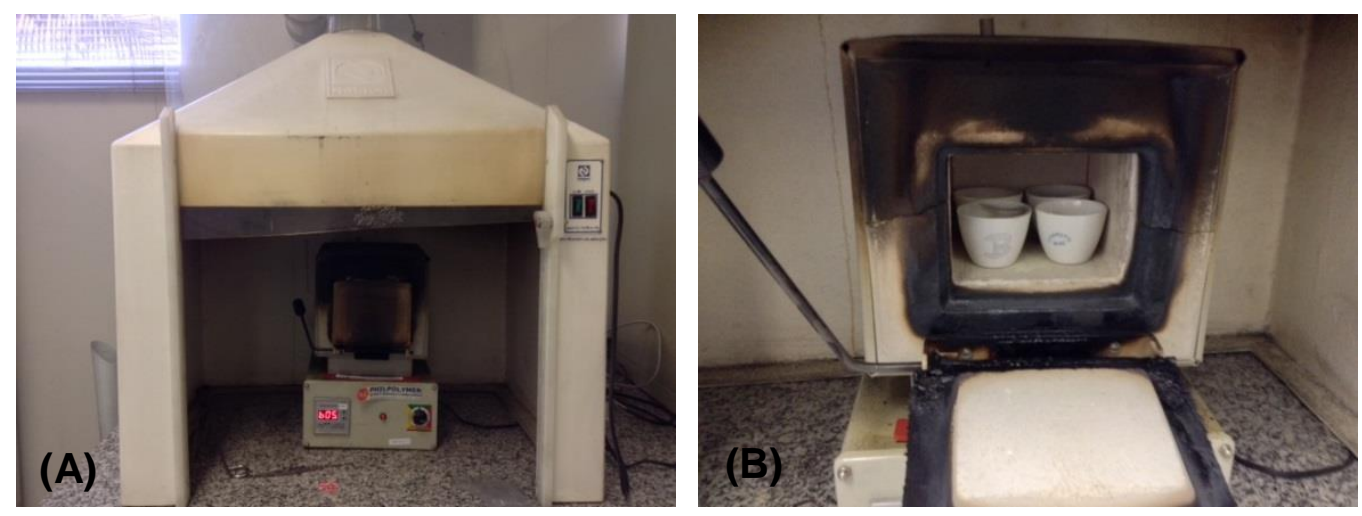

Figura 13. Análise do teor de carga. (A) Mufla; (B) Mufla com os cadinhos com as amostras. 


\subsubsection{Ensaio de tração}

Os ensaios de tração foram realizados conforme a norma (ASTM D 638) em uma máquina universal de ensaios modelo Instron 5567 - localizado no Centro de Tecnologia das Radiações (CTR), IPEN/CNEN - SP, com velocidade de deslocamento de $50 \mathrm{~mm} / \mathrm{min}$, pré-carga de 10,0 N em temperatura ambiente. Através deste ensaio obtiveram-se valores de resistência à tração na ruptura. Foram realizados testes com dez corpos de prova de cada tipo de amostra (Figura 14).

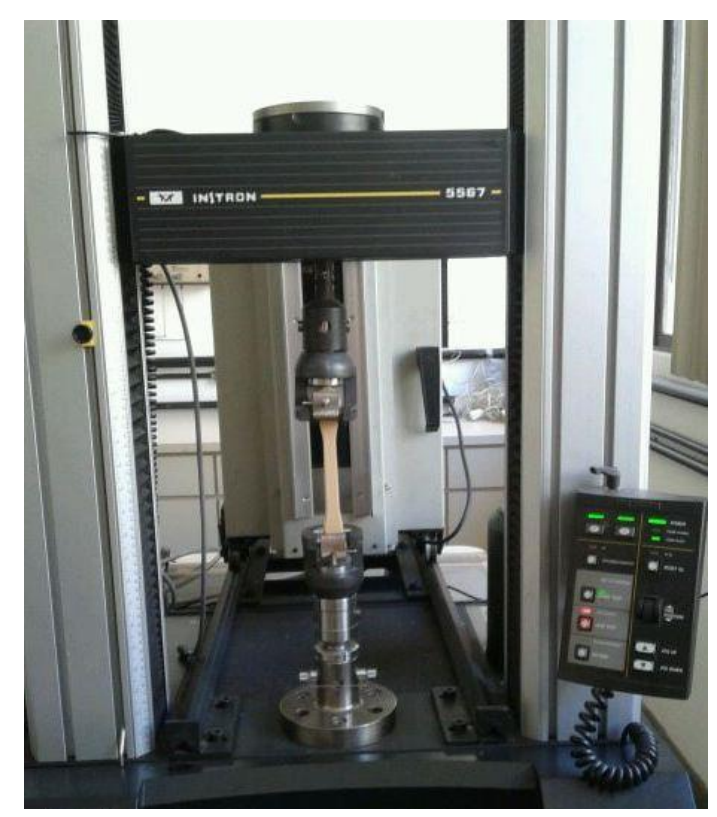

Figura 14. Máquina universal de ensaios Instron durante a realização do ensaio de tração.

\subsubsection{Ensaio de flexão}

Foi utilizado o método carregamento de três pontos segundo a norma (ASTM D790) utilizando a máquina universal de ensaios modelo Instron 5567, localizada no Centro de Tecnologia das Radiações (CTR), IPEN/CNEN - SP. Foram obtidos 
valores de módulo de flexão e resistência à flexão. Utilizaram-se dez corpos de prova de cada formulação.

\subsubsection{Ensaio de resistência ao impacto}

O ensaio de impacto izod (ASTM D 256) foi realizado no equipamento XJC 25D do Laboratório de Qualidade da empresa NZ Cooperpolymer - SP. Antes de serem submetidos ao ensaio de impacto Izod, os corpos de prova foram entalhados para prevenir a deformação dos mesmos sob o efeito do impacto e para evitar influência nos resultados foram retiradas quaisquer rebarbas dos corpos de prova. Foram utilizados cinco corpos de prova para cada composição.
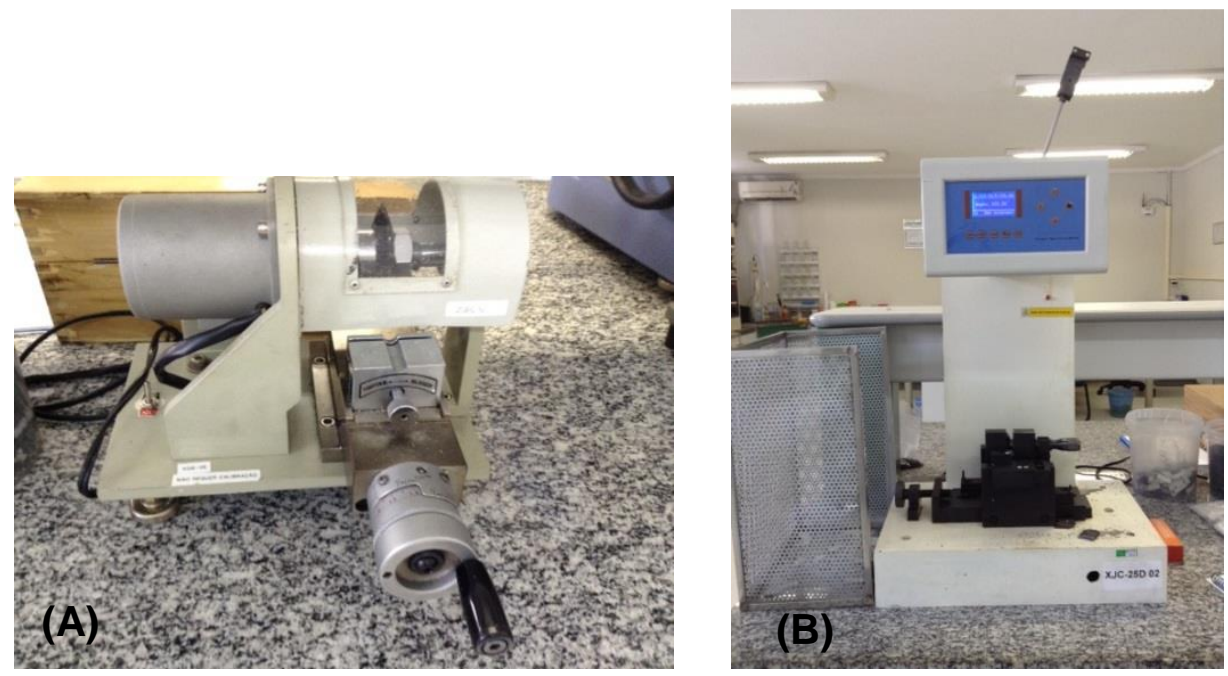

Figura 15. Ensaio de resistência ao impacto izod (A) Entalhador elétrico para corpo de prova do teste de impacto; (B) Equipamento utilizado para teste de impacto. 


\subsubsection{Ensaio de temperatura de distorção térmica}

A temperatura de distorção térmica (HDT) foi obtida, conforme a norma (ASTM D 648), no equipamento PV 300 PC (Figura 16) localizado no Laboratório de Qualidade da empresa NZ Cooperpolymer - SP. Com uma tensão de 1,82 MPa taxa de aquecimento de $120^{\circ} \mathrm{C} / \mathrm{h}$ (método A), onde o meio de imersão foi um óleo de silicone. A temperatura foi determinada após a amostra ter defletido 0,25 mm. Foram utilizados três corpos de prova de cada amostra.

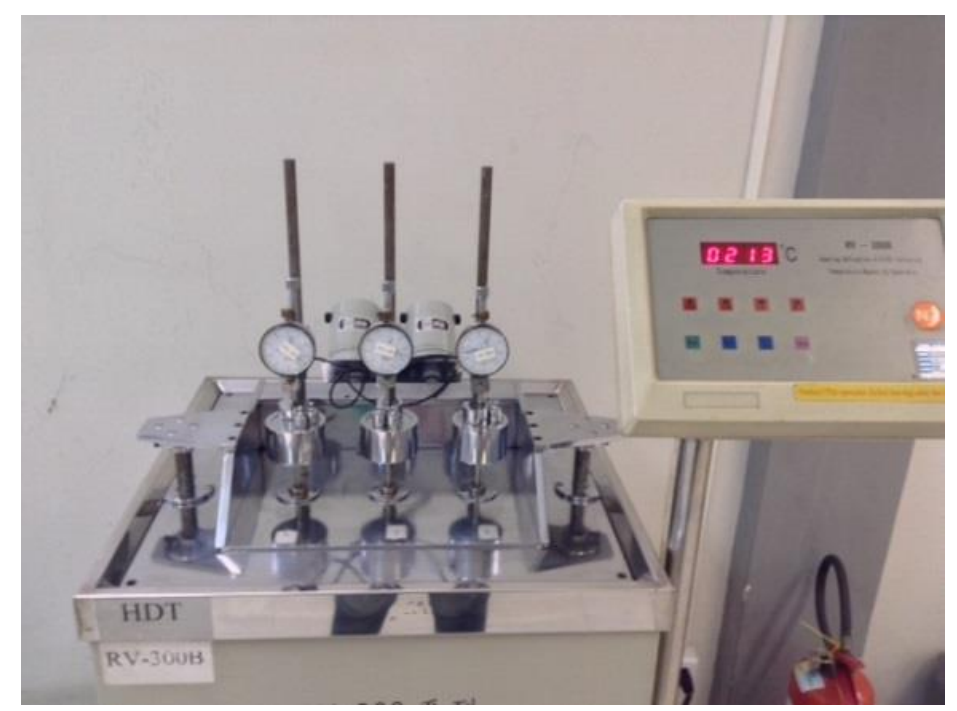

Figura 16. Equipamento para ensaios de HDT do Laboratório de Qualidade da empresa NZ Cooperpolymer.

\subsection{8. Índice de fluidez}

O ensaio foi realizado de acordo com a norma (ASTM D 1238) com temperatura fixa a $250^{\circ} \mathrm{C}$ e carga de $2,160 \mathrm{~kg}$. No equipamento Plastômetro $\mathrm{XRL}$ 400 localizado no Laboratório de Qualidade da empresa NZ Cooperpolymer - SP. 


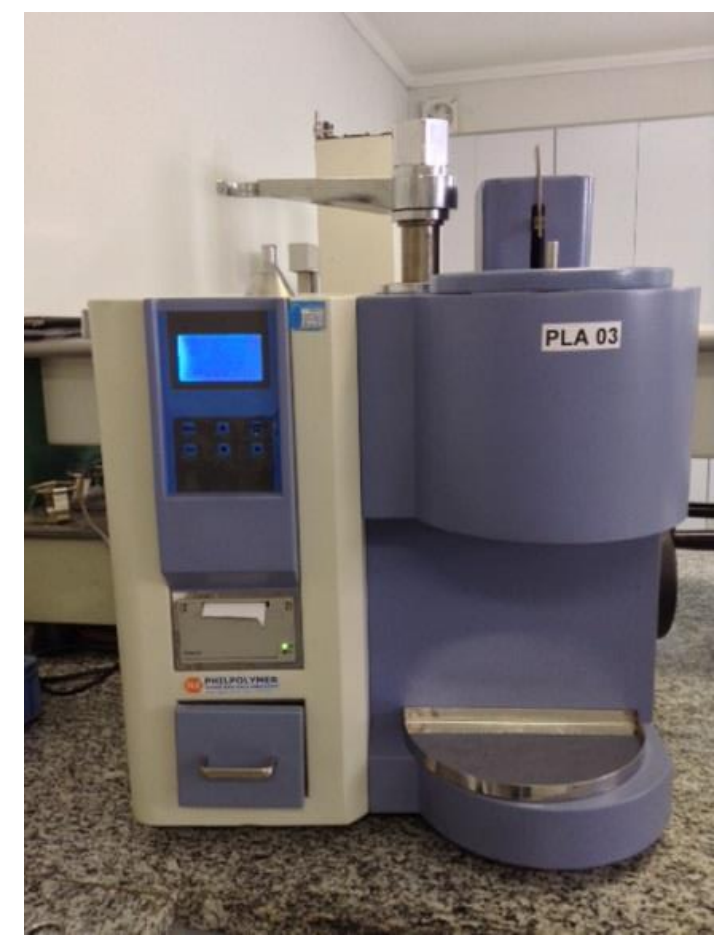

Figura 17. Plastômetro utilizado para análise do índice de fluidez.

\subsubsection{Termogravimetria (TG)}

As analises de TG foram realizadas com o equipamento Toledo TGA 851 do laboratório do Centro de Materiais Avançados (T-CAM) da Universidade Tuskegee (Tuskegee, Alabama, EUA) sob atmosfera de nitrogênio. Uma amostra com 10,0 \pm $1,0 \mathrm{mg}$ das amostras irradiadas e não irradiadas foram pesadas e colocadas em porta- amostras de alumínio, e então aquecidas até $550{ }^{\circ} \mathrm{C}$ a partir da temperatura ambiente $\left(25^{\circ} \mathrm{C}\right)$ e razão de aquecimento de $10^{\circ} \mathrm{C} / \mathrm{min}$.

\subsubsection{Calorimetria Exploratória Diferencial (DSC)}

As análises de DSC foram realizadas utilizando o equipamento Toledo DSC 822 pertencente ao laboratório do Centro de Materiais Avançados (T-CAM) da 
Universidade Tuskegee (Tuskegee, Alabama, EUA), e no intervalo de temperatura 30 a $300^{\circ} \mathrm{C}$ com o grau de aquecimento de $10^{\circ} \mathrm{C} / \mathrm{min}$ sob atmosfera de nitrogênio.

\subsubsection{Microscopia Eletrônica de Varredura (MEV)}

O estudo da superfície de fratura do ensaio de tração foi realizado utilizando JEOL JSM 5800 laboratório do Centro de Materiais Avançados (T-CAM) da Universidade Tuskegee (Tuskegee, Alabama, EUA). Primeiro as amostras foram envolvidas sob uma camada condutiva de ouro para evitar a absorção de elétron pela amostra. Então foram colocados no equipamento para análise.

\subsubsection{Fração - Gel}

Para as análises de fração gel foram utilizadas amostras de $300 \mathrm{mg} \pm 10 \mathrm{mg}$ para cada formulação dos materiais. Esta técnica utiliza o método gravimétrico para realizar o experimento no extrator Soxlet. As amostras foram envolvidas em malha de aço inoxidável de 500 mesh, a fim de que a amostra não escapasse do sitema (Figura 18) e mantidas em contato com o solvente por $12 \mathrm{~h}$ contando a partir do ponto de ebulição. As amostras foram, em seguida, secas em estufa a $70{ }^{\circ} \mathrm{C} \pm 2{ }^{\circ} \mathrm{C}$ até atingirem massa constante. Os testes foram realizados em triplicata e as massas iniciais e finais das amostras foram comparadas. A fração gel foi calculada de acordo com as equações abaixo:

$$
\begin{aligned}
& F_{S}=\left[(w i-w f) \cdot w i^{-1}\right] \cdot 100 \\
& F_{G}=100-F_{S}
\end{aligned}
$$


Onde: $F_{S}=$ fração solúvel; $F_{G}=$ fração gel; wi = massa inicial da amostra; wf = massa da amostra após o ensaio

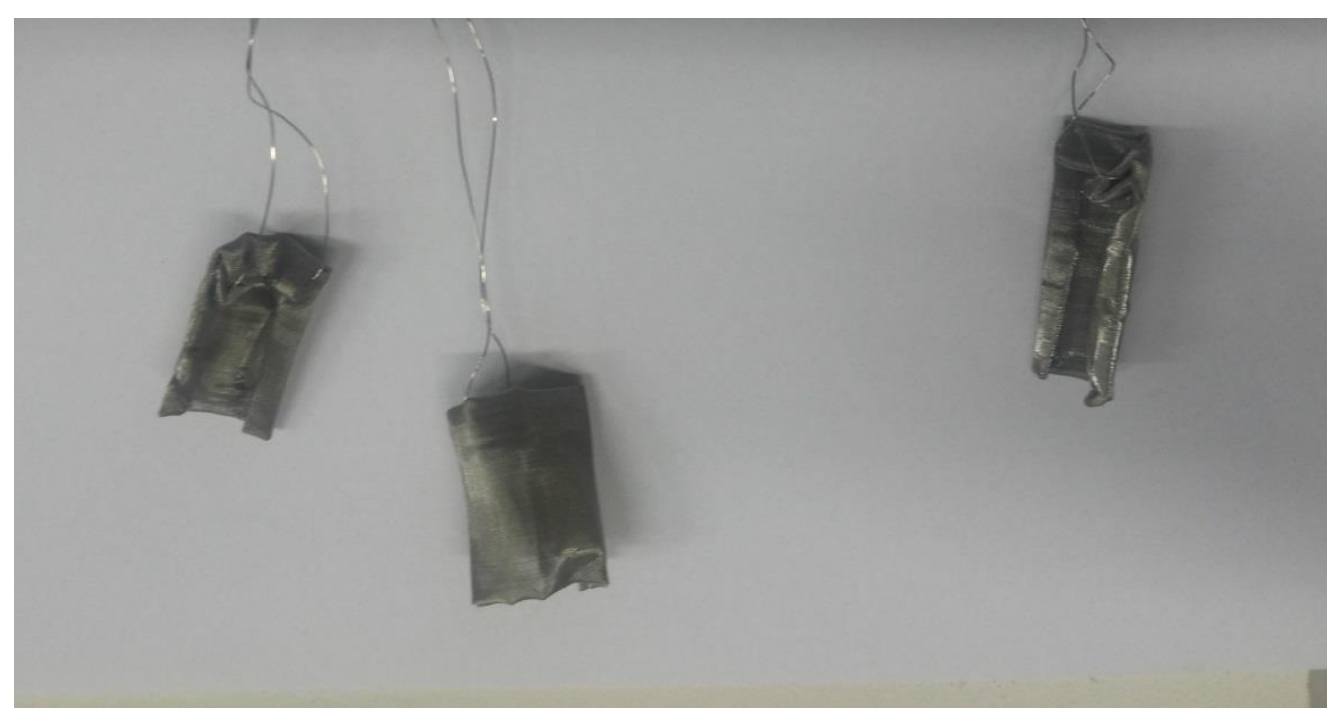

Figura 18. Amostras mantidas em malha de aço para ensaio de fração - gel. 


\section{RESULTADOS E DISCUSSÃO}

\subsection{Difração de raios $X$}

Os resultados de DRX da argila chocolate natural e modificada são mostradas na figura 19.

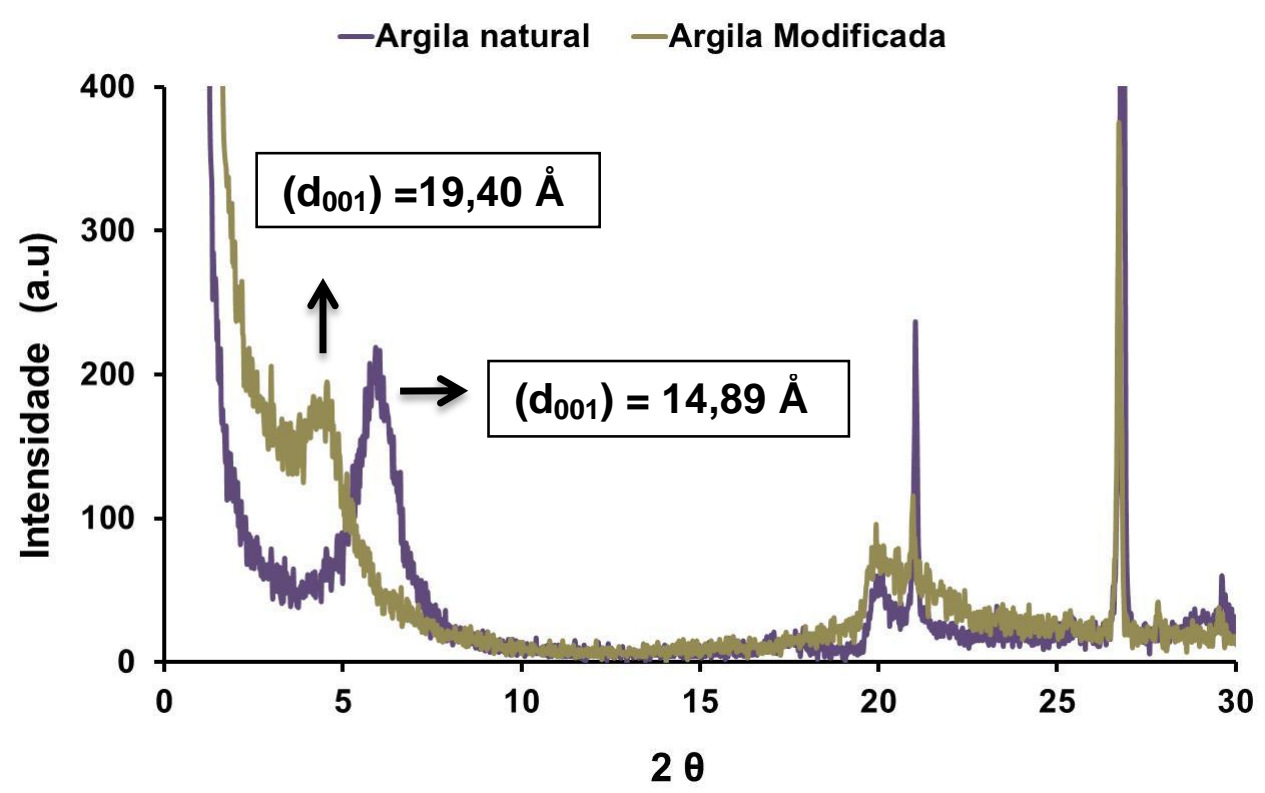

Figura 19. Espectro de difração de raios $X$ de argila chocolate natural e argila chocolate modificada.

Pode-se notar que a modificação orgânica da argila provocou um deslocamento do pico para ângulos mais baixos, esse deslocamento caracteriza o aumento do espaçamento basal. A argila bentonita chocolate natural apresenta uma distância interlamelar $\left(\mathrm{d}_{001}\right)=14,89 \AA$ e, após a modificação essa distância aumentou para 19,40 A. Este aumento nos espaços interlamerares da argila modificada após o tratamento com sal quaternário, evidencia a intercalação dos cátions quaternários de amônio nas camadas interlamelares da argila, formando assim argila organofílica. 
A figura 20 mostra o espectro de difração das amostras não irradiadas de PBT/GMA, PBT/GMA $3 \%$ Argila e PBT/GMA $5 \%$ argila. Os resultados mostram uma alteração na intensidade e inclinação dos picos, indicando uma intercalação parcial. Não se obtiveram estruturas completamente esfoliadas, pois o aparecimento dos picos $d_{001}$ indica ao menos um determinado grau de intercalação. Pode ter ocorrido intercalação do polímero entre as lamelas da argila e esfoliação parcial das partículas, uma vez que os picos mostraram-se mais alargados. Este comportamento fica evidenciado com o aumento significativo das propriedades térmicas e mecânicas a serem mostrados nos itens 5.4., 5.5. e 5.7.

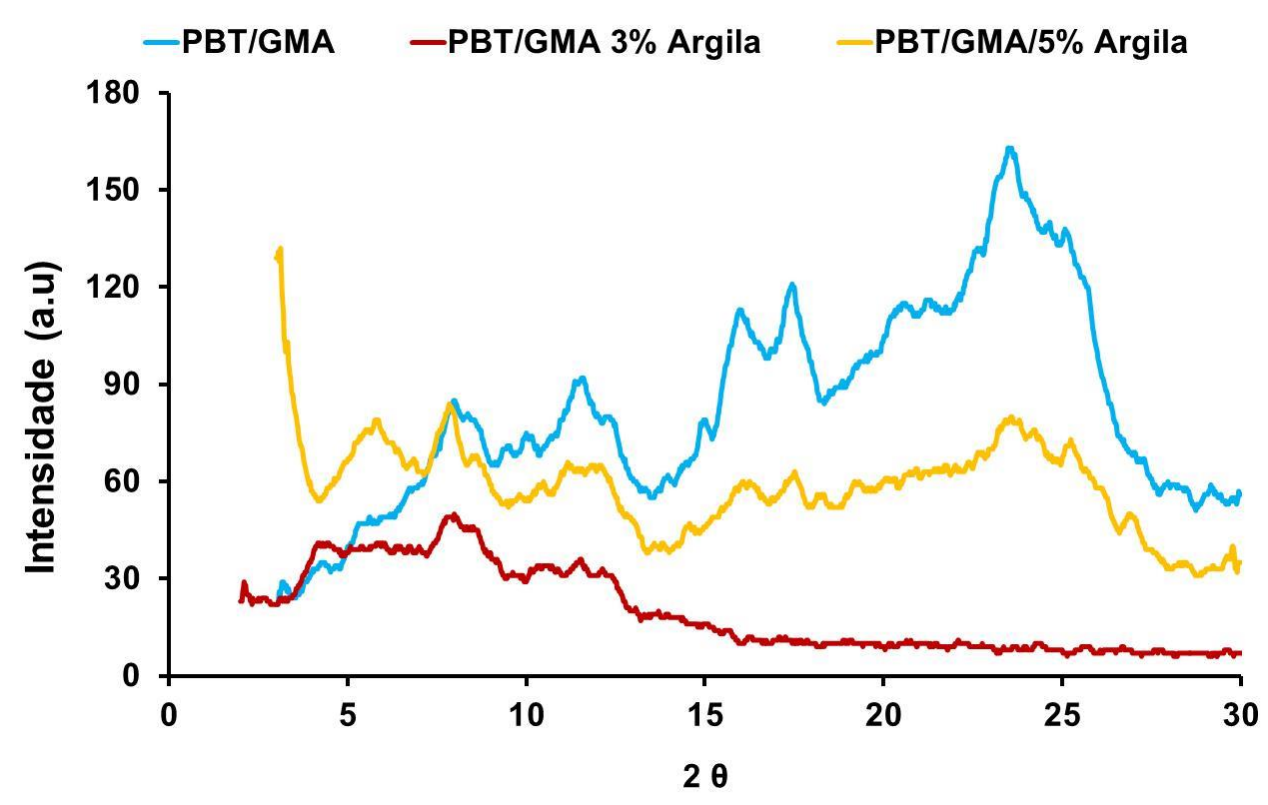

Figura 20. Espectro de difração de raios $X$ das amostras não irradiadas de PBT/GMA, PBT/GMA/3 \% Argila e PBT/GMA5 \% Argila. 


\subsection{Espectrometria de fluorescência de raios $X$ (WDXRF)}

A Tabela 4 apresenta a lista de componentes inorgânicos que constituem a nanoargila bentonita chocolate. A sílica é o principal componente de argila, correspondendo a mais de $40 \%$ do seu total. O resultado mostra também que o óxido de alumínio é outro componente importante da nanoargila. O teor de $\mathrm{SiO}_{2}$ é proveniente da camada tetraédrica enquanto o teor de $\mathrm{Al}_{2} \mathrm{O}_{3}$ é proveniente da camada octaédrica.

Tabela 4. Componentes inorgânicos da nanoargila bentonita chocolate.

\begin{tabular}{cccc}
\hline Componente & $(\%)$ & Componente & $(\%)$ \\
\hline $\mathrm{SiO}_{2}$ & $42 \pm 1$ & $\mathrm{CaO}$ & $2,3 \pm 0,1$ \\
$\mathrm{Al}_{2} \mathrm{O}_{3}$ & $13 \pm 1$ & $\mathrm{Cl}$ & $1,5 \pm 0,1$ \\
$\mathrm{Fe}_{2} \mathrm{O}_{3}$ & $5,4 \pm 0,1$ & Outros & $2,5 \pm 0,1$ \\
$\mathrm{MgO}$ & $2,3 \pm 0,1$ & $\mathrm{PF}^{*}$ & $31 \pm 1$ \\
\hline
\end{tabular}

${ }^{*}$ Perda ao fogo

\subsection{Teor de carga}

Os resultados para o teor de carga nos nanocompósitos são mostrados na tabela a seguir.

Tabela 5. Teor de carga dos materiais

\begin{tabular}{cc}
\hline Material & Teor de carga (\%) \\
\hline $\mathrm{PBT} / 3 \%$ Argila & 2,852 \\
$\mathrm{PBT} / 5 \%$ Argila & 4,886 \\
$\mathrm{PBT} / \mathrm{GMA} / 3 \%$ Argila & 2,796 \\
$\mathrm{PBT} / \mathrm{GMA} / 5 \%$ Argila & 4,867 \\
\hline
\end{tabular}


Os resultados obtidos indicam que o teor de carga é compatível com os teores de argila misturados inicialmente. É possível notar que ocorreu uma pequena diferença na incorporação da argila quando comparado a aditivação planejada. Tal diferença pode ter sido causada no processo de extrusão, onde a argila pode ter acumulado nas roscas e funil da máquina, já que após a obtenção dos nanocompósitos foi feita a limpeza da extrusora e pode-se notar que o material adicionado para limpar a máquina (Poliestireno - PS) apresentava ao sair, por certo tempo, a cor característica da argila, durante o processo de extrusão ocorre também a perca de hidroxilas das argilas o que pode contribuir nessa diferença. Foi observado um acúmulo de argila na embalagem utilizado para a homogeneização da mistura. Tal diferença não altera o trabalho, já que tais perdas são consideradas normais no processo. A figura 21 apresenta os cadinhos de porcelana utilizados para o ensaio de teor de carga com o pó de argila que sobrou após a queima dos grânulos de nanocompósitos.

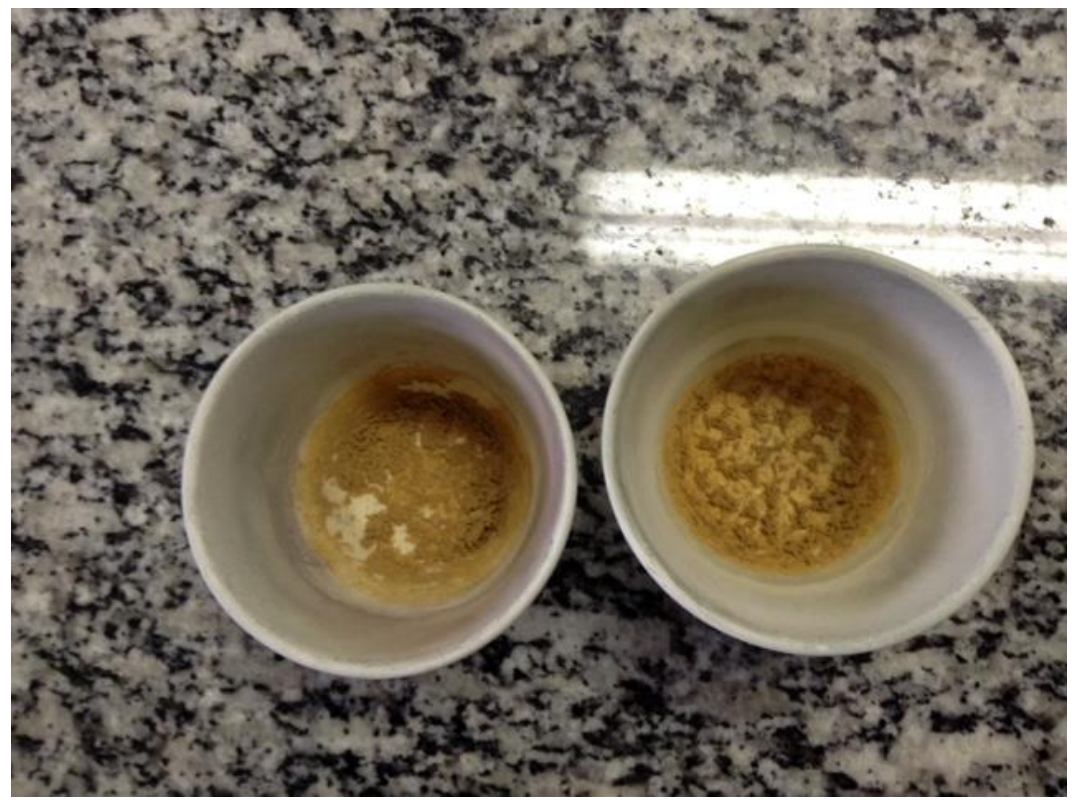

Figura 21. Cadinhos de porcelanas com a argila residual após a queima. 


\subsection{Ensaio de tração}

A adição de argila na matriz polimerica de PBT promoveu ganhos significativos na resistência à tração de ruptura dos materiais. Esse aumento foi de cerca de $65 \%$ no PBT/GMA/3\% Argila e cerca de $55 \%$ no PBT/GMA/5\% Argila. Considerando as amostras sem a adição do agente compatibilizante GMA o aumento foi de cerca de $60 \%$ em ambas as formulações (Figura 22).

Em seu estudo sobre as propriedades térmicas e mecânicas do PBT reforçado com argila montmorilonita organofílica, obtidos através do processo de intercalação por fusão (CHOW, 2008) observou que a adição de 3 \% de argila na matriz PBT promoveu aumento significativo na resistência do nanocompósito quando comparado ao polímero puro e atribuiu tal ganho a boa interação da argila na matriz polimérica.

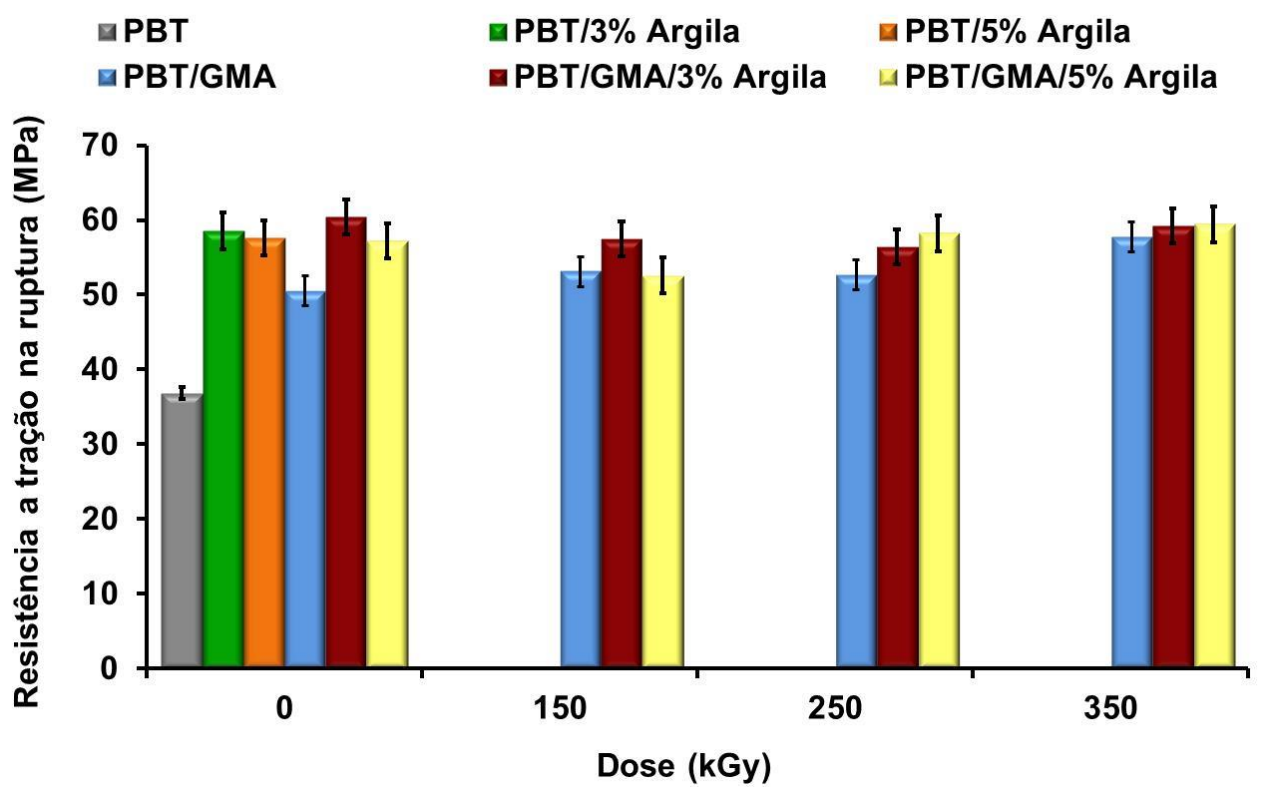

Figura 22. Resultados dos ensaios de resistência à tração na ruptura para as amostras não irradiadas do PBT puro, PBT/3\% Argila, PBT/5\% Argila, PBT/GMA, 
$\mathrm{PBT} / \mathrm{GMA} / 3 \%$ Argila, PBT/GMA/5\% Argila e para as amostras irradiadas de PBT/GMA, PBT/GMA/3\% Argila, PBT/GMA/5\% Argila.

A curva de tensão $x$ deformação mostra que o PBT Puro e o PBT/GMA apresentam curva caracteristica de um material termoplastico dúctil. Após a adição da argila em todas as formulações, os nanocompósitos apresentam curva característica de um material frágil, essa mudança está no fato da argila ser um material cerâmico e fragil, concedendo tais características ao nanocompósito formado (Figura 23).

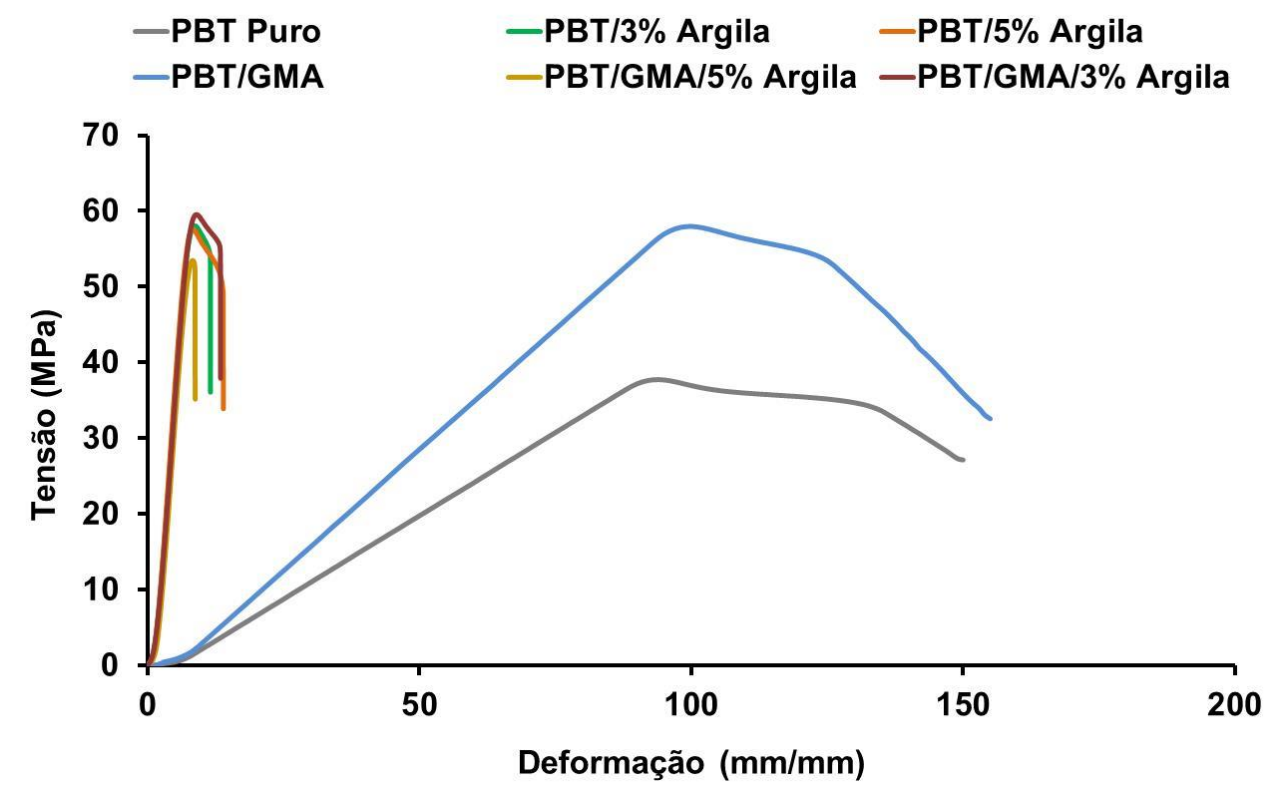

Figura 23. Curva de tensão $x$ deformação para as amostras não irradiadas de PBT/Puro, PBT/3 \% Argila, PBT/5\% Argila, PBT/GMA, PBT/GMA/3 \% Argila e $\mathrm{PBT} / \mathrm{GMA} / 5 \%$ Argila. 


\subsection{Ensaio de Flexão}

A figura apresenta os resultados de resistência à flexão do PBT, PBT/3 \% Argila, PBT/5 \% Argila, PBT/GMA, PBT/GMA/3 \% Argila, PBT/GMA/5 \% Argila, irradiado e não irradiado. A adição da argila promoveu um aumento de cerca de 10 \% na resistência a flexão quando comparado ao polímero puro. Os valores entre as porcentagens de argila e a adição de GMA ficaram muito parecidos, com uma diferença de cerca de $1 \%$ entre as formulações de nanocompósitos realizadas (Figura 24).

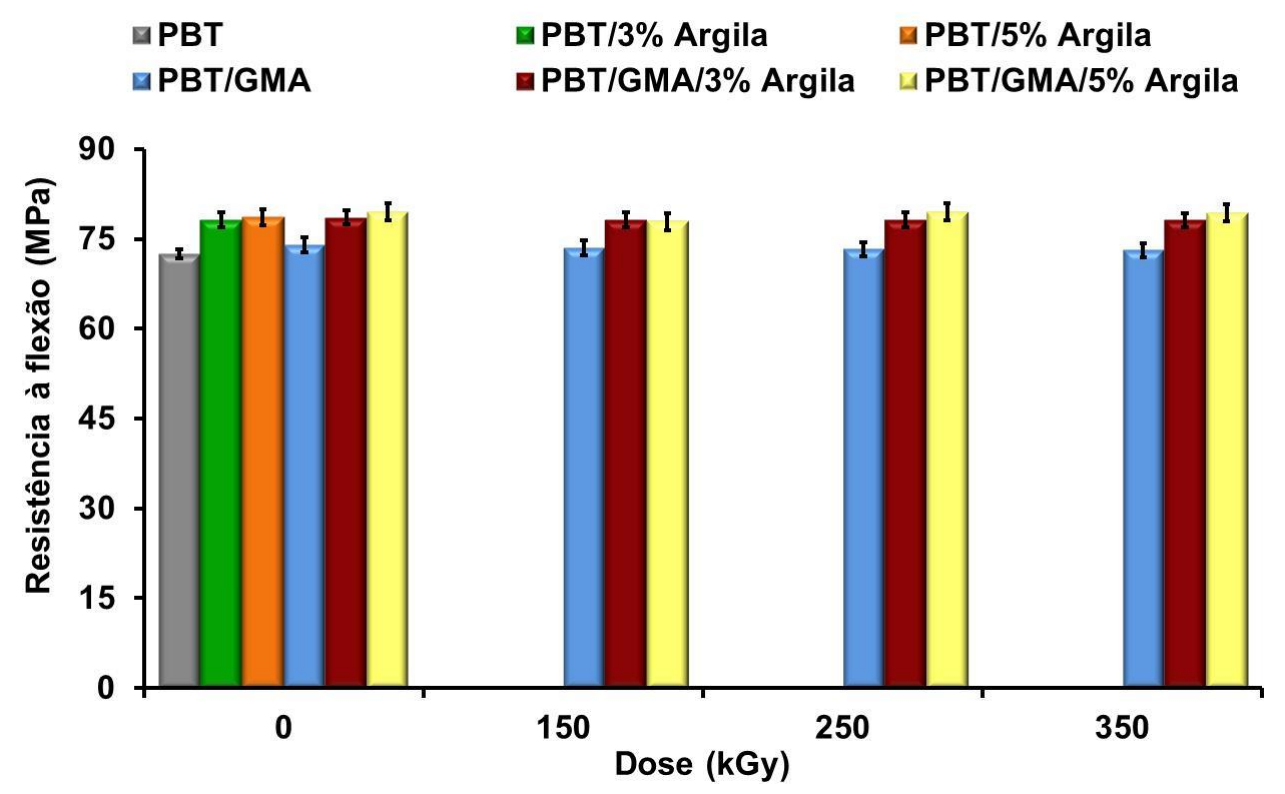

Figura 24. Resultados dos ensaios de resistência à flexão dos materiais para as amostras não irradiadas do PBT puro, PBT/3 \% Argila, PBT/5 \% Argila, PBT/GMA, $\mathrm{PBT} / \mathrm{GMA} / 3 \%$ Argila, PBT/GMA/5 \% Argila e para as amostras irradiadas de PBT/GMA, PBT/GMA/3 \% Argila, PBT/GMA/5 \% Argila.

Assim como na resistência a flexão, a adição de argila trouxe um aumento ao módulo de flexão do PBT. Segundo NIRUKHE E SHERTUKDE, 2009 que estudaram a preparação e caracterização de nanocompósitos de PBT com a adição de 1 a 5 \% 
(em peso) de diferentes tipos de argila organofílica também observaram tal comportamento e relataram que o aumento do módulo de flexão indica um aumento da rigidez dos nanocompósitos, ao mesmo nível de deformação (Figura 25).

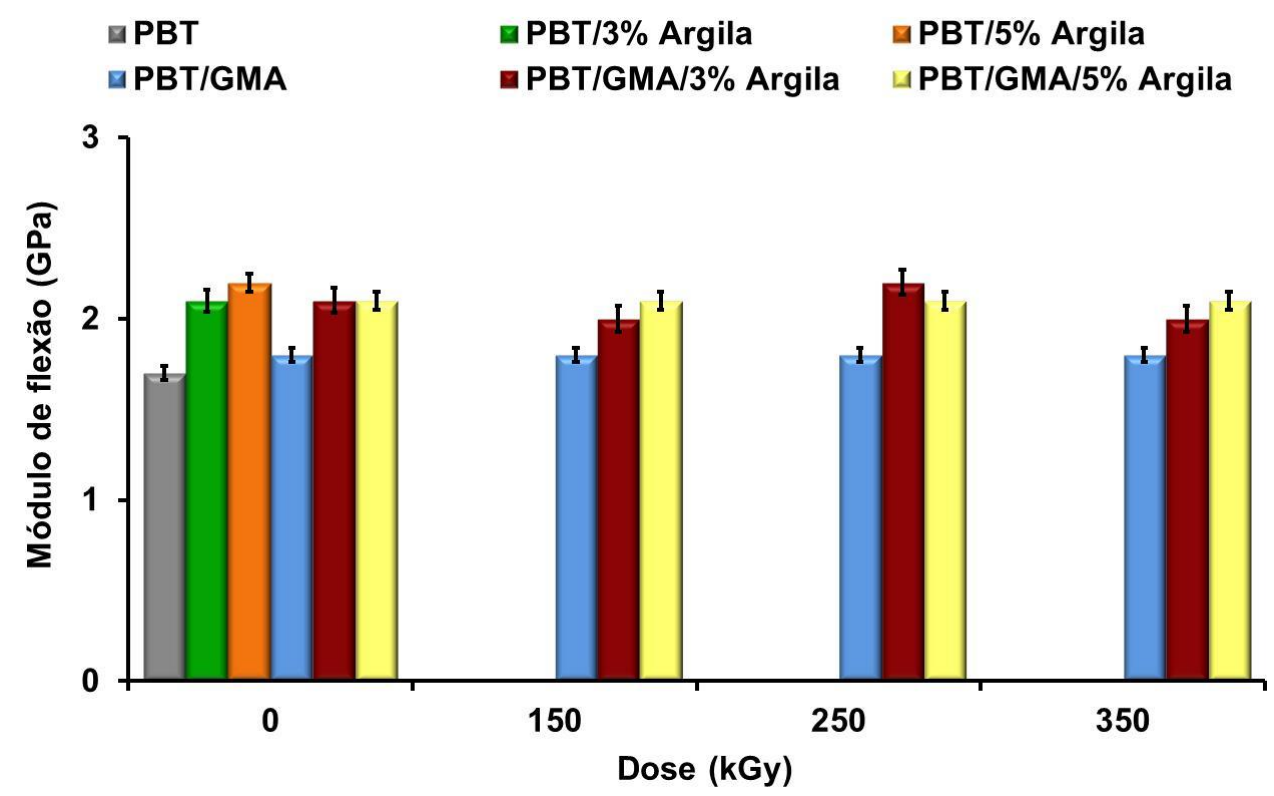

Figura 25. Resultados dos ensaios do módulo de flexão para as amostras não irradiadas do PBT puro, PBT/3 \% Argila, PBT/5 \% Argila, PBT/GMA, PBT/GMA/3 \% Argila, PBT/GMA/5 \% Argila e para as amostras irradiadas de PBT/GMA, $\mathrm{PBT} / \mathrm{GMA} / 3 \%$ Argila, PBT/GMA/5 \% Argila.

\subsection{Ensaio de resistência ao impacto}

A adição da argila na resina PBT promoveu uma redução na resistência ao impacto. (Figura 26).

NIRUKHE e SHERTUKDE, 2009 também observaram uma diminuição na resistência ao impacto da matriz polimérica PBT com a adição de argila. E esta diminuição está ligada à falta de absorção de energia de impacto, transferência e dissipação, que pode ter sido devido à má ligação interfacial entre a argila e o 
polímero, com formação de aglomerados. A adição do reforço restringiu a mobilidade das moléculas da matriz, resultando na diminuição da resistência ao impacto.

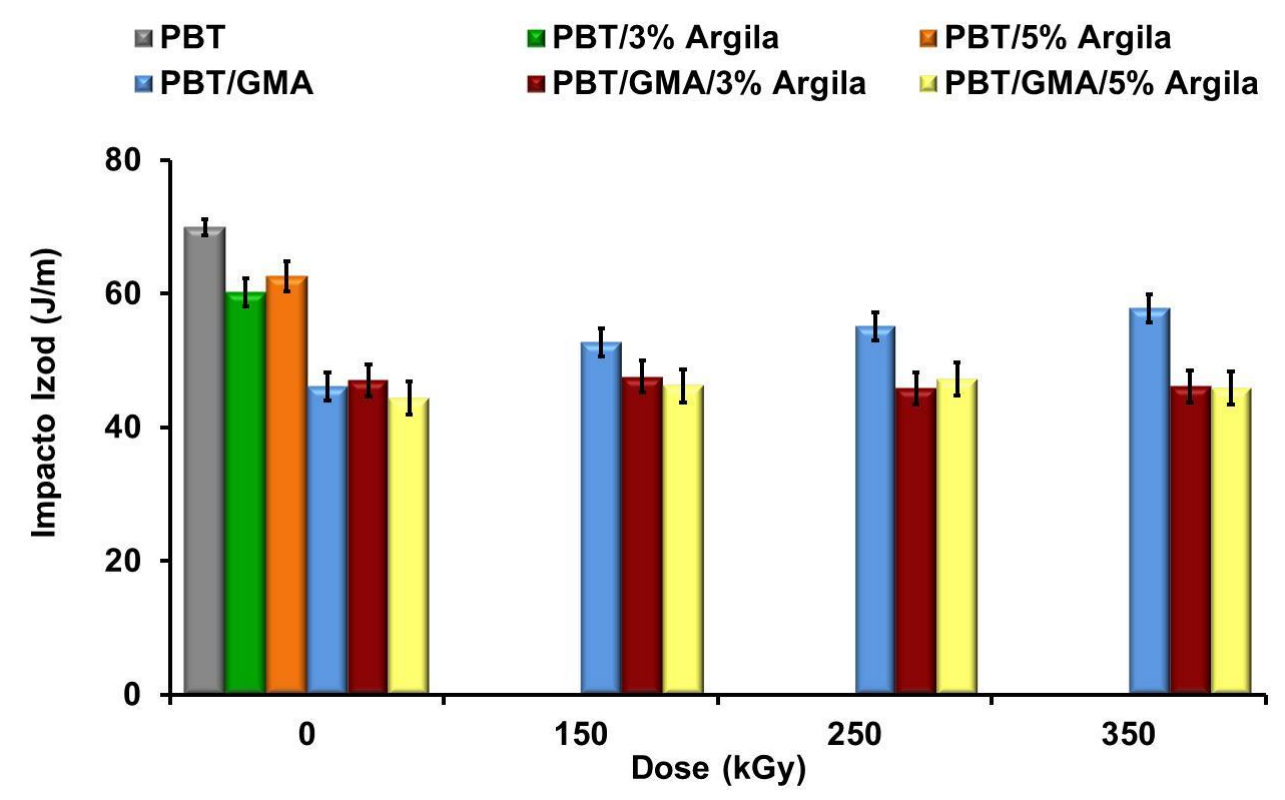

Figura 26. Resultados dos ensaios de resistência ao impacto para as amostras não irradiadas do PBT puro, $\mathrm{PBT} / 3 \%$ Argila, $\mathrm{PBT} / 5 \%$ Argila, PBT/GMA, PBT/GMA/3 \% Argila, PBT/GMA/5 \% Argila e para as amostras irradiadas de PBT/GMA, $\mathrm{PBT} / \mathrm{GMA} / 3 \%$ Argila, PBT/GMA/5 \% Argila.

\subsection{Temperatura de distorção térmica}

Considerando a resistência de temperatura distorção térmica do PBT a adição de argila em ambas as formulações, com e sem o agente compatibilizante GMA, representou um aumento superior a $35 \%$ quando comparado ao PBT puro. Este aumento pode ser atribuído à ocorrência da dispersão das camadas do silicato na matriz polimérica, o que eleva as propriedades mecânicas e termomecânicas. 
Nos resultados dos ensaios mecânicos e térmicos de PBT/Argila observou-se que os valores para os nanocompósitos com e sem adição do agente compatibilizante GMA ficaram muito parecidos, isto sugere que a adição de $0,5 \%$ de GMA não foi suficiente para uma melhor compatibilização entre a matriz e o reforço.

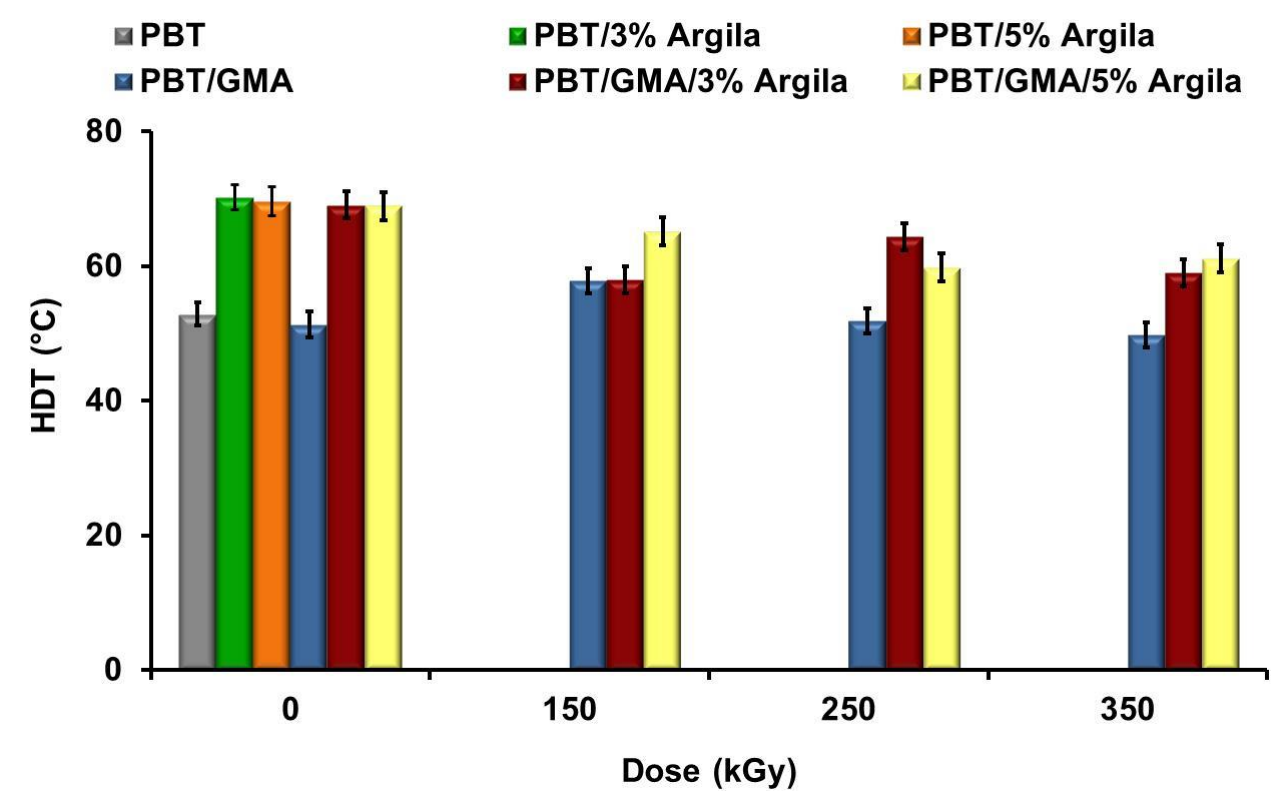

Figura 27. Resultados dos ensaios de temperatura de distorção térmica dos materiais para as amostras não irradiadas do PBT puro, PBT/3 \% Argila, PBT/5 \% Argila, PBT/GMA, PBT/GMA/3\% Argila, PBT/GMA/5\% Argila e para as amostras irradiadas de PBT/GMA, PBT/GMA/3\% Argila, PBT/GMA/5 \% Argila.

\section{8. Índice de fluidez}

$\mathrm{Na}$ tabela 6 são mostrados os resultados do índice de fluidez do PBT puro $\mathrm{PBT} / 3 \%$ Argila, PBT/5 \% Argila, PBT/GMA, PBT/GMA/3 \% argila e PBT/GMA/5 \% argila. Considerando as amostras irradiadas, como não houve mudanças signifcativas nos ensaios mecânicos esta análise foi realizada apenas para os materiais sem o tratamento por radiação ionizante. Os valores para o PBT puro e PBT após adição de $0,5 \%$ de GMA aparecem inalterados. Com relação à adição da 
argila houve um aumento de cerca de $90 \%$ e $100 \%$ com a adição de $3 \%$ e $5 \%$ de argila, respectivamente. No PBT/GMA/3 \% argila houve um aumento de aproximadamente de $25 \%$ e $40 \%$ no PBT/GMA/5 \% argila quando comparado com o polímero puro. Esse aumento sugere que a adição da argila pode levar à obtenção de um nanocompósito PBT/GMA/Argila com peso molecular mais baixo e maior fluidez do que o polímero puro. Outro fator que justifica essa mudança de propriedade é uma possivel degradação durante o processamento do material.

Tabela 6. Valores de índice de fluidez para as amostras não irradiadas de PBT/Puro, PBT/GMA e seus nanocompósitos.

\begin{tabular}{cc}
\hline Materiais & $\begin{array}{c}\text { Índice de fluidez } \\
(\mathbf{g} / \mathbf{1 0} \text { } \mathbf{i n})\end{array}$ \\
\hline PBT Puro & 8,10 \\
$\mathrm{PBT} / 3 \%$ Argila & 15,60 \\
$\mathrm{PBT} / 5 \%$ Argila & 17,16 \\
$\mathrm{PBT} / \mathrm{GMA}$ & 8,10 \\
$\mathrm{PBT} / \mathrm{GMA} / 3 \%$ Argila & 10,14 \\
$\mathrm{PBT} / \mathrm{GMA} / 5 \%$ Argila & 11,34 \\
\hline
\end{tabular}

\subsection{Análise Termogravimétrica (TG)}

As curvas de TG para o PBT/GMA, PBT/GMA/3\% Argila, PBT/GMA/5\% Argila, irradiado e não irradiado, são mostrados nas figuras 28 a 30. 


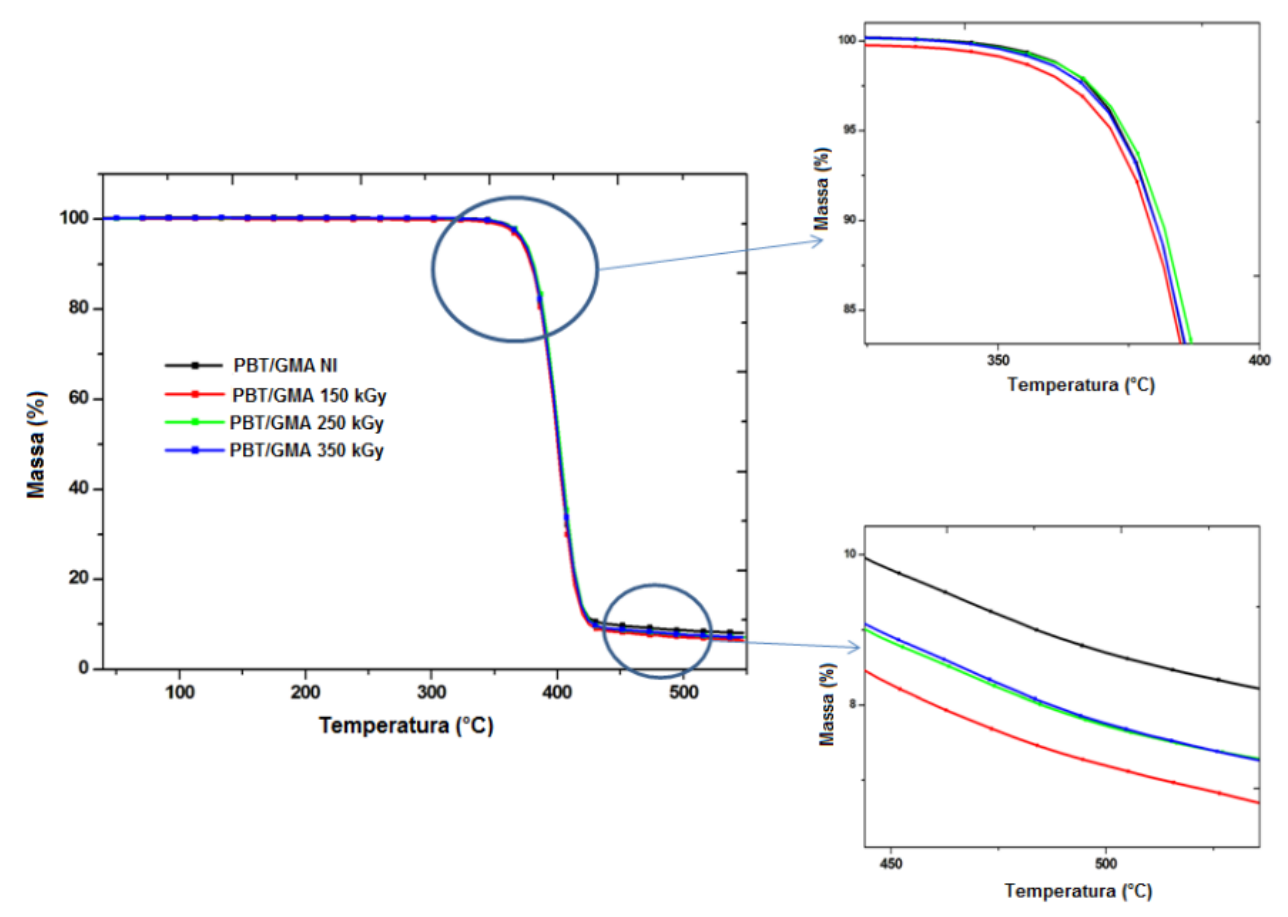

Figura 28. Curva de TG para PBT/GMA NI, PBT/GMA $150 \mathrm{kGy}, \mathrm{PBT} / \mathrm{GMA}$ 250 kGy e PBT/GMA 350 kGy.
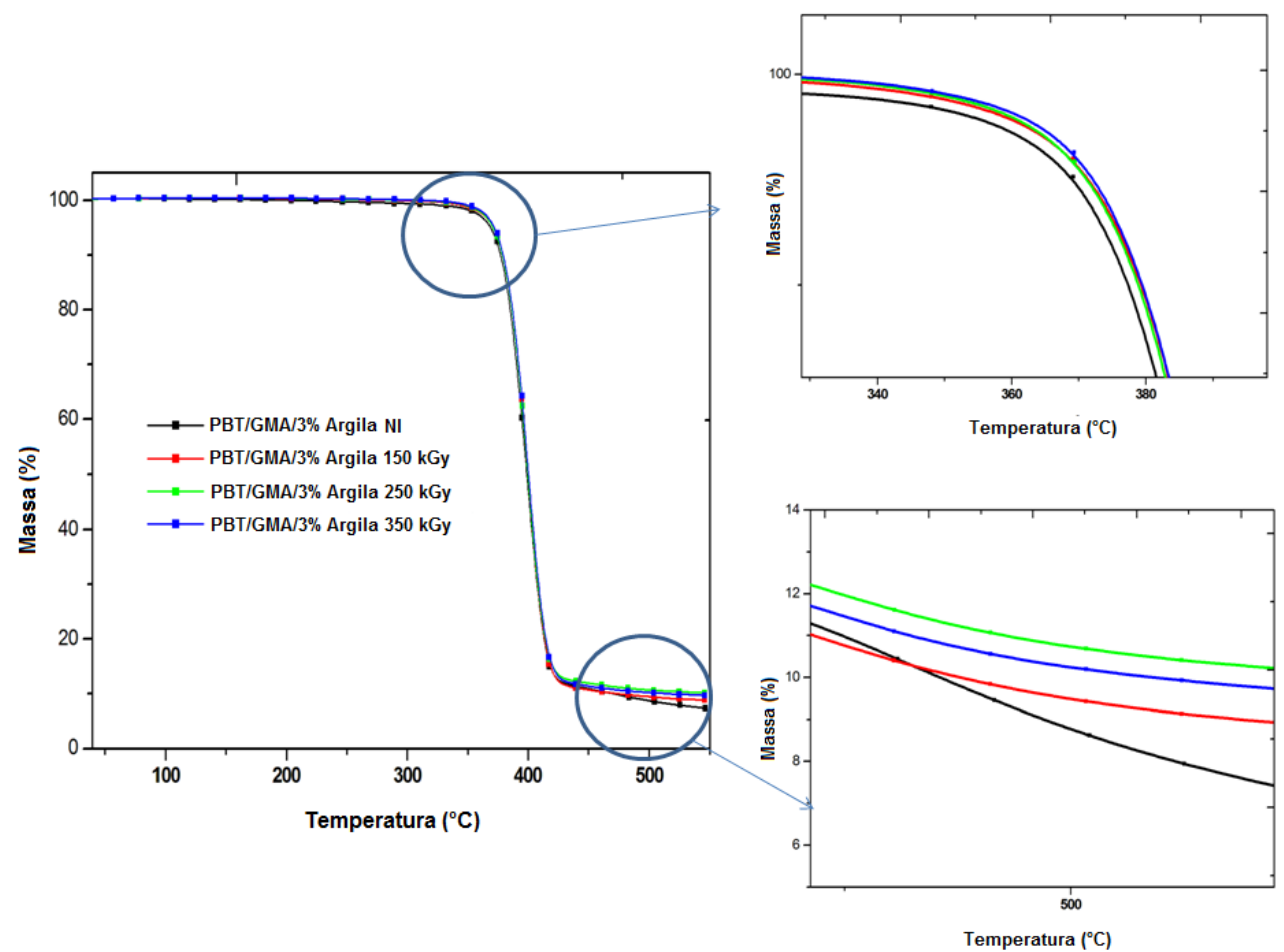

Figura 29. Curva de TG para PBT/GMA/3\% Argila NI, PBT/GMA/3 \% Argila 150 kGy, $\mathrm{PBT} / \mathrm{GMA} / 3$ \% Argila 250 kGy e PBT/GMA/3 \% Argila 350 kGy. 


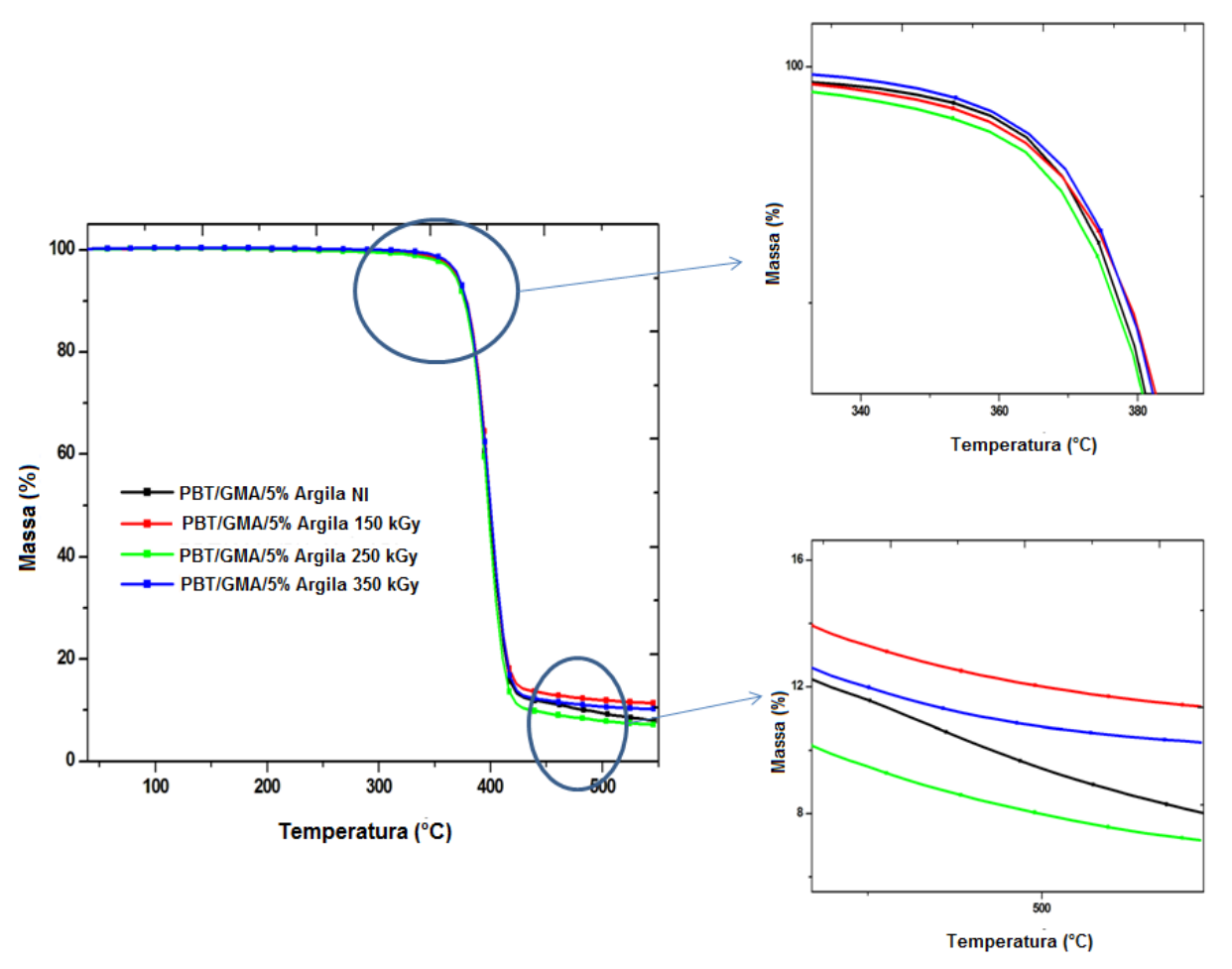

Figura 30. Curva de TG para PBT/GMA/5 \% Argila NI, PBT/GMA/5 \% Argila 150 kGy, PBT/GMA/5 \% Argila 250 kGy e PBT/GMA/3 \% Argila 350 kGy.

A tabela 7 apresenta os resultados de temperatura de degradação dos materiais. Através dos resultados é possível observar que nas amostras não irradiadas a adição da argila promoveu uma diminuição na temperatura de degradação térmica quando comparada a amostra sem argila. Este comportamento pode ser causado devido à formação de aglomerados e pela não existência de estruturas esfoliadas conforme foi observado na análise de DRX. 
Tabela 7. Temperatura de degradação térmica para o PBT/GMA e seus nanocompósitos, irradiados e não irradiados.

\begin{tabular}{cc}
\hline Materiais & $\begin{array}{c}\text { Temperatura } \\
\left({ }^{\circ} \mathbf{C}\right)\end{array}$ \\
\hline PBT/GMA NI & 382,65 \\
PBT/GMA 150 kGy & 382,71 \\
PBT/GMA 250 kGy $/ G M A 350$ kGy & 384,25 \\
\hline PBT/GMA/ 3\% Argila NI & 387,19 \\
\hline PBT/GMA/ 3\% Argila 150 kGy & 381,12 \\
PBT/GMA/ 3\% Argila 250 kGy & 383,19 \\
PBT/GMA/ 3\% Argila 350 kGy & 382,25 \\
\hline PBT/GMA/ 5\% Argila NI & 382,79 \\
\hline PBT/GMA/ 5\% Argila 150 kGy & 380,84 \\
PBT/GMA/ 5\% Argila 250 kGy & 382,68 \\
PBT/GMA/ 5\% Argila 350 kGy & 381,33 \\
\hline
\end{tabular}

\subsection{Calorimetria Exploratória Diferencial (DSC)}

A Tabela 8 apresenta os resultados da análise de DSC para a temperatura de fusão, e percentagem de cristalinidade para o PBT/GMA, PBT/GMA/3 \% argila e $\mathrm{PBT} / \mathrm{GMA} / 5 \%$ argila, irradiados e não irradiados. Os resultados mostram uma pequena redução na temperatura de fusão com adição de argila e tratamento por radiação ionizante. O mesmo acontece para a cristalinidade dos materiais. 
Tabela 8. Temperatura de fusão e percentual de cristalinidade para o PBT/GMA e seus nanocompósitos, irradiados e não irradiados.

\begin{tabular}{clc}
\hline Materiais & $\begin{array}{c}\text { Tm } \\
\left({ }^{\circ} \mathbf{C}\right)\end{array}$ & $\begin{array}{c}\text { Tc } \\
(\%)\end{array}$ \\
\hline PBT/GMA NI & 221,37 & 29,75 \\
PBT/GMA 150 kGy & 217,41 & 27,81 \\
PBT/GMA 250 kGy & 218,21 & 29,61 \\
PBT/GMA 350 kGy & 216,04 & 28,14 \\
\hline PBT/GMA/ 3\% Argila NI & 220,11 & 25,11 \\
PBT/GMA/ 3\% Argila 150 kGy & 217,33 & 24,72 \\
PBT/GMA/ 3\% Argila 250 kGy & 220,17 & 17,35 \\
PBT/GMA/ 3\% Argila 350 kGy & 220,84 & 19,56 \\
\hline PBT/GMA/ 5\% Argila NI & 219,37 & 24,84 \\
PBT/GMA/ 5\% Argila 150 kGy & 219,27 & 21,68 \\
PBT/GMA/ 5\% Argila 250 kGy & 218,73 & 23,01 \\
PBT/GMA/ 5\% Argila 350 kGy & 216,46 & 23,12 \\
\hline
\end{tabular}

\subsection{Fração gel}

Foi possível observar visualmente a não formação de fração gel, uma vez que as malhas utilizadas no sistema aparentavam estar vazias após o período de exposição ao solvente em ebulição, sofrendo dissolução. Os resultados de fração gel para os materiais (Figura 31) não apresentaram valores mensuráveis de gel nas amostras irradiadas no intervalo de dose estudado. Pode-se sugerir que não ocorreram predominantemente reações de reticulação no PBT e seus nanocompósitos irradiados nas doses aplicadas neste estudo. O mesmo foi 
observado nas análises mecânicas e térmicas onde o tratamento por radiação ionizante por feixe de elétrons não alterou signifitivamente as propriedades dos materiais estudados.

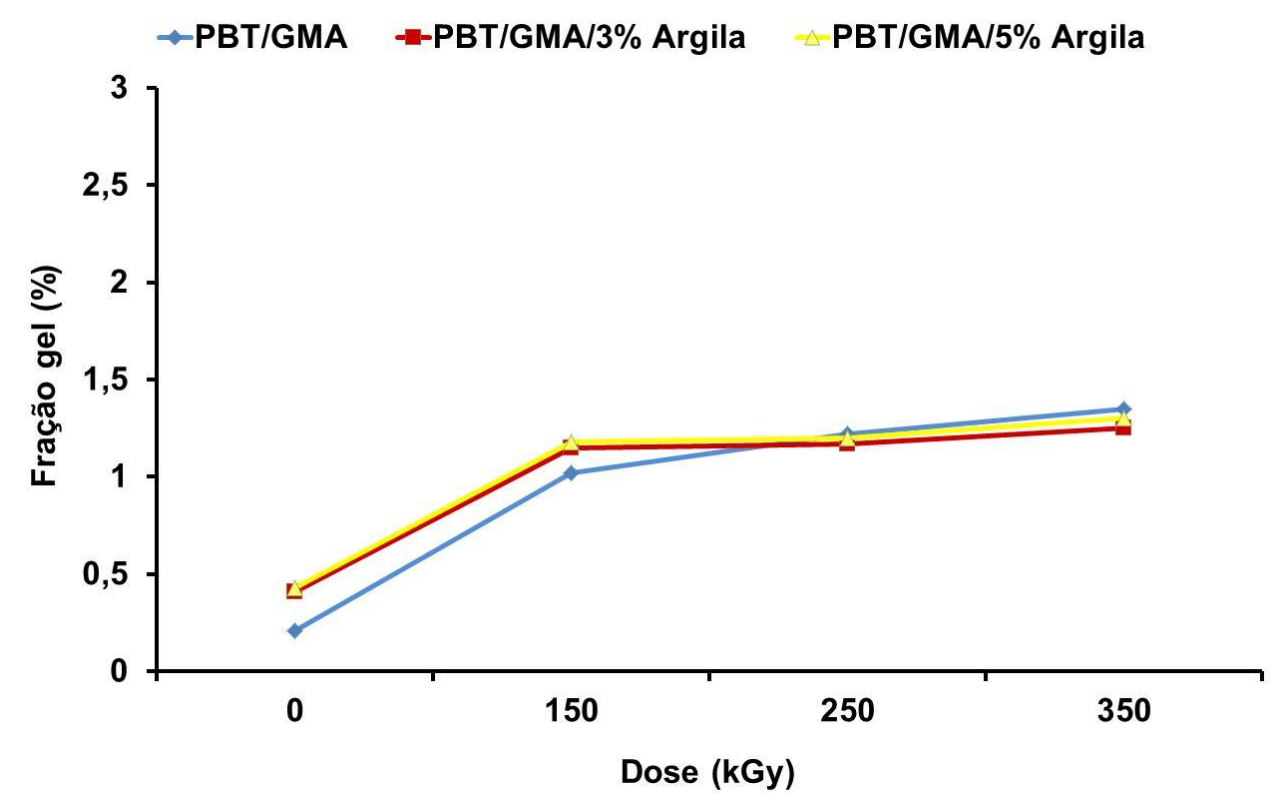

Figura 31. Resultados dos ensaios de fração gel para o PBT GMA e seus nanocompósitos, irradiados e não irradiados.

\subsection{Microscopia Eletrônica de Varredura (MEV)}

As micrografias das superfícies de fratura do ensaio à tração de PBT / GMA, PBT/GMA/3 \% Argila e de PBT/GMA/5 \% Argila, irradiado e não irradiado (ampliação de 1000 x) são mostrados nas Figuras 32 a 42 . É possível observar a distribuição da argila na matriz polimérica. As micrografias não são conclusivas para a determinação da esfoliação ou intercalação da argila no polímero. 


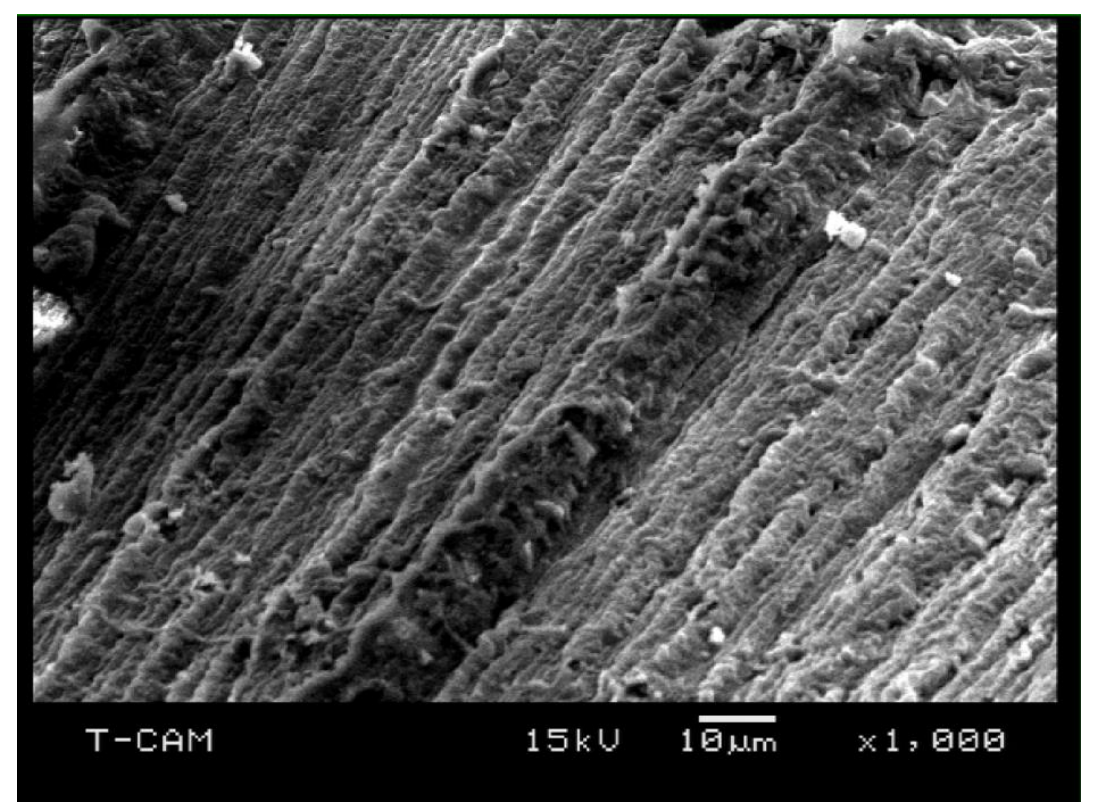

Figura 32. Micrografia da superfície de fratura do ensaio à tração do PBT/GMA 150 kGy.

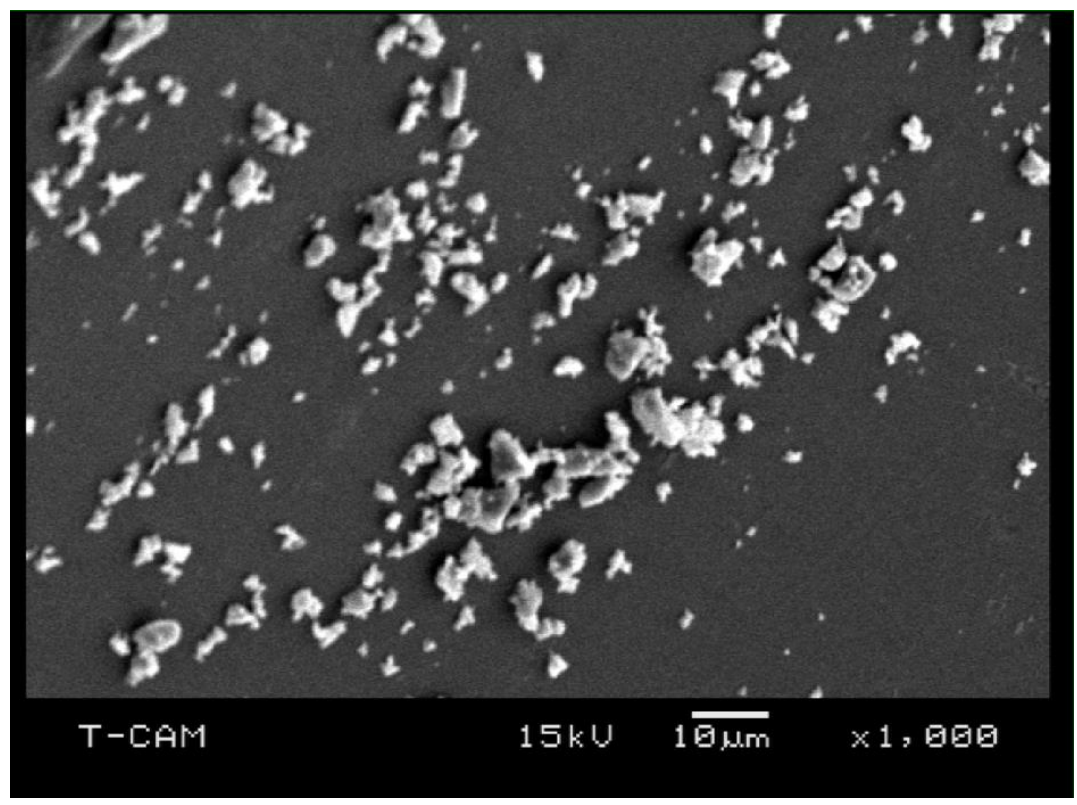

Figura 33. Micrografia da superfície de fratura do ensaio à tração do PBT/GMA 250 kGy. 


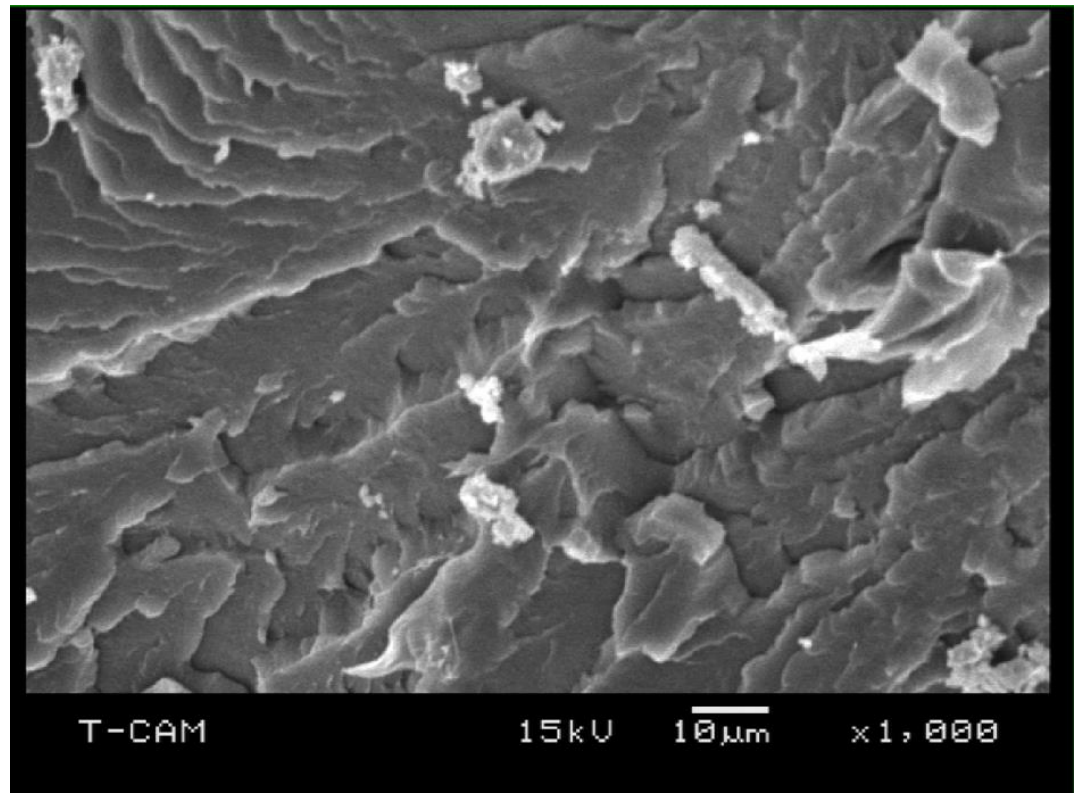

Figura 34. Micrografia da superfície de fratura do ensaio à tração do PBT/GMA 350 kGy.

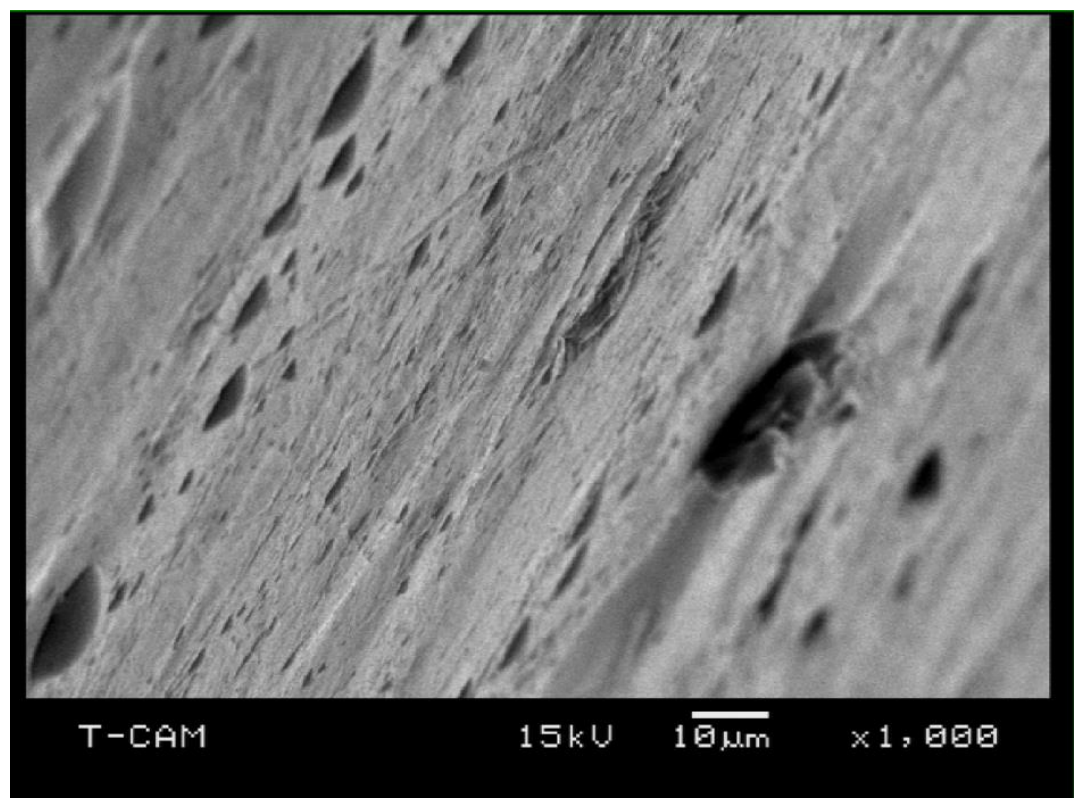

Figura 35. Micrografia da superfície de fratura do ensaio à tração do PBT/GMA/3\% Argila NI. 


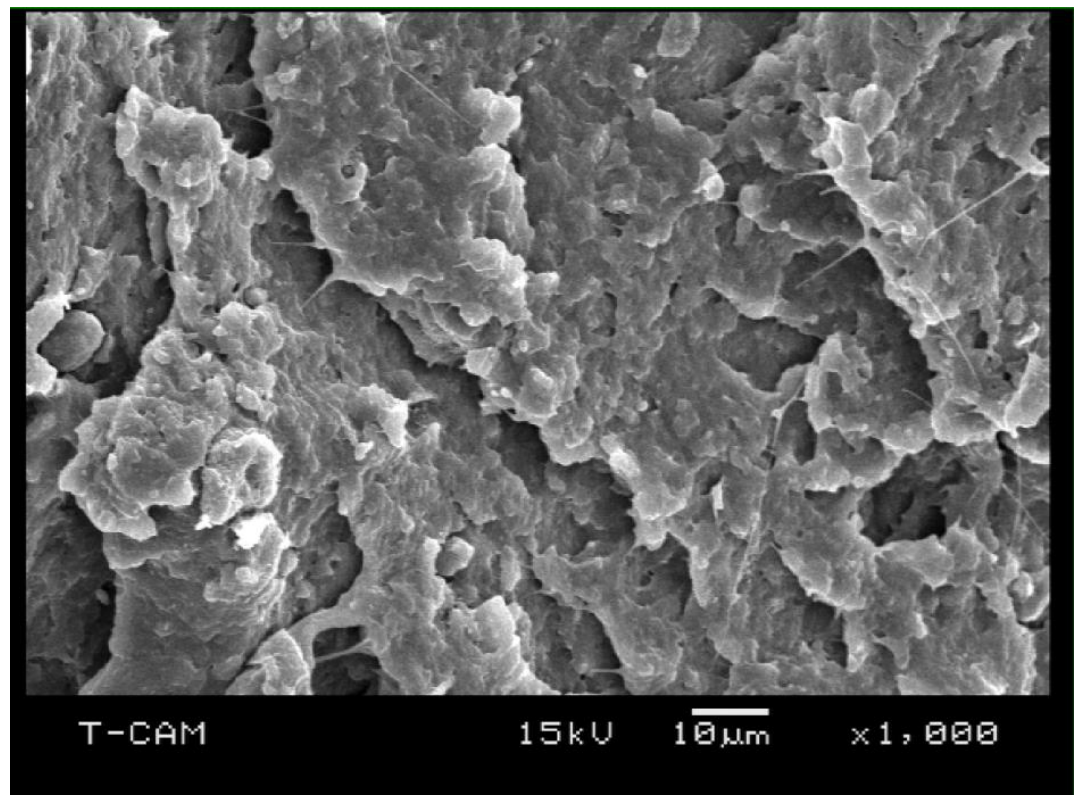

Figura 36. Micrografia da superfície de fratura do ensaio à tração do $P B T / G M A / 3 \%$ Argila 150 kGy.

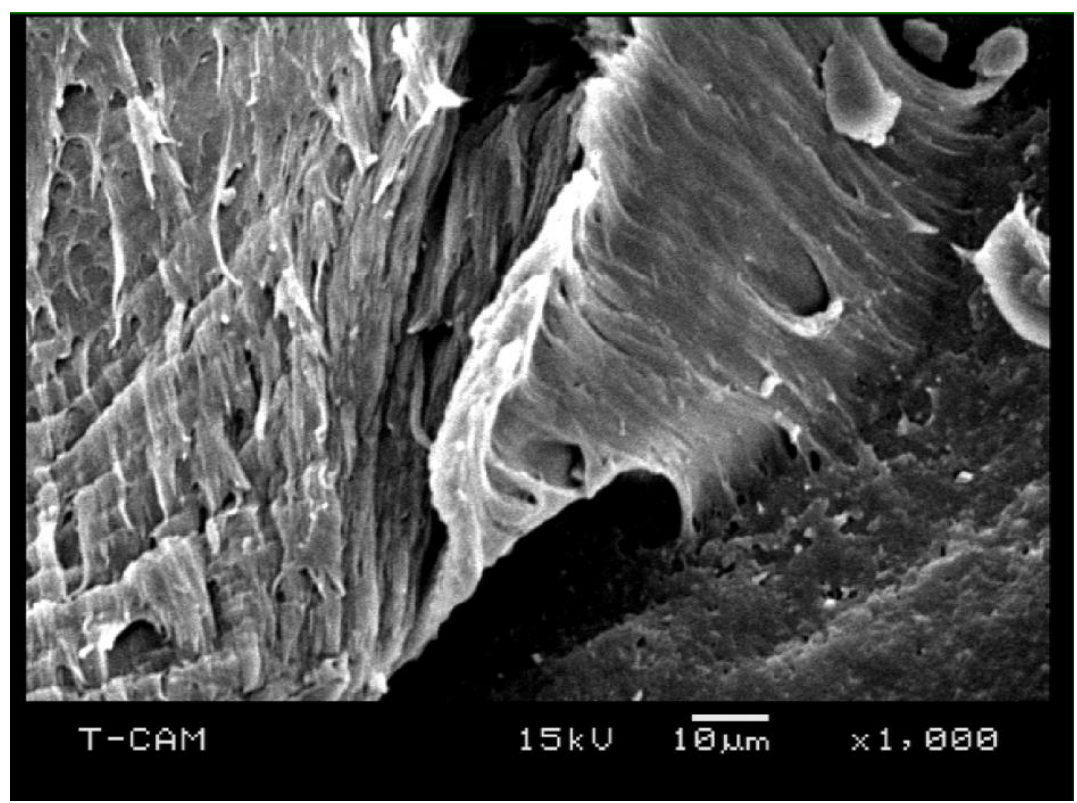

Figura 37. Micrografia da superfície de fratura do ensaio à tração do $P B T / G M A / 3 \%$ Argila $250 \mathrm{kGy}$. 


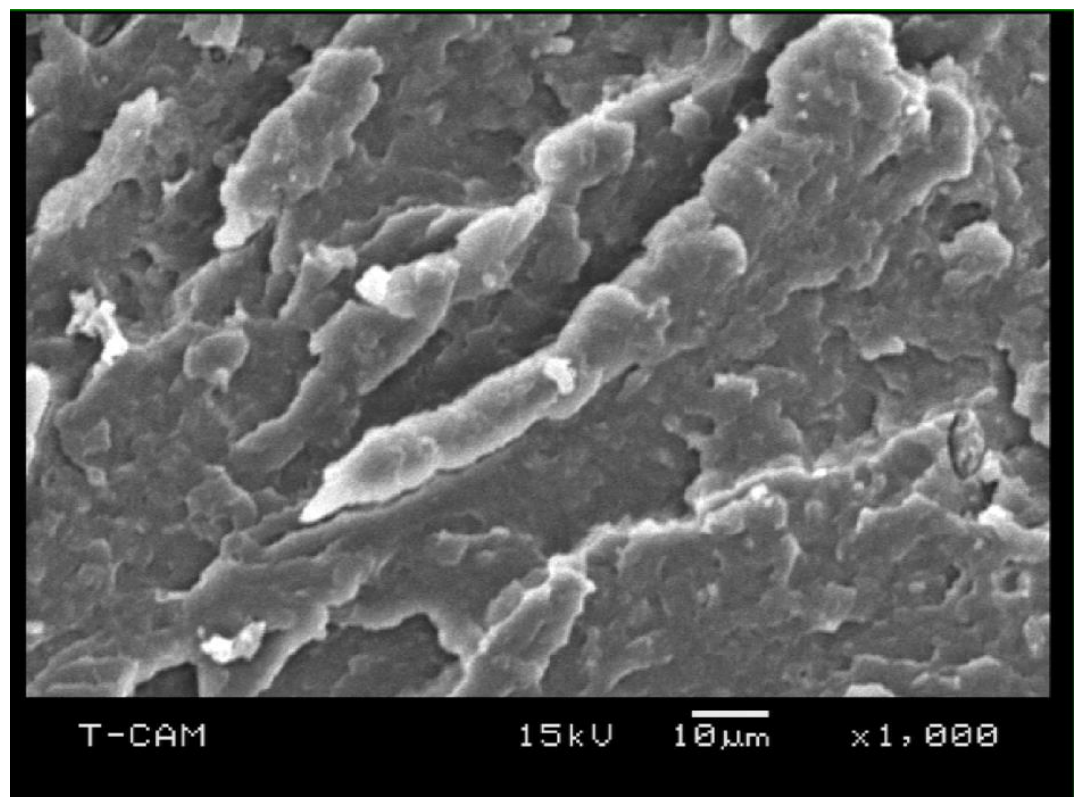

Figura 38. Micrografia da superfície de fratura do ensaio à tração do PBT/GMA/3\% Argila 350 kGy.

Nas figuras de 39 a 42 são apresentadas as micrografias para os nanocompósitos de PBT com $5 \%$ de argila e GMA

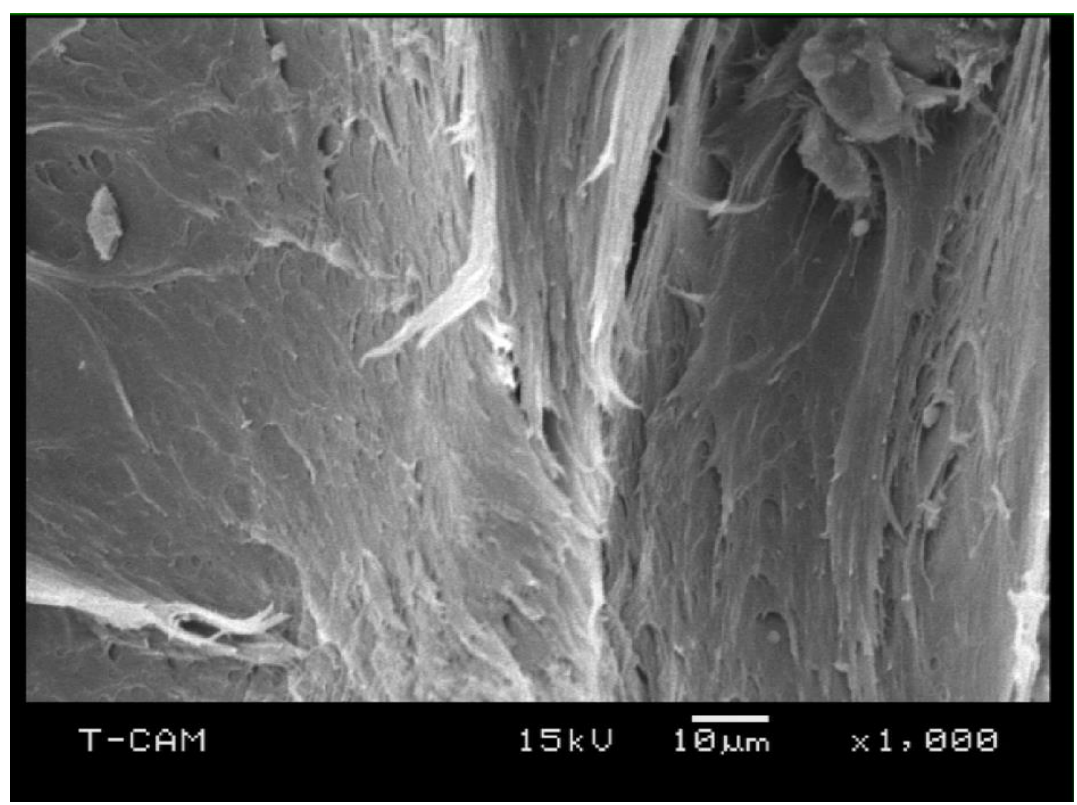

Figura 39. Micrografia da superfície de fratura do ensaio à tração do PBT/GMA/5\% Argila NI 


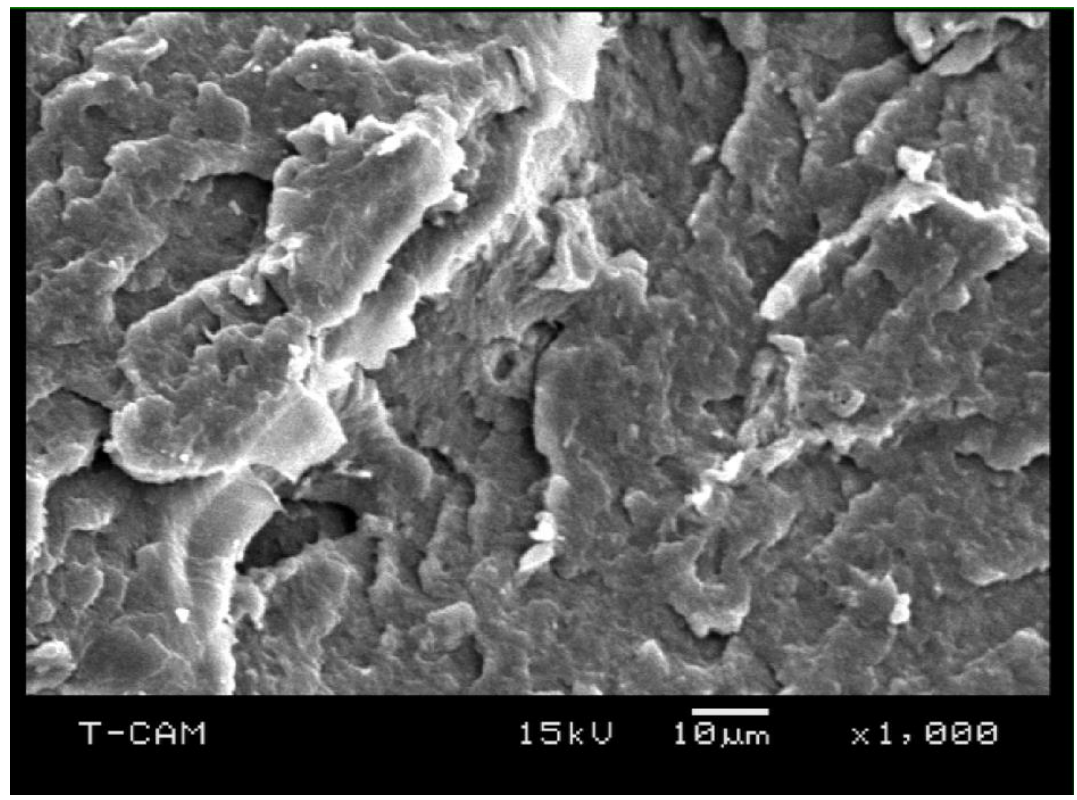

Figura 40. Micrografia da superfície de fratura do ensaio à tração do PBT/GMA/5\% Argila $150 \mathrm{kGy}$

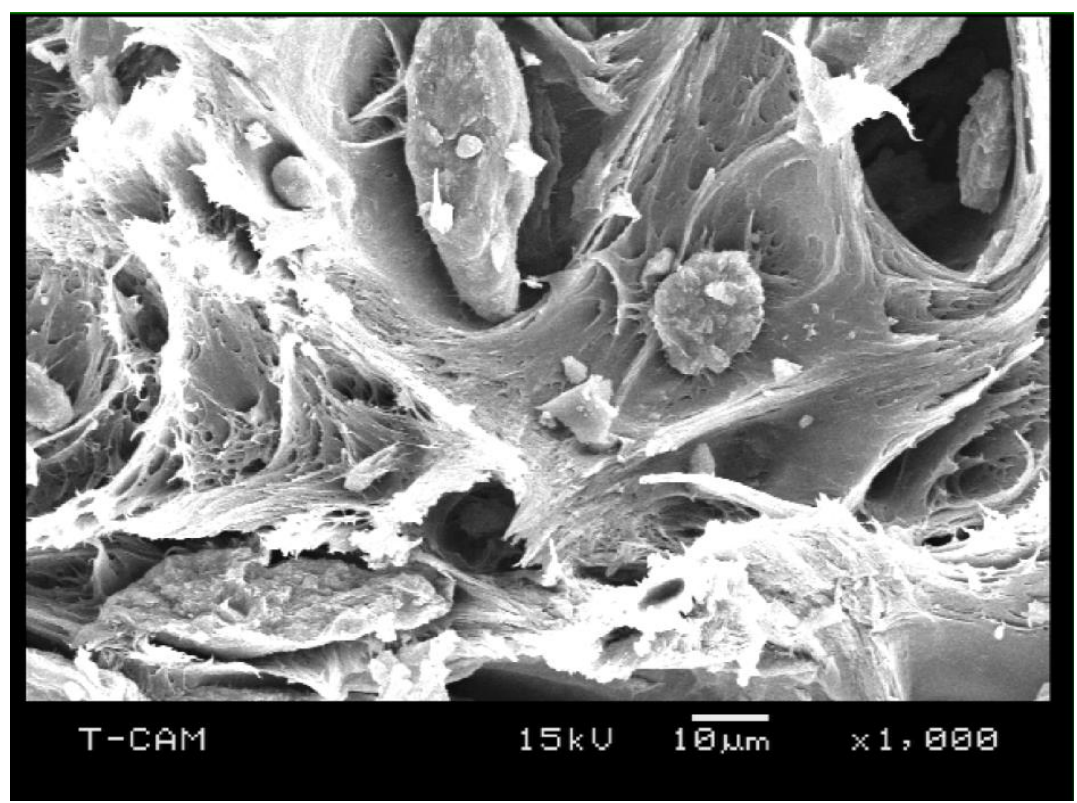

Figura 41. Micrografia da superfície de fratura do ensaio à tração do $P B T / G M A / 5 \%$ Argila $250 \mathrm{kGy}$. 


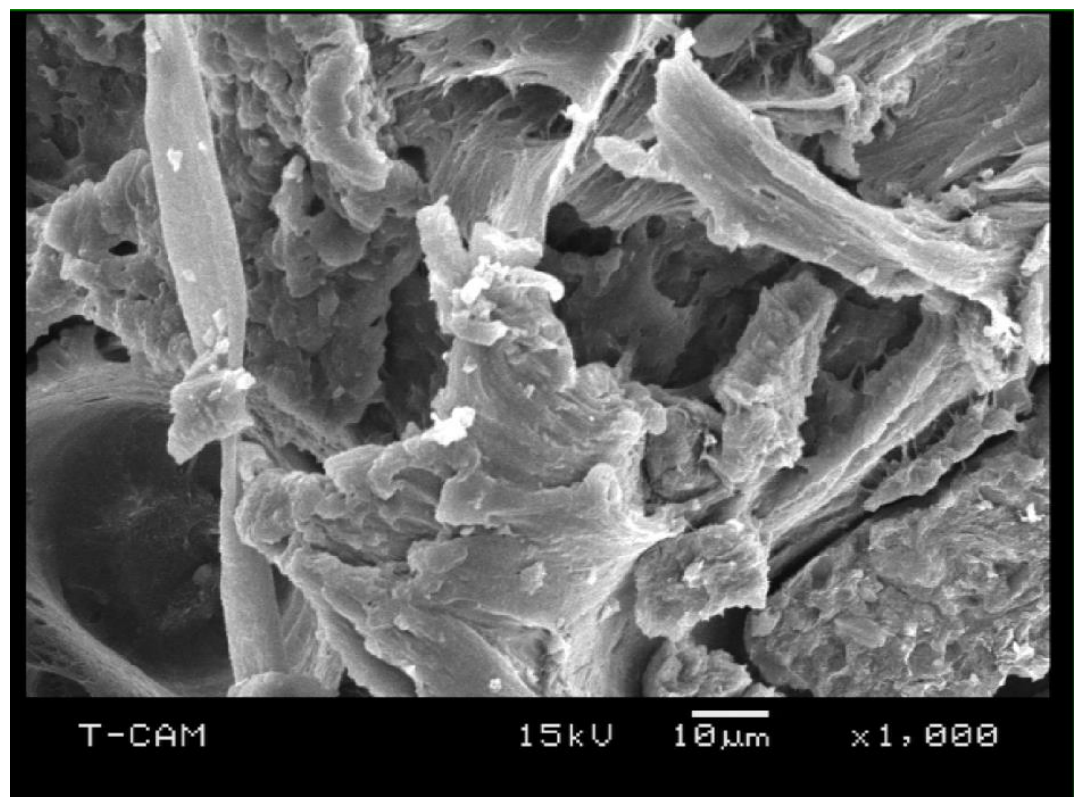

Figura 42. Micrografia da superfície de fratura do ensaio à tração do PBT/GMA/5\% Argila 350 kGy. 


\section{CONCLUSÃO}

As análises de difração de raios $\mathrm{X}$ mostraram que 0 tratamento da argila natural em laboratório com o sal quaternário de amônio foi eficiente, aumentando o espaçamento basal entre as camadas e obteve-se argila organofílica. Observou-se também a uma boa interação das argilas com a matriz polimérica.

Nos ensaios mecânicos de resistência à tração a adição da argila chocolate, em ambas as formulações, promoveu um aumento na resistência à tração na ruptura da matriz polimérica PBT superior a $50 \%$. Considerando a resistência a flexão houve aumento de cerca de $10 \%$ na resistência à flexão também em ambas as formulações comparado ao polímero puro.

Nos resultados de resistência ao impacto Izod observou-se que a adição da argila promoveu uma redução na tenacidade do material.

A temperatura de distorção térmica teve um aumento de cerca de $35 \%$ após a adição de argila em ambas formulações.

Os resultados de um modo geral mostraram que adição de 3 e $5 \%$ de argila levaram a ganhos de propriedades semelhantes. Nas composições com o agente compatibilizante GMA os aumentos nas propriedades térmicas e mecânicas também foram similares. A adição do agente compatibilizante não mostrou ganhos na resistência à tração na ruptura, resistência a flexão, módulo de flexão e temperatura de distorção térmica, significativos quando comparados as formulações sem o GMA. 
Indicando que a adição de $0,5 \%$ de metacrilato de glicidila na matriz polimérica PBT com argila não foi suficiente para uma melhor compatibilização matriz-reforço.

$\mathrm{Na}$ análise térmica por DSC observou-se uma pequena redução na temperatura de fusão e no percentual de cristalinidade dos materiais

As micrografias da superfície de fratura realizadas nas amostras após o ensaio de tração não foram conclusivas para avaliar a dispersão da argila na matriz polimérica.

O tratamento por radiação ionizante nas doses propostas neste estudo não foram efetivas para promover reticulação da cadeia polimérica dos materiais. Este resultado foi evidenciado pela análise de fração gel onde se observou que os materiais sofreram dissolução, não restando assim fração gel. 


\section{SUGESTÕES PARA TRABALHOS FUTUROS}

Para um melhor conhecimento dos nanocompósitos PBT/Argila bentonita tratados por radiação ionizante, sugere-se os seguintes pontos:

- Realizar a análise de microscopia eletrônica de transmissão (MET) para estudar a dispersão da argila na matriz polimérica de PBT e avaliar a formação de nanocompósitos esfoliados e intercalados.

- Processar o PBT com argila em diferentes condições para avaliar a influência da velocidade de rotação das roscas na dispersão das argilas.

- Estudar o percentual ideal de agente compatibilizante para uma melhor interação matriz-nanoreforço.

- Realizar o tratamento de radiação ionizante dos nanocompósitos em diferentes doses e a utilização de um agente de reticulação. 


\section{REFERÊNCIAS}

ABPOL. Associação brasileira de polímeros, 1998.

ACIERNO, D.; SCARFATO, P. Preparation and Characterization of PBT Nanocomposites Compounded With Different Montmorillonites. Polymer Engineering and Science v. 44, n. 6, 2004.

ALEXANDRE, M.; DUBOIS, P. Polymer-layered silicate nanocomposites: preparation, properties and uses for a new class of materials. Materials Science and Engineering. v. 28. p. 1-63, 2000.

ASTM D 5630 - 13 American Society for Testing and Materials. Standard Test Method for Ash Content in Plastics, 2013

ASTM D 648 - 07, American Society for Testing and Materials. Standard Test Method for Deflection Temperature of Plastics Under Flexural Load in the Edgewise Position, 2007.

ASTM D 256 - 10, American Society for Testing and Materials. Standard Test Methods for Determing the Izod Pendulum Impact Resistance of Plastics, 2010.

ASTM, D 790 - 00, American Society for Testing and Materials. Standard Test Methods for Flexural Properties of Unreinforced and Reinforced Plastics and Electrical Insulating Materials, 2000.

ASTM D 1238 - 13, American Society for Testing and Materials. Standard Test Method for Melt Flow Rates of Thermoplastics by Extrusion Plastometer, 2013.

ASTM, D 638 - 01, American Society for Testing and Materials. Standard Test Methods for Tensile Properties of Plastics, 2001.

BALJINDER, K.K. Nanocomposites. Faculty of Technology, Bolton Institute, Bolton, fire retardants materials, Woodhead Publishing, 2001. 
BASF Ultradur, Poly (butylene terephthalate) (PBT), application, types, properties, processing, Product Information, 2000.

BAYER AG POCAN, Application Technology Information, Product Range, Reference Data, 1999.

BORDES, P.; POLLET, E.; AVÉROUS, L. Nano-biocomposites: Biodegradable polyester/nanoclay systems. Polymer Science, v. 34, p. 125-155, 2009.

BRADLEY, R. Radiation Technology Handbook, Marcel Dekker, New York, NY, 1984.

CANEVAROLO Jr., S. V. Ciência dos polímeros: Um texto básico para tecnólogos e engenheiros. 3aㅡ edição. São Paulo: Editora Artliber, 2010.

CANEVAROLO Jr., S. V. Técnicas de caracterização de polímeros. São Paulo: Editora Artliber, 2003.

CHANG, Y. W.; KIM, S.; KYUNG, Y. Poly(butylene terephthalate)-clay nanocomposites prepared by melt intercalation: morphology and thermo mechanical properties. Polymer International, v. 54, v. 2, p.348-353, 2005.

CHOW, W. S. Cyclic Extrusion of Poly(butylene terephthalate)/OrganoMontmorillonite Nanocomposites: Thermal and Mechanical Retention Properties. Journal of Applied Polymer Science, v. 110, p. 1642-1648, 2008.

CHOW. W. S. Tensile and Thermal Properties of Poly(Butylene Terephtalate)/ Organo-Montmorillonite Nanocomposites. Malaysian Polymer Journal (MPJ), v. 3, N. 1, p 1-13, 2008.

CLEGG, G. Mechanisms of polymer degradation and stabilization, New York, N.Y.: Elsevier, 1991.

DENG, J.; HE, Q.; WU, Z.; YANG, W. Using Glycidyl Methacrylate as Crosslinking Agent to Prepare Thermosensitive Hydrogels by a Novel One-Step Method. Journal of Polymer Science: Part A: Polymer Chemistry, v. 46, p.21932201, 2008. 
DENNIS, H. R.; HUNTER, D. L.; CHANG, D.; KIM, S.; WHITE, J. L.; CHO, J. W.; PAUL, D.R. Effect of melt processing conditions on the extent of exfoliation in organoclay-based nanocomposites. Polymer, v. 42, p. 9513-9522, 2001.

DEVI, R. R.; MAJI, T. K. Chemical modification of simul wood with styreneacrylonitrile copolymer and organically modified nanoclay. Wood Science and Technology, v.46, p.299-315, 2012.

DNPM. Departamento Nacional de Produção Mineral, Anuário Mineral Brasileiro, Bentonita, 2013.

FISCHER, H. Polymer nanocomposites: from fundamental research to specific applications. Materials Science and Engineering, p.1-10, 2003.

FREITAS, C. A. Nanocompósitos poliméricos de Poli (tereftalato de butileno) PBT. Tese de Doutorado - Escola Politécnica da Universidade de São Paulo, 2010.

GIANNELIS, E. Polymer Layered Silicate Nanocomposites. Advanced Materials. v. 8, p. 29-35, 1996.

GIANNELIS, E. Polymer Layered Silicate Nanocomposites: Synthesis, Properties and Applications. Applied Organometalic Chemistry. v.12, p. 675-680, 1998.

HAJIRAISSI, R.; PARVINZADEH, M.; Preparation of polybutylene terephthalate/silica nanocomposites by melt compounding: Evaluation of surface properties. Applied Surface Science v. 257 p. 8443- 8450, 2011.

HAMMOND, P.T. Encyclopedia of Materials: Science and Technology, Elsevier Ltd. 2001

HUANG, J. Poly(butylene terephthalate)/Clay Nanocomposite Compatibilized with Poly(ethylene-co-glycidyl methacrylate). I. Isothermal Crystallization. Wiley Inter Science, 2008.

KORNMANN, $X$. Synthesis and characterization of thermoset-clay nanocomposites: Introduction. Lulea Tekniska Univeresitet, 2000. 
KORNMANN, X.; LINDERBERG, H.; BERGUND, L.A. Synthesis of Epoxy-Clay Nanocomposites: Influence of the Nature of the Clay on Structure. Polymer, v. 42, p. 4493- 4499, 2001.

LEROUX, F. Organo-Modified Anionic Clays into Polymer Compared to Smectite-Type Nanofiller: Potential Applications of the Nanocomposites. Journal of Nanoscience and nanotechnology, v. 6, p. 303-315, 2006.

LUCAS, E. F.; SOARES, B. G.; MONTEIRO, E. Caracterização de polímeros. Epapers. Rio de Janeiro, 2001.

LUO, J. J.; DANIEL, I. M. Characterization and modeling of mechanical behavior of polymer/clay nanocomposites. Composites Science and Technology v. 63, 1607-1616, 2003

MANO, E. B.; MENDES, L. C. Introdução a polímeros. 2. ed. São Paulo:Edgard Blücher, 2001.

MARTINS, P. R.; FERNANDES, M. F. M. Engajamento público em nanotecnologia. Lecotec, 2009.

MAI, Y. W.; YU Z. Z. Polymer nanocomposites. Woodhead Publishing in Materials, 2006.

MELO, C. P.; PIMENTA, M. Nanociencias e nanotecnologia. Parcerias estratégicas, 2004. Disponível em:< www.cgee.org.br> Acesso em 12 de fevereiro de 2014.

MORAES, R. P. Nanocompósitos do tipo Polímero/Silicatos Lamelares (PLSN): Síntese de látices híbridos de estireno-acrilato de $n$-butila reforçados com montmorilonita brasileira pela técnica de polimerização em miniemulsão. Dissertação de mestrado. Escola de Engenharia de Lorena - Universidade de São Paulo, 2007.

NAGASAWA, N.; KANEDA, A.; KANAZAWA, S.; YAGI, T.; MITOMO, H.; YOSHII, F.; TAMADA, M. Application of poly(lactic acid) modified by radiation crosslinking. Nuclear Instruments and Methods in Physics Research B, v. 236, p.611-616, 2005. 
NANOTECH. Introdução a Nanotecnologia. Disponível em:<http://nanotech.ica.ele.puc-rio.br/nano_introducao.asp> Acesso em: 08 de março de 2014.

NIRUKHE, A. B.; SHERTUKDE, V. V. Preparation and Characterization of Poly(butylene terephthalate) Nanocomposites with Various Organoclays. Journal of Applied Polymer Science, v. 113 p. 585 - 592, 2009.

PAIVA, L. B.; MORALES, A. R.; GUIMARÃES, T. R. Propriedades Mecânicas de Nanocompósitos de Polipropileno e Montmorilonita Organofílica. Polímeros: Ciência e Tecnologia, v. 16, n², p. 136-140, 2006.

PAIVA, L. B.; MORALES, A. R.; VALENZUELA- DÍAZ F. Argilas organofílicas: características, metodologias de preparação, compostos de intercalação e técnicas de caracterização. Cerâmica, v. 54, p. 213-226, 2008.

PEREIRA, K. R. O.; RODRIGUES, M. G. F.; VALENZUELA DIAZ, F. R. Síntese e caracterização de argilas organofílicas: comparação no uso de dois métodos. Revista Eletrônica de Materiais e Processos, v.2.2, p. 01-08, 2007.

O'DONNELL, J. H.; SANGSTER, D. F. Principles of radiation chemistry. London: Edward Arnold (Publishers), 1970.

OLABISI, O. Handbook of Termoplastics: Pastics Engineering. Nova York, 1997.

OLEJNICZAK, J.; ROSIAK, J. M.; CHARLESBY, A. Gel/dose curves for polymers undergoing simultaneous cross-linking and scission. Radiation Physics and Chemistry. v. 38, N. 1, p. 113-118, 1991.

OTA, W. N. Análise de compósitos de polipropileno e fibras de vidro utilizados pela indústria automotiva nacional. Dissertação de mestrado. Universidade Federal do Paraná, 2004.

RABELlO, M. Ativação de Polímeros. São Paulo: Artiliber editora, 2000.

RADUSCH, H. J. Handbook of Thermoplastic Polymers: Homopolymers, Copolymers, Blends, and Composites, 2002. 
RATNAM, C. T.; RAJU, G.; YUNUS, W. Z. W. Oil palm empty fruit bunch (OPEFB) fiber reinforced PVC/ENR blend-electron beam irradiation. Nuclear Instruments and Methods in Physics Research B, v.265, p.510-514, 2007.

RAY, S. S. Clay - containing polymer nanocompósitos: From fundamentals to real applications. Elsevier, 2013.

RAY, S. S.; OKAMOTO, M. Polymer/layered silicate nanocomposites: a review from preparation to processing. Progress in Polymer Science, 2003.

RICHARD, R.; CHARLES, A. Encyclopedia of material characterization: surface, interface thin film. Ed. Brundle, p.57-99, 1992.

ROSIAK, J. M. Gel/Sol analysis of irradiated polymers. Radiation Physics and Chemistry. v. 51, N 1, p. $13-17,1998$.

SANTOS, P. S. Ciência e tecnologia de argilas. São Paulo, Edgard Blucher, v.3, 2 Ed., 1992.

SANTOS, P. S. Tecnologia de argilas, aplicada às argilas brasileiras. São Paulo, Edgard Blucher, 1975.

SCATTEIA L.; SCARFATO, P.; ACIERNO D. Rheology of PBT-layered silicate nanocomposites prepared by melt compounding. Plastics, Rubbers and Composite,. v. 33, 2004.

SESI. Programa Educacional de Nanociência e Nanotecnologia, s.d. Disponível em: < http://www.sesisp.org.br/educacao/nanociencia-enanotecnologia/institucional> Acesso em 12 de fevereiro de 2014.

SILVA, A. A. Contribuição ao estudo das bentonitas do município de Boa Vista estado da Paraíba. Tese de Doutorado, Departamento de Engenharia Metalúrgica e de Materiais da Escola Politécnica da Universidade de São Paulo, 2010.

SWALLOW, A. J. Radiation chemistry of organic compounds. Cambridge: Pergamon Press, 1960. 
TICONA ENGINEERING POLYMER. Celanex PBT, 2014

TWARDOWSKI, T. E. Introduction to nanocomposite materials: properties, processing, characterization. Lancaster, P.A.: Destech Publications, Inc., 2007.

VALENZUELA-DIAZ, F. R. Preparação a nível de laboratório de algumas argilas esmectíticas organofílicas. Tese de Doutorado. Departamento de Engenharia Química da Escola Politécnica da Universidade de São Paulo, 1994.

VÉRTES, A.; NAGY, S.; KLENCSÁR Z. Handbook of nuclear chemistry: chemical applications of nuclear reactions and radiations. Dordrecht: Kluwer Academic Pub, v. 3, 2003.

VOSSEN, C. A. Nanocompósito de ABS/PA e argilas organofílicas. Dissertação de Mestrado Departamento de Engenharia Metalúrgica e de Materiais da Escola Politécnica da Universidade de São Paulo, 2009

WESTDYK, R.; MCNAIIY, D. Handbook of Plastic Materials and Technology. John Wiley \& Sons, Inc., New York, p. 629-637, 1990.

WIEBECK, H., HARADA, J. Plásticos de Engenharia: Tecnologia e Aplicações. São Paulo: Editora Artliber, p. 137- 140, 2005.

WILLIAMS, D. .B.; CARTER. C. B. Transmission Electron Microscopy. Plenum Press, New York, 1996.

WU, F.; YANG, G. Poly(butylene terephthalate)/organoclay nanocomposites prepared by in-situ bulk polymerization with cyclic poly(butylene terephthalate). Materials Letters 63 1686-1688, 2009.

WU, D.; ZHOU, C.; HONG, Z.; MAO, D.; BIAN, Z. Study on rheological behaviour of poly(butylene terephthalate)/montmorillonite nanocomposites. European Polymer Journal v. 41 p. 2199-2207, 2005.

YIU, W. M; ZHING, Z. Y. Polymer Nanocomposites. Cambrige and New York: woodhead Publishing Limited, 2006. 
